\title{
Review \\ Recent Development in Vanadium Pentoxide and Carbon Hybrid Active Materials for Energy Storage Devices
}

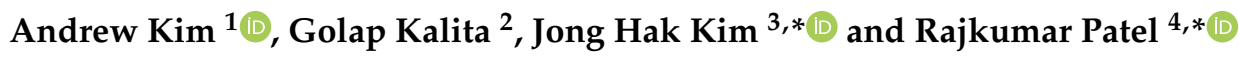 \\ 1 Department of Chemical Engineering, The Cooper Union for the Advancement of Science and Art, \\ New York, NY 10003, USA; kim70@cooper.edu \\ 2 Department of Physical Science and Engineering, Nagoya Institute of Technology, Gokiso-Cho, Showa-ku, \\ Nagoya 466-8555, Japan; golapkalita@gmail.com \\ 3 Department of Chemical and Biomolecular Engineering, Yonsei University, 50, Yonsei-ro, Seodaemun-gu, \\ Seoul 03722, Korea \\ 4 Energy \& Environmental Science and Engineering (EESE), Integrated Science and Engineering \\ Division (ISED), Underwood International College, Yonsei University, 85 Songdogwahak-ro, Yeonsugu, \\ Incheon 21983, Korea \\ * Correspondence: jonghak@yonsei.ac.kr (J.H.K.); rajkumar@yonsei.ac.kr (R.P.)
}

Citation: Kim, A.; Kalita, G.; Kim, J.H.; Patel, R. Recent Development in Vanadium Pentoxide and Carbon Hybrid Active Materials for Energy Storage Devices. Nanomaterials 2021, 11, 3213. https://doi.org/10.3390/ nano11123213

Academic Editors: Marc Cretin, Sophie Tingry and Zhenghua Tang

Received: 4 November 2021

Accepted: 24 November 2021

Published: 26 November 2021

Publisher's Note: MDPI stays neutral with regard to jurisdictional claims in published maps and institutional affiliations.

Copyright: (c) 2021 by the authors. Licensee MDPI, Basel, Switzerland. This article is an open access article distributed under the terms and conditions of the Creative Commons Attribution (CC BY) license (https:/ / creativecommons.org/licenses/by/ $4.0 /)$.

\begin{abstract}
With the increasing energy demand for portable electronics, electric vehicles, and green energy storage solutions, the development of high-performance supercapacitors has been at the forefront of energy storage and conversion research. In the past decade, many scientific publications have been dedicated to designing hybrid electrode materials composed of vanadium pentoxide $\left(\mathrm{V}_{2} \mathrm{O}_{5}\right)$ and carbon nanomaterials to bridge the gap in energy and power of traditional batteries and capacitors. $\mathrm{V}_{2} \mathrm{O}_{5}$ is a promising electrode material owing to its natural abundance, nontoxicity, and high capacitive potential. However, bulk $\mathrm{V}_{2} \mathrm{O}_{5}$ is limited by poor conductivity, low porosity, and dissolution during charge/discharge cycles. To overcome the limitations of $\mathrm{V}_{2} \mathrm{O}_{5}$, many researchers have incorporated common carbon nanostructures such as reduced graphene oxides, carbon nanotubes, carbon nanofibers, and other carbon moieties into $\mathrm{V}_{2} \mathrm{O}_{5}$. The carbon components facilitate electron mobility and act as porous templates for $\mathrm{V}_{2} \mathrm{O}_{5}$ nucleation with an enhanced surface area as well as interconnected surface morphology and structural stability. This review discusses the development of various $\mathrm{V}_{2} \mathrm{O}_{5}$ /carbon hybrid materials, focusing on the effects of different synthesis methods, $\mathrm{V}_{2} \mathrm{O}_{5}$ /carbon compositions, and physical treatment strategies on the structure and electrochemical performance of the composite material as promising supercapacitor electrodes.
\end{abstract}

Keywords: electrochemical energy storage; supercapacitor; vanadium pentoxide; carbon nanocomposite

\section{Introduction}

The demand for improved energy storage devices has increased due to the rapid development of portable electronics, electric vehicles, and green energy storage devices [1]. Supercapacitors are promising replacements for traditional energy storage devices such as batteries and capacitors with high energy and power densities, respectively, because supercapacitors can be fabricated using readily accessible materials with outstanding cyclability and can provide a balance of both high power and energy densities (Figure 1) [2-5]. The two main classifications of supercapacitors are electric double-layer capacitors (EDLCs) and pseudocapacitors (faradic supercapacitors) [6,7]. EDLCs produce a charge separation at the boundary between the electrode and electrolyte to store energy [8]. In contrast, pseudocapacitors rely on fast faradic reactions at the electrode surface to store energy [9]. Depending on the electrode material, supercapacitors primarily exhibit electric double-layer (EDL) or pseudocapacitive characteristics or a combination of both. 


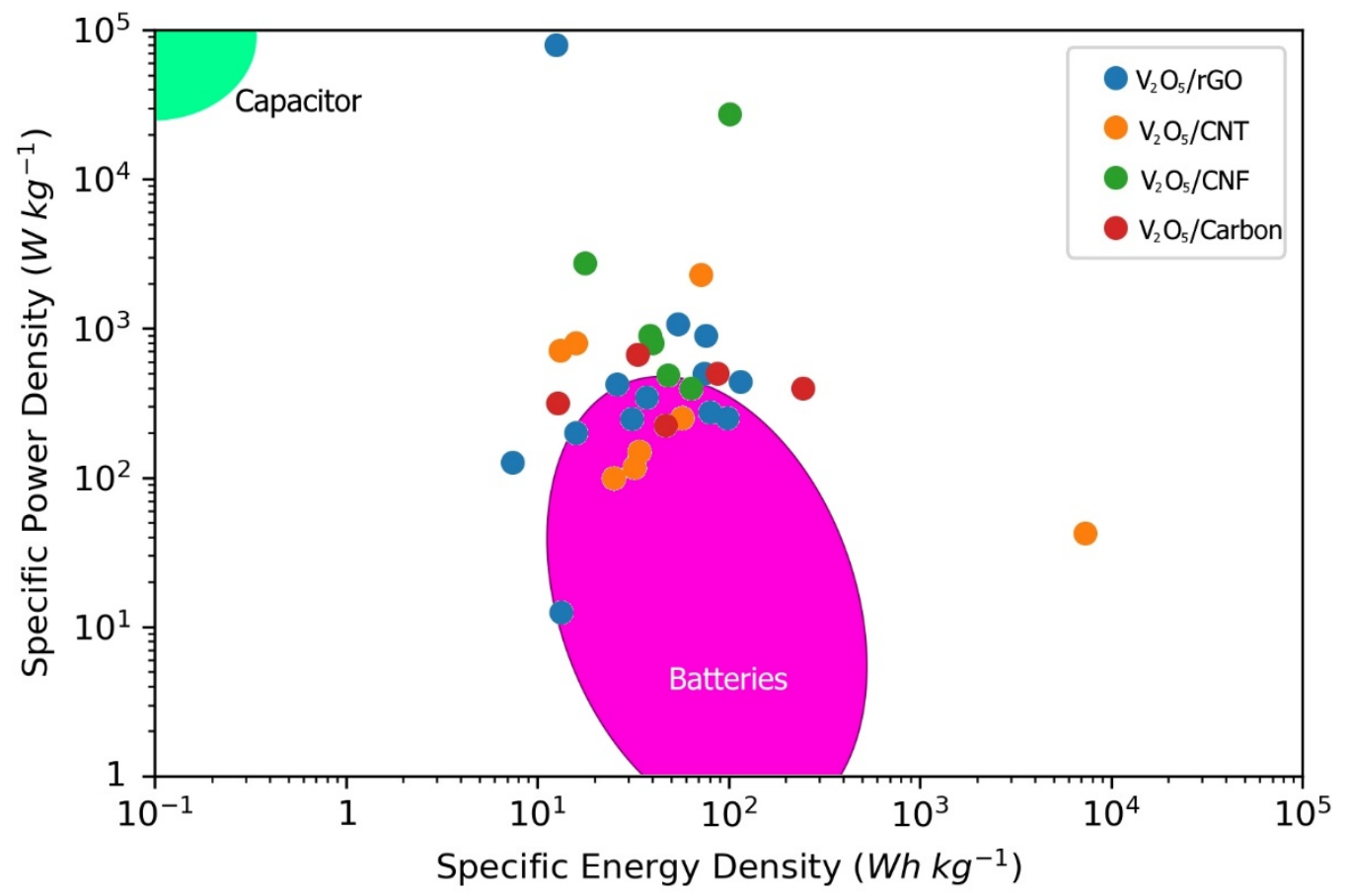

Figure 1. Ragone plot showing the energy and power density ranges of common electrochemical energy storage devices such as capacitors, supercapacitors, and batteries.

Transition metal oxide/carbon hybrid materials have recently attracted considerable attention as composites with easily controllable pseudocapacitive and EDL characteristics. Transition metal oxides such as vanadium pentoxide $\left(\mathrm{V}_{2} \mathrm{O}_{5}\right)$ are pseudocapacitive, yielding supercapacitors with high specific capacitances $\left(\mathrm{C}_{\mathrm{sp}}\right)$ and energy densities [10]. However, $\mathrm{V}_{2} \mathrm{O}_{5}$ is limited by poor conductivity, low power density, and minimal cyclic stability [11]. In contrast, carbon nanostructures, such as reduced graphene oxide (rGO), carbon nanotubes (CNTs), and carbon nanofibers (CNFs), show dominant EDL characteristics, resulting in highly stable and power-dense supercapacitors. However, carbon-based materials suffer from low specific capacitances and energy densities [12]. Transition metal oxide/carbon composite materials supplement the high energy potential of transition metal oxides with the high power potential and stability of carbon nanostructures [13-15]. These composite materials will be essential to meet the demand for fast-charging portable electronics, long-lasting electric vehicles, and environmentally friendly energy storage devices.

$\mathrm{V}_{2} \mathrm{O}_{5}$ has attracted significant attention as a transition metal oxide with multiple oxidation states (II-V), enabling a high maximum theoretical capacitance of $2120 \mathrm{~F} \mathrm{~g}^{-1}$ [16]. With a wide effective potential window, $\mathrm{V}_{2} \mathrm{O}_{5}$ can provide a high theoretical energy density [17]. Additionally, owing to its natural abundance and low toxicity, $\mathrm{V}_{2} \mathrm{O}_{5}$ is a low-cost material that is ideal for mass production $[18,19]$. The crystal structure of $\mathrm{V}_{2} \mathrm{O}_{5}$ allows electrolyte ions such as $\mathrm{Li}^{+}$to reversibly intercalate/de-intercalate, thereby improving the faradic reactivity with the electrolyte $[20,21]$. However, bulk $\mathrm{V}_{2} \mathrm{O}_{5}$ is limited by poor electrical conductivity, slow reaction kinetics, and vanadium dissolution [22,23]. To improve the properties of bulk $\mathrm{V}_{2} \mathrm{O}_{5}$, the bulk crystal nanostructure has been converted into nanorods [24], nanotubes [25], nanosheets [26], nanobelts [27], and other porous nanostructures [28]. These nanostructures allow better reaction kinetics with shorter diffusion pathways than those observed in the bulk crystal structure, and they improve cyclability with less strain on the crystal structure during ion intercalation/de-intercalation. However, these $\mathrm{V}_{2} \mathrm{O}_{5}$ materials still have drawbacks, such as low electrical conductivity [29,30].

Recent developments in improving $\mathrm{V}_{2} \mathrm{O}_{5}$ supercapacitor materials involve the addition of carbon nanomaterials, such as graphene [31], rGO [32], CNTs [33], and activated carbon (AC) [34], to improve the conductivity and structural stability of $\mathrm{V}_{2} \mathrm{O}_{5}$. Carbon materials are ideal sources of EDL capacitance for efficient supercapacitors, owing to high 
porosities, conductivities, and natural abundances $[35,36]$. Highly porous carbon materials have large surface areas, resulting in more active sites on the electrode material [37]. Increased porosity allows fast ion intercalation/de-intercalation with short ion diffusion pathways [38]. The large surface area improves the interfacial contact between the electroactive material and the current collector, resulting in more efficient electron transfer. Moreover, the carbon content improves the overall conductivity of the electrode, increasing the specific capacitance and decreasing the energy losses during charge/discharge [39].

Despite the recent developments in $\mathrm{V}_{2} \mathrm{O}_{5}$ / carbon composites, many review articles on supercapacitor electrode materials only briefly discuss $\mathrm{V}_{2} \mathrm{O}_{5}$ materials as part of a broader review of transition metal oxide [40-45] or carbon-based supercapacitors [46-48]. $\mathrm{V}_{2} \mathrm{O}_{5} /$ carbon hybrid materials are promising materials that have been the focus of recent research, so it is essential to organize the most up-to-date information on factors affecting the performances of $\mathrm{V}_{2} \mathrm{O}_{5}$ /carbon composite electrodes. This review describes the physical and electrochemical characteristics of different $\mathrm{V}_{2} \mathrm{O}_{5} /$ carbon nanostructures, including $\mathrm{V}_{2} \mathrm{O}_{5} / \mathrm{rGO}, \mathrm{V}_{2} \mathrm{O}_{5} / \mathrm{CNTs}, \mathrm{V}_{2} \mathrm{O}_{5} / \mathrm{CNFs}$, and other $\mathrm{V}_{2} \mathrm{O}_{5} /$ carbon hybrid materials. This review focuses on the effects of different synthesis methods, carbon to $\mathrm{V}_{2} \mathrm{O}_{5}$ ratios, and physical treatment procedures on the structures and performances of $\mathrm{V}_{2} \mathrm{O}$ and carbon hybrid nanomaterials.

\section{2. $\mathrm{V}_{2} \mathrm{O}_{5} / \mathrm{rGO}$}

rGOs have been extensively investigated as additive materials for $\mathrm{V}_{2} \mathrm{O}_{5}$ composites because of their large surface areas, high conductivities, and good stabilities [49]. Similar to pristine graphene (sometimes reported in the literature as graphene), $\mathrm{rGO}$ is a monolayer of $\mathrm{sp}^{2}$ hybridized carbon atoms arranged in a hexagonal lattice $[50,51]$. However, unlike pure graphene, rGO contains varying degrees of defects caused by functional groups such as hydroxyl and carbonyl groups remaining after the reduction of highly functionalized graphene oxide (GO) [52]. Various factors involved in the fabrication of a $\mathrm{V}_{2} \mathrm{O}_{5} / \mathrm{rGO}$ (VrG) electrode affect its electrochemical performance by altering the morphology and crystalline structure of the hybrid material. VrG composites are versatile materials that often possess a lamellar structure with high porosity and surface area. The effects of different synthesis pathways, $\mathrm{V}_{2} \mathrm{O}_{5}$ /carbon compositions, and physical treatment conditions were closely examined for their impact on the nanostructures and the resulting capacitive performances of the $\mathrm{VrG}$ electrodes. The morphology and electrochemical performances of $\mathrm{V}_{2} \mathrm{O}_{5} / \mathrm{rGO}$ electrodes for supercapacitor applications reported in the literature are summarized in Table 1.

\subsection{Effects of Synthesis Method}

Many synthesis strategies for the fabrication of $\mathrm{VrG}$ composites include a hydro/ solvothermal method. Typically, a mixture of $\mathrm{V}_{2} \mathrm{O}_{5}$ precursors such as vanadium oxytriisopropoxide (VTIP), rGO precursors such as GO, and water or other solvents are heated at high temperatures and pressures for extended periods in a Teflon-lined stainless steel autoclave [53]. The hydro/solvothermal procedure is frequently used because it is facile and allows the formation of diverse $\mathrm{V}_{2} \mathrm{O}_{5}$ morphologies on the 2D rGO substrate. Pandey et al. synthesized $\mathrm{V}_{2} \mathrm{O}_{5}$ nanospheres anchored to thin $\mathrm{rGO}$ sheets via a hydrothermal synthesis route. A uniform dispersion of VTIP, GO, isopropyl alcohol, and DI water was heated at $180{ }^{\circ} \mathrm{C}$ in an autoclave for $18 \mathrm{~h}$, yielding a mesoporous $\mathrm{VrG}$ composite material [54]. The resulting material had a layered structure with large $\mathrm{V}_{2} \mathrm{O}_{5}$ nanospheres intercalated into the rGO layers. The vanadium crystals had an organized orthorhombic crystal structure that promoted deep ion adsorption. The lamellar structure of rGO increased the surface area for additional surface redox reactions and porosity for abundant electrolyte ion intercalation/de-intercalation. In a symmetric, two-electrode configuration with the VrG working electrodes, the composite exhibited a large maximum $\mathrm{C}_{\mathrm{sp}}$ of $448 \mathrm{~F} \mathrm{~g}^{-1}$ at a current density of $0.75 \mathrm{~A} \mathrm{~g}^{-1}$ that decreased slightly to $296 \mathrm{~F} \mathrm{~g}^{-1}$ at a significantly higher current density of $15.5 \mathrm{~A} \mathrm{~g}^{-1}$. The excellent rate capability was due to the low charge 
transfer resistance $(0.6 \Omega)$, which was enabled by the strong bonds formed between the intercalated $\mathrm{V}_{2} \mathrm{O}_{5}$ nanospheres and conductive $\mathrm{rGO}$ sheets.

Table 1. $\mathrm{V}_{2} \mathrm{O}_{5}$ morphology and electrochemical performances of $\mathrm{V}_{2} \mathrm{O}_{5}$ /reduced graphene oxide composite electrodes for supercapacitor applications.

\begin{tabular}{|c|c|c|c|c|c|}
\hline Morphology & Maximum $C_{s p}\left(F g^{-1}\right)$ & $\begin{array}{c}\text { Cycling } \mathrm{C}_{\mathrm{sp}} \\
\text { Retention (\%) }\end{array}$ & Cycle Number & $\begin{array}{l}\text { Energy Density } \\
\left(\mathrm{Wh} \mathrm{kg}^{-1}\right)\end{array}$ & $\begin{array}{l}\text { Power Density } \\
\left(\mathrm{W} \mathrm{kg}^{-1}\right)\end{array}$ \\
\hline Nanowires & 579 & 79 & 5000 & - & - \\
\hline Nanowires & 710 & 95 & 20,000 & 98.6 & 250 \\
\hline Nanosheets & 635 & 94 * & 3000 * & 75.9 & 900 \\
\hline Nanostrips & 309 & 95.2 & 10,000 & 475 & - \\
\hline Amorphous & 178.5 & 85 & 8000 & 13.3 & 12.5 \\
\hline Nanoflowers & 1235 & 92 & 5000 & 116 & 440 \\
\hline Nanoribbons & - & 720 & 500 & 16 & 200 \\
\hline Nanorods & 37.2 & 90 * & 1000 * & 54.2 & 1075.9 \\
\hline Amorphous & 484 & 83 & 1000 & 7.4 & 127 \\
\hline Amorphous & 226 & 92 & 5000 & 12.5 & 79,900 \\
\hline Nanobelts & 128.8 & 82 & 5000 & - & - \\
\hline Nanobelts & 310.1 & $90.2 *$ & 5000 * & 31.3 & 249.7 \\
\hline Nanofibers & 218 & $87 *$ & $700 *$ & 37.2 & 345 \\
\hline Nanowires & 272 & 80 & 1000 & 26.22 & 425 \\
\hline Nanorods & 537 & 84 & 1000 & 74.58 & 500 \\
\hline Nanospheres & 386 & - & - & 80.4 & 275 \\
\hline
\end{tabular}

${ }^{*}$ Cycling performance was determined using a two-electrode configuration.

The hydro/solvothermal synthesis route can also yield $\mathrm{V}_{2} \mathrm{O}_{5}$ nanowires. Ahirrao et al. followed a similar hydrothermal process with ammonium metavanadate $\left(\mathrm{NH}_{4} \mathrm{VO}_{3}\right)$ to yield a similar lamellar rGO structure with intercalated $\mathrm{V}_{2} \mathrm{O}_{5}$ nanowires [55]. First, $\mathrm{NH}_{4} \mathrm{VO}_{3}$ was calcinated into $\mathrm{V}_{2} \mathrm{O}_{5}$, and the $\mathrm{V}_{2} \mathrm{O}_{5}$ powder was then sonicated with $\mathrm{GO}$ in DI water and heated at $180{ }^{\circ} \mathrm{C}$ for two days in an autoclave. The hydrothermal processes yielded thin nanowires with lengths ranging from $100 \mathrm{~nm}$ to several micrometers anchored to the rGO layers. The nanowire morphology increased the surface area of $\mathrm{V}_{2} \mathrm{O}_{5}$ for more active sites and decreased the ion diffusion pathways. The VrG composite was drop-cast onto carbon paper to yield a supercapacitor electrode. The VrG electrode exhibited a maximum $\mathrm{C}_{\mathrm{sp}}$ of $1002 \mathrm{~F} \mathrm{~g}^{-1}$ at a current density of $1 \mathrm{~A} \mathrm{~g}^{-1}$. Because of its low charge transfer resistance $(0.53 \Omega)$, the composite exhibited good rate capability, as indicated by the high $\mathrm{C}_{\mathrm{sp}}$ of $828 \mathrm{~F} \mathrm{~g}^{-1}$ at a high current density of $3 \mathrm{~A} \mathrm{~g}^{-1}$. Similarly, Geng et al. synthesized thin $\mathrm{V}_{2} \mathrm{O}_{5}$ nanowires anchored to curly rGO sheets using a hydrothermal process [56]. As the hydro/solvothermal process often yields a $\mathrm{VrG}$ composite powder, it is combined with a conducting filler and polymer binder and coated onto a current collector for use as an electrode. The VrG material was combined with Super P carbon (conducting filler), polyvinylidene fluoride (PVDF) (polymer binder), and N-methyl-2-pyrrolidone (NMP) (solvent) in an 8:1:1 ratio. The resulting slurry was coated onto Ni foam, vacuum dried, and compressed into a thin sheet. Unlike a 2D metal foil current collector, $\mathrm{Ni}$ foam provided a 3D macroporous network for large volumes of electrolyte diffusion. Anchoring the $\operatorname{VrG}$ material to the porous foam increased the surface area for more active redox sites. The electrochemical performance of the $\mathrm{VrG}$ hybrid material was tested in a three-electrode configuration with a VrG working electrode, Pt counter electrode, and $\mathrm{Ag} / \mathrm{AgCl}$ reference electrode in $1 \mathrm{M} \mathrm{KCl}$ electrolyte. The $\mathrm{Ni}$ foam-based $\mathrm{VrG}$ electrode exhibited a high $\mathrm{C}_{\mathrm{sp}}$ of $579 \mathrm{~F} \mathrm{~g}^{-1}$ at a current density of $1 \mathrm{~A} \mathrm{~g}^{-1}$. Despite the lower conductivity than that of $\mathrm{Cu}$, the relatively high conductivity and larger pore size of $\mathrm{Ni}$ foam enabled good rate capability, as indicated by a large $\mathrm{C}_{\mathrm{sp}}$ of $534 \mathrm{~F} \mathrm{~g}^{-1}$ at a high current density of $4 \mathrm{~A} \mathrm{~g}^{-1}$. Because of its rigid and porous structure, the $\mathrm{VrG}$ material was less susceptible to mechanical strain arising from electrolyte intercalation/de-intercalation, resulting in a high $\mathrm{C}_{\mathrm{sp}}$ retention of $79 \%$ after 5000 cycles at a current density of $4 \mathrm{~A} \mathrm{~g}^{-1}$. Sun et al. found that the duration of the hydro/solvothermal reaction affected the growth of $\mathrm{V}_{2} \mathrm{O}_{5}$ nanowires on $\mathrm{rGO}$ sheets [57]. 
$\mathrm{V}_{2} \mathrm{O}_{5}$ was modified with the $\mathrm{N}$-doped $\mathrm{rGO}(\mathrm{N}-\mathrm{rGO})$ aerogel via solvothermal synthesis in an autoclave at $160^{\circ} \mathrm{C}$ for different durations. The composite was then freeze-dried to yield a marshmallow-shaped, free-standing $\mathrm{VrG}$ electrode. Tiny hair-like $\mathrm{V}_{2} \mathrm{O}_{5}$ nanowires were vertically anchored on the surfaces of the amorphous N-rGO sheets (Figure 2).
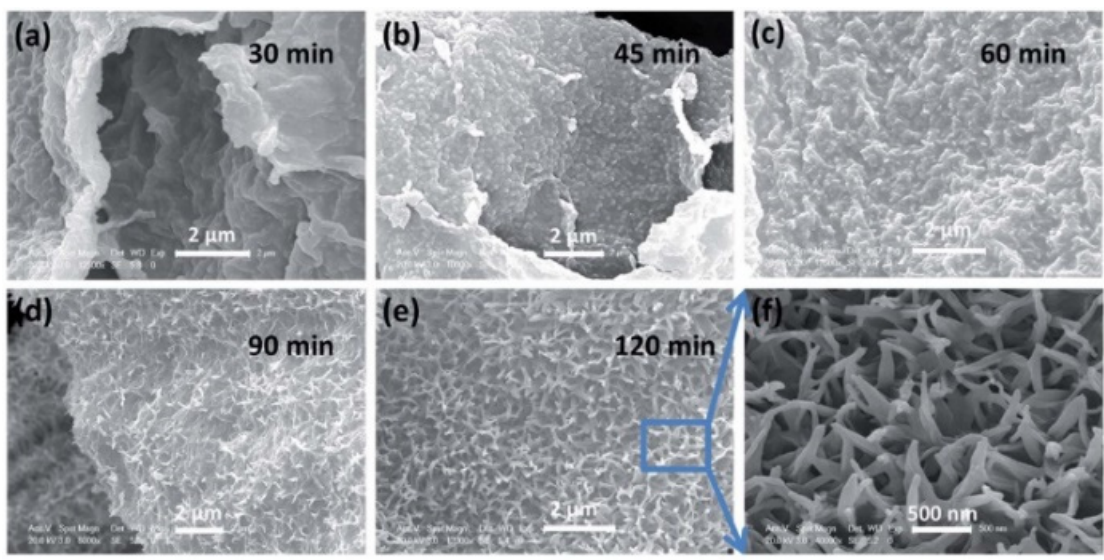

Figure 2. SEM images of $\mathrm{N}$-doped $\mathrm{rGO}$ anchored to vertically aligned $\mathrm{V}_{2} \mathrm{O}_{5}$ nanowires after solvothermal synthesis for (a) 30, (b) 45, (c) 60, (d) 90, and (e) 120 min. (f) Magnified SEM image of the N-doped $\mathrm{VrG}$ after solvothermal reaction for $120 \mathrm{~min}$. Reprinted with permission from Ref. [57]. Copyright 2018 Royal Society of Chemistry.

A short reaction time of 30 min between $\mathrm{V}_{2} \mathrm{O}_{5}$ and $\mathrm{rGO}$ resulted in a smooth $\mathrm{rGO}$ surface without many $\mathrm{V}_{2} \mathrm{O}_{5}$ nanowire growths (Figure 2a). After 45 to $60 \mathrm{~min}$, larger $\mathrm{V}_{2} \mathrm{O}_{5}$ nanowires were obtained (Figure $2 \mathrm{~b}$,c), suggesting additional $\mathrm{V}_{2} \mathrm{O}_{5}$ nucleation and growth. Prolonged reactions for 90 to 120 min resulted in long, vertical $\mathrm{V}_{2} \mathrm{O}_{5}$ crystal growths uniformly spread on the rGO surface (Figure 2d,e). A magnified view of the $\mathrm{V}_{2} \mathrm{O}_{5}$ coated surface (Figure 2f) showed the porosity of vertically grown $\mathrm{V}_{2} \mathrm{O}_{5}$ nanowires. The mesoporous network of $\mathrm{N}-\mathrm{rGO}$ sheets combined with the nanowire extrusions resulted in a large BET surface area of $416 \mathrm{~m}^{2} \mathrm{~g}^{-1}$, which allowed fast ion diffusion and increased the number of active sites for surface reactions. The porous $\mathrm{VrG}$ electrode exhibited an excellent $C_{\text {sp }}$ of $710 \mathrm{~F} \mathrm{~g}^{-1}$ at a current density of $0.5 \mathrm{~A} \mathrm{~g}^{-1}$. The nitrogen defects in the rGO frame lowered the charge transfer resistance of the electrode from 1.54 to $1.11 \Omega$, resulting in improved rate capability, indicated by a high $\mathrm{C}_{\mathrm{sp}}$ of $360 \mathrm{~F} \mathrm{~g}^{-1}$ at a large current density of $10 \mathrm{~A} \mathrm{~g}^{-1}$. As the nitrogen groups in rGO were more reactive than carbon, N-rGO contained more $\mathrm{V}_{2} \mathrm{O}_{5}$ nucleation sites than bare rGO, resulting in denser distributions of $\mathrm{V}_{2} \mathrm{O}_{5}$ nanowires throughout the N-rGO-based composite. The $\mathrm{V}_{2} \mathrm{O}_{5} / \mathrm{N}$-rGO material exhibited excellent cyclic stability with $95 \% \mathrm{C}_{\mathrm{sp}}$ retention after 20,000 cycles at a high current density of $10 \mathrm{~A} \mathrm{~g}^{-1}$.

In addition to nanospheres and nanowires, the hydrothermal process can yield more sheet-like $\mathrm{V}_{2} \mathrm{O}_{5}$ morphologies anchored to rGO. Nagaraju et al. synthesized a $\mathrm{VrG}$ composite with $\mathrm{V}_{2} \mathrm{O}_{5}$ and rGO nanosheets via a hydrothermal method to obtain a lamellar composite structure [58]. $\mathrm{V}_{2} \mathrm{O}_{5}$ had a pure orthorhombic crystal structure that allowed good ion diffusion. The layered structure of the $\mathrm{V}_{2} \mathrm{O}_{5}$ and $\mathrm{rGO}$ nanosheets resulted in a large surface area of $36.2 \mathrm{~m}^{2} \mathrm{~g}^{-1}$, which was four times larger than that of bulk $\mathrm{V}_{2} \mathrm{O}_{5}$. The VrG material exhibited both EDL and pseudocapacitive characteristics because of the even composition of $\mathrm{V}_{2} \mathrm{O}_{5}$ and $\mathrm{rGO}$. The porosity and crystallinity enhanced the pseudocapacitive capability to a maximum $\mathrm{C}_{\mathrm{sp}}$ of $635 \mathrm{~F} \mathrm{~g}^{-1}$ at a current density of $1 \mathrm{~A} \mathrm{~g}^{-1}$. Even at a high current density of $30 \mathrm{~A} \mathrm{~g}^{-1}$, the composite exhibited a large $240 \mathrm{~F} \mathrm{~g}^{-1} \mathrm{C}_{\mathrm{sp}}$, highlighting the layered composite's potential for high-energy and high-power applications. An asymmetric supercapacitor with the $\mathrm{VrG}$ electrode exhibited an energy density of $75.9 \mathrm{Wh} \mathrm{kg}^{-1}$ with a power density of $900 \mathrm{~W} \mathrm{~kg}^{-1}$. Sahu et al. used a hydrothermal method to synthesize $\mathrm{V}_{2} \mathrm{O}_{5}$ nanostrips anchored to $\mathrm{rGO}$ nanoribbon [59]. The $\mathrm{V}_{2} \mathrm{O}_{5}$ nanostrips shrank during the hydrothermal reaction with $\mathrm{rGO}$ as the rGO template inhibited large $\mathrm{V}_{2} \mathrm{O}_{5}$ growth. The 
retention of small $\mathrm{V}_{2} \mathrm{O}_{5}$ crystals doubled the surface area to $15.6 \mathrm{~m}^{2} \mathrm{~g}^{-1}$, thereby increasing the efficiencies of surface redox reactions. The composite material had high mesoporosity, facilitating the fast diffusion of electrolytes through the ion channels. Thus, the $\mathrm{C}_{\mathrm{sp}}$ of the composite ( $309 \mathrm{~F} \mathrm{~g}^{-1}$ ) was approximately five times greater than that of bulk $\mathrm{V}_{2} \mathrm{O}_{5}$ nanostrips. The $\mathrm{VrG}$ material had a low equivalent series resistance and charge transfer resistance of 4.6 and $1.2 \Omega$, respectively, which provided good rate capability, indicated by the relatively high $114 \mathrm{~F} \mathrm{~g}^{-1} \mathrm{C}_{\mathrm{sp}}$ at a high scan rate of $100 \mathrm{mV} \mathrm{s}^{-1}$. A solid-state electrode comprising the $\mathrm{VrG}$ composite exhibited a high conductivity of $1.4 \times 10^{-2} \mathrm{~S} \mathrm{~m}^{-1}$, which minimized the energy loss as heat. A symmetric VrG electrode supercapacitor had an energy density of $42.09 \mathrm{Wh} \mathrm{kg}^{-1}$ at a power density of $475 \mathrm{~W} \mathrm{~kg}^{-1}$, which decreased to 13.44 $\mathrm{Wh} \mathrm{kg}^{-1}$ at a power density of $8400 \mathrm{~W} \mathrm{~kg}^{-1}$.

The facile hydrothermal method can also alter the large sheet-like structure of rGO. Zhang et al. employed a hydrothermal and freeze-drying procedure to fabricate a $\mathrm{VrG}$ hydrogel with thin rGO strips instead of large sheets [60]. The outer appearance of the hydrogel constituted a marshmallow-like macrostructure. The rGO strips were laced together to form a macroporous 3D structure. The $\mathrm{V}_{2} \mathrm{O}_{5}$ nanobelts were uniformly intercalated in the web-like rGO architecture. The $\mathrm{VrG}$ electrode with $64 \mathrm{wt} \% \mathrm{~V}_{2} \mathrm{O}_{5}$ exhibited a large $\mathrm{C}_{\mathrm{sp}}$ of $320 \mathrm{~F} \mathrm{~g}^{-1}$ at a current density of $1.0 \mathrm{~A} \mathrm{~g}^{-1}$. In a symmetric supercapacitor setup, $\mathrm{VrG}$ retained $70 \%$ of its initial $C_{\mathrm{sp}}$ after 1000 cycles at a current density of $1 \mathrm{~A} \mathrm{~g}^{-1}$.

An alternative to the versatile hydrothermal process is the sol-gel method, which is a low-cost synthesis strategy that involves the formation of a $\mathrm{V}_{2} \mathrm{O}_{5}$ sol that is converted into a gel via hydrolysis and condensation reactions. The resulting porous $\mathrm{V}_{2} \mathrm{O}_{5}$ xerogel can be used as a free-standing, binderless material used directly as a supercapacitor electrode [61]. Yilmaz et al. utilized the sol-gel synthesis route to fabricate free-standing $\operatorname{VrG}$ electrodes [62]. The $\mathrm{V}_{2} \mathrm{O}_{5}$ gel was first synthesized via a hydrothermal process involving $\mathrm{V}_{2} \mathrm{O}_{5}$ powder and $\mathrm{H}_{2} \mathrm{O}_{2}$. The $\mathrm{V}_{2} \mathrm{O}_{5}$ gel, GO, and thiourea (cross-linking agent) were reacted for two weeks in a cylindrical glass vial. The resulting $\mathrm{VrG}$ aerogel was washed with ethanol, freeze-dried, and annealed at $300{ }^{\circ} \mathrm{C}$ in air. The highly porous composite had a large BET surface area of $83.4 \mathrm{~g} \mathrm{~m}^{2}$ because of the lamellar rGO sheet structure with $\mathrm{V}_{2} \mathrm{O}_{5}$ nanoribbons anchored to the rGO surface. The addition of thiourea increased the chemical grafting between $\mathrm{rGO}$ and $\mathrm{V}_{2} \mathrm{O}_{5}$ by functioning as a redox couple, temporarily reducing $\mathrm{V}^{5+}$ to $\mathrm{V}^{4+}$ to initiate the polymerization between $\mathrm{rGO}$ and $\mathrm{V}_{2} \mathrm{O}_{5}$. The reduced $\mathrm{V}^{4+}$ was subsequently oxidized to $\mathrm{V}^{5+}$ during the final annealing step, yielding a hydrated orthorhombic $\mathrm{V}_{2} \mathrm{O}_{5}$ crystal structure. The symmetric supercapacitor with the thioureadoped $\mathrm{VrG}$ electrodes exhibited a $\mathrm{C}_{\mathrm{sp}}$ of $484.9 \mathrm{~F} \mathrm{~g}^{-1}$ at a current density of $0.6 \mathrm{~A} \mathrm{~g}^{-1}$, which was twice that of a thiourea-less VrG. Using thiourea during the synthesis also resulted in sulfur and nitrogen functionalization of rGO. The functional groups decreased the equivalent series resistance to $1.6 \Omega$, resulting in good rate capability with a high $C_{\mathrm{sp}}$ of $\sim 300 \mathrm{~F} \mathrm{~g}^{-1}$ at a high current density of $10 \mathrm{~A} \mathrm{~g}^{-1}$. The mesoporous structure allowed high ion adsorption and decreased the mechanical strain during rapid ion intercalation/deintercalation, resulting in a high $\mathrm{C}_{\mathrm{sp}}$ retention of $80 \%$ after 10,000 cycles at a high current density of $5 \mathrm{~A} \mathrm{~g}^{-1}$. A symmetric capacitor with the $\operatorname{VrG}$ xerogel electrodes possessed an energy density of $43.0 \mathrm{Wh} \mathrm{kg}^{-1}$ at a power density of $480 \mathrm{~W} \mathrm{~kg}^{-1}$, which decreased to $24.2 \mathrm{Wh} \mathrm{kg}^{-1}$ at a power density of $9300 \mathrm{~W} \mathrm{~kg}^{-1}$. Kiruthiga et al. also used the solgel method to synthesize $\mathrm{V}_{2} \mathrm{O}_{5}$ nanorods anchored to rGO sheets [63]. $\mathrm{A}_{2} \mathrm{O}_{5}$ sol was prepared by reacting ammonium metavanadate with citric acid, and the sol was heated to form a gel that was subsequently heated at $450{ }^{\circ} \mathrm{C}$ in air to produce $\mathrm{V}_{2} \mathrm{O}_{5}$ powder. $\mathrm{V}_{2} \mathrm{O}_{5}$ was subsequently intercalated into the rGO sheets via sonication in DI water. The $\operatorname{VrG}$ composite exhibited a $\mathrm{C}_{\mathrm{sp}}$ of $224 \mathrm{~F} \mathrm{~g}^{-1}$ at a current density of $0.01 \mathrm{~A} \mathrm{~g}^{-1}$ with a high $\mathrm{C}_{\mathrm{sp}}$ retention of $85 \%$ after 1000 cycles at a current density of $0.06 \mathrm{~A} \mathrm{~g}^{-1}$. An asymmetric Na-ion supercapacitor with a $\operatorname{VrG}$ anode and an AC cathode exhibited a maximum $\mathrm{C}_{\mathrm{sp}}$ of $62 \mathrm{~F} \mathrm{~g}^{-1}$ at a current density of $0.01 \mathrm{~A} \mathrm{~g}^{-1}$ with $74 \% \mathrm{C}_{\mathrm{sp}}$ retention after 1000 cycles at a current density of $0.06 \mathrm{~A} \mathrm{~g}^{-1}$. The supercapacitor produced a maximum energy density of $65 \mathrm{Wh} \mathrm{kg}^{-1}$ at a power density of $72 \mathrm{~W} \mathrm{~kg}^{-1}$ and a current density of $0.03 \mathrm{~A} \mathrm{~g}^{-1}$. 
Another method of synthesizing a VrG composite involves the filtration of an rGO and $\mathrm{V}_{2} \mathrm{O}_{5}$ suspension through a membrane. Unlike the hydrothermal method, the filtration process produces a stable and binderless thin-film electrode material. Wang et al. synthesized a VrG composite via the filtration of a solution of poly(3,4-ethylenedioxythiophene) (PEDOT), a conducting polymer, $\mathrm{V}_{2} \mathrm{O}_{5}$, and rGO through a cellulose acetate membrane [64]. The resulting binderless $\mathrm{VrG}$ thin film was then roll pressed onto various substrates such as ITO glass and Al to yield a substrate/PEDOT/VrG electrode. During synthesis, the $\mathrm{V}_{2} \mathrm{O}_{5}$ crystals were recrystallized into thin nanobelts coated evenly with PEDOT without the intercalation of the 3,4-ethylenedioxythiophene (EDOT) monomer into the $\mathrm{V}_{2} \mathrm{O}_{5}$ lattice. PEDOT acted as a bridge between $\mathrm{V}_{2} \mathrm{O}_{5}$ and $\mathrm{rGO}$ through $\pi-\pi$ conjugation, such that $\mathrm{V}_{2} \mathrm{O}_{5}$ did not interact directly with rGO. These strong bonds allowed the composite material to form a stable film structure that was easily transferred to and compressed onto different substrates without a binder between the substrate and composite material. Figure 3a shows the procedure for transferring the thin-film hybrid material. A facile electrode fabrication procedure was applied to various substrates such as ITO, plastic, and glass. The VrG material exhibited smooth surface adhesion and good optical transparency for all tested substrates (Figure 3b,c). A large thin-film electrode with a diameter of $170 \mathrm{~mm}$ was easily fabricated (Figure 3d) and placed in an array (Figure 3e), demonstrating the viability of this fabrication strategy for scale-up. When placed on an Ag/PET current collector, the PEDOT/VrG electrode yielded an areal capacitance of $22.4 \mathrm{mF} \mathrm{cm}^{-2}$ at a current density of $0.7 \mathrm{~A} \mathrm{~m}^{-2}$. A lack of binder between the substrate and PEDOT/VrG enabled direct contact between the conductive Ag substrate and composite material, increasing the overall electrochemical performance. The PEDOT coating on $\mathrm{V}_{2} \mathrm{O}_{5}$ reduced the dissolution of $\mathrm{V}_{2} \mathrm{O}_{5}$, resulting in a high capacitance retention of $98 \%$ after 150,000 cycles. Moreover, the outer rGO layer trapped the vanadium ions within the composite structure for maximum vanadium retention. A symmetric supercapacitor yielded a high $\mathrm{C}_{\mathrm{sp}}$ retention of $92.4 \%$ after 50,000 cycles with a maximum energy density of $1800 \mathrm{Wh} \mathrm{m}^{-2}$ at a power density of $110,000 \mathrm{~W} \mathrm{~m}^{-2}$. Similarly, Liu et al. synthesized a stable $\mathrm{V}_{2} \mathrm{O}_{5} / \mathrm{rGO}$ composite electrode via vacuum filtration through a cellulose acetate membrane [65]. A thin $\mathrm{VrG}$ film was fabricated by first preparing a lytropic liquid crystal suspension of $\mathrm{rGO}$ and $\mathrm{V}_{2} \mathrm{O}_{5}$ in DI water. The lamellar phase suspension was filtered through the cellulose membrane, yielding a $\mathrm{VrG}$ thin film that could withstand a maximum pressure of $120 \mathrm{MPa}$. With a $67 \mathrm{wt} \% \mathrm{~V}_{2} \mathrm{O}_{5}$, the thin film possessed a maximum $\mathrm{C}_{\mathrm{sp}}$ of $205 \mathrm{~F} \mathrm{~g}^{-1}$ at a current density of $1 \mathrm{~A} \mathrm{~g}^{-1}$. The electrode exhibited excellent rate capability by retaining more than $50 \%$ of its initial $C_{s p}$ at a high current density of $50 \mathrm{~A} \mathrm{~g}^{-1}$. The electrode retained $94 \%$ of its $C_{s p}$ after 3000 cycles at a current density of $10 \mathrm{~A} \mathrm{~g}^{-1}$. An added advantage of thin-film VrG materials is their high flexibility. Foo et al. utilized vacuum filtration through a nitrocellulose filter to synthesize a flexible VrG composite [66]. The VrG was peeled from the filter, heated in an autoclave with hydrazine monohydrate, dried, and acid-treated to yield a flexible, binderless VrG electrode. The hydrazine exfoliated the $\mathrm{VrG}$ into layers with an average spacing of $30 \mu \mathrm{m}$. Small amorphous $\mathrm{V}_{2} \mathrm{O}_{5}$ crystals were embedded on the surface of planar rGO layers. The thin-film material possessed a large Young's modulus of $1.7 \mathrm{GPa}$ and tensile strength of $6.1 \mathrm{MPa}$ and could be repeatedly bent and unbent around a test tube with no sign of permanent deformation. The flexible electrode material exhibited a $\mathrm{C}_{\mathrm{sp}}$ of $178.5 \mathrm{~F} \mathrm{~g}^{-1}$ at a current density of $0.05 \mathrm{~A} \mathrm{~g}^{-1}$. The hybrid thin film had a moderate rate capability due to a low equivalent series resistance of $3.36 \Omega$, resulting in a $C_{s p}$ of 129.7 $\mathrm{F} \mathrm{g}^{-1}$ at twice the current density. An asymmetric supercapacitor with a flexible $\operatorname{VrG}$ anode had maximum energy densities of $13.3 \mathrm{Wh} \mathrm{kg}^{-1}$ (unbent) and $13.6 \mathrm{Wh} \mathrm{kg}^{-1}$ (bent) at a power density of $12.5 \mathrm{~W} \mathrm{~kg}-1$. 
a
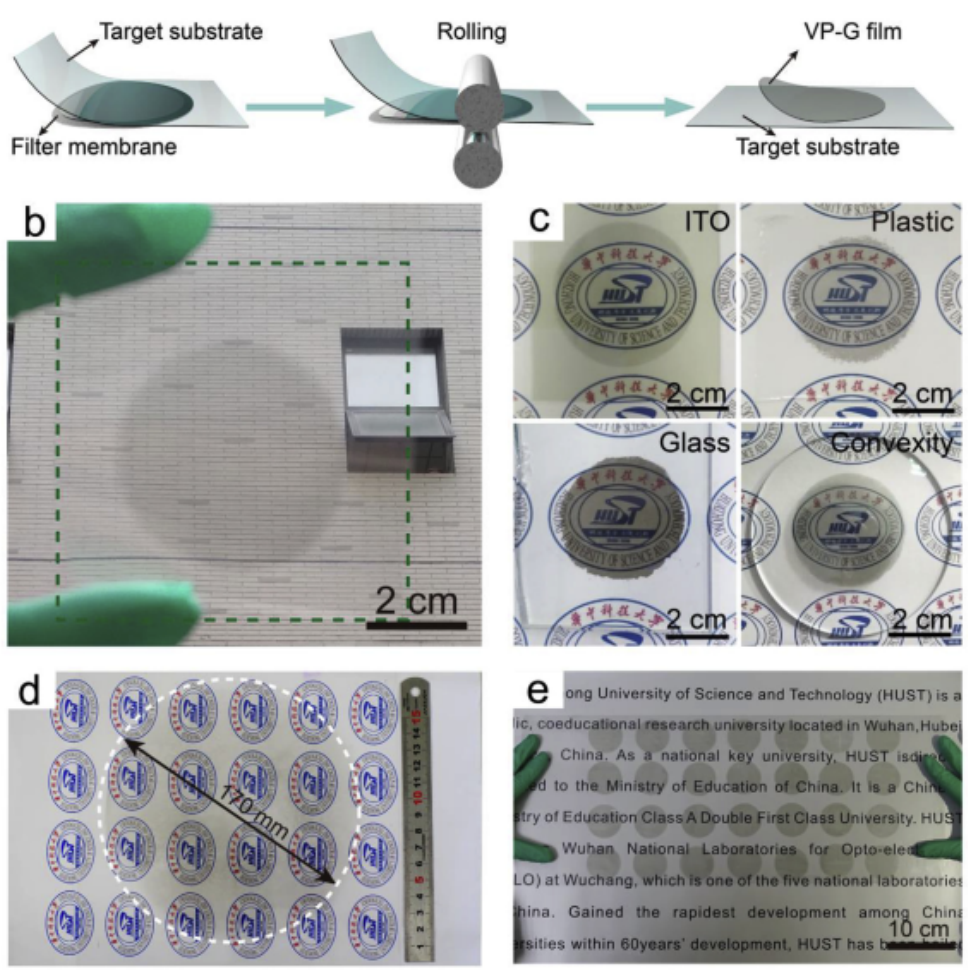

Figure 3. (a) Illustration of the transfer of the $\operatorname{VrG}$ film onto a substrate via a rolling process. Digital photographs of (b) transparent VrG films with a thickness of $22 \mathrm{~nm}$, (c) transparent VrG on ITO, plastic, and glass with good convexity, and (d) a large VrG disc pressed on a substrate. (e) Digital photograph of a $7 \times 4$ array of the large-scale VrG films. Reprinted with permission from Ref. [64]. Copyright 2020 Elsevier.

Chemical deposition is a facile strategy for synthesizing a $\mathrm{VrG}$ composite directly on a conductive substrate. Different deposition techniques allow the composite material to bind to a well-structured, porous 3D network for structural stability and maximum porosity without the need for insulative additives or binders. Van Hoa et al. utilized chemical vapor deposition (CVD) to fabricate a free-standing graphene $/ \mathrm{V}_{2} \mathrm{O}_{5}$ composite with a $\mathrm{Ni}$ foam template [67]. First, graphene was deposited on a Ni foam template using CVD, yielding a porous macrostructure with smooth graphene plates. Subsequently, $\mathrm{V}_{2} \mathrm{O}_{5}$ was deposited on the graphene/Ni foam substrate via a solvothermal method in an oxalic acid solution. The Ni foam was covered with uneven graphene plates after the initial CVD, increasing the surface area of the template. Small $\mathrm{V}_{2} \mathrm{O}_{5}$ nanoflowers were uniformly packed on the graphene surface. The flower-like nanostructures were intricately connected ultrathin $\mathrm{V}_{2} \mathrm{O}_{5}$ nanosheets with a highly orthorhombic crystal phase. The nanoflower extrusions on the porous graphene/ $\mathrm{Ni}$ foam template further increased the BET surface area to $49.4 \mathrm{~m}^{2} \mathrm{~g}^{-1}$ for increased redox reactions. As $\mathrm{V}_{2} \mathrm{O}_{5}$ was synthesized directly on the graphene/ $\mathrm{Ni}$ foam template, there was no binder material to reduce the number of active sites. The electrode exhibited one of the highest reported $\mathrm{C}_{\mathrm{sp}}$ values of $1235 \mathrm{~F} \mathrm{~g}^{-1}$ at a current density of $2 \mathrm{~A} \mathrm{~g}^{-1}$. The direct contact between graphene and $\mathrm{Ni}$ foam resulted in high conductivity throughout the electrode material, resulting in a slight decrease in $\mathrm{C}_{\mathrm{sp}}$ to $800 \mathrm{~F} \mathrm{~g}^{-1}$, even at a large current density of $20 \mathrm{~A} \mathrm{~g}^{-1}$. The large capacitance was due to the high specific surface area provided by the porous template and gaps between the petal-like $\mathrm{V}_{2} \mathrm{O}_{5}$. The composite electrode retained $92 \%$ of its $\mathrm{C}_{\mathrm{sp}}$ after 5000 cycles at a high current density of $4 \mathrm{~A} \mathrm{~g}^{-1}$, indicating good reversibility because of stable chemical bonding and enhanced conductivity. The energy density was $116 \mathrm{Wh} \mathrm{kg}^{-1}$ at a power density of $440 \mathrm{~W} \mathrm{~kg}^{-1}$, which decreased to $\sim 330 \mathrm{Wh} \mathrm{kg}^{-1}$ at a power density of $\sim 3500 \mathrm{~W} \mathrm{~kg}^{-1}$. Wang et al. employed a similar synthesis strategy to fabricate a $\mathrm{Ni}$ foam-based $\mathrm{V}_{2} \mathrm{O}_{5} / \mathrm{rGO}$ electrode [68]. $\mathrm{HCl}$ 
and $\mathrm{FeCl}_{3}$ were used to etch the $\mathrm{Ni}$ foam before graphene $\mathrm{CVD}$ to ensure strong, more homogeneously spread bonding. $\mathrm{V}_{2} \mathrm{O}_{5}$ was then synthesized directly on the $\mathrm{rGO} / \mathrm{Ni}$ foam substrate via a solvothermal method in an ethanol solution, resulting in long $\mathrm{V}_{2} \mathrm{O}_{5}$ nanoribbons that were several micrometers in length. $\mathrm{V}_{2} \mathrm{O}_{5}$ was not completely oxidized and possessed a monoclinic crystal phase, while rGO showed a dominant graphitic crystal phase. The areal capacitance of the free-standing electrode was $822 \mathrm{mF} \mathrm{cm}^{-2}$ at a current density of $1 \mathrm{~mA} \mathrm{~cm}^{-2}$. An asymmetric supercapacitor composed of a VG cathode had an energy density of $16 \mathrm{Wh} \mathrm{kg}^{-1}$ at a power density of $200 \mathrm{~W} \mathrm{~kg} \mathrm{~kg}^{-1}$. Using chemical bath deposition (CBD) instead of CVD, Korkmaz et al. synthesized a binder-free, thin-film VrG [69]. Glass (G), poly(methyl methacrylate) (PMMA) (P), fluorine-doped tin oxide (FTO) glass (F), and indium tin oxide (ITO) glass (I) substrates were added to a solution of GO, $\mathrm{NaVO}_{3}$, galactic acid, and methanol, and reacted for $24 \mathrm{~h}$ at ambient temperature. The coated substrate materials were removed via chemical blanket removal. The texture of the film surface differed for each substrate, showing spherical structures of different sizes for VrG-G, a smooth and homogeneous structure for VrG-P, a dense and grainy structure for VrG-F, and dispersed agglomerations for VrG-I. The crystallinity also changed depending on the substrate with amorphous, orthorhombic crystal growth observed in VrG-G and VrG-P, but well-oriented orthorhombic crystal growth in VrG-F and VrG-I. The thickness of the VrG film was also different, with values of 1025, 988, 689, and $393 \mathrm{~nm}$ for VrG-G, VrG-P, VrG-F, and VrG-I, respectively. Despite containing a thin $\mathrm{V}_{2} \mathrm{O}_{5}$ layer for limited pseudocapacitance potential, VrG-F exhibited the largest $\mathrm{C}_{\mathrm{sp}}$ of $949.6 \mathrm{~F} \mathrm{~g}^{-1}$ owing to its organized crystalline structure.

Different synthesis strategies such as hydro/solvothermal, sol-gel, filtration, and chemical deposition methods are available for the preparation of $\mathrm{VrG}$ composites with varying $\mathrm{V}_{2} \mathrm{O}_{5}$ and rGO morphologies. The hydrothermal method is frequently used as a facile and versatile means of embedding $\mathrm{V}_{2} \mathrm{O}_{5}$ nanospheres, nanowires, nanorods, and nanosheets onto lamellar rGO sheets. The product is typically a VrG powder that must be combined with a conductive filler and binder for use as an electrode. The sol-gel method is an alternate process that yields a porous gel instead of a powder that can be directly applied as a supercapacitor electrode. The filtration method yields a thin-film, binderless electrode that can be physically transferred to different substrates such as ITO and plastic. Chemical deposition techniques such as CVD and CBD also allow the direct growth of $\mathrm{V}_{2} \mathrm{O}_{5}$ on porous and conductive substrates such as $\mathrm{Ni}$ foam and ITO for improved conductivity and stability.

\subsection{Effects of Composition}

Altering the ratio of $\mathrm{rGO}$ and $\mathrm{V}_{2} \mathrm{O}_{5}$ can improve the overall electrochemical performance by balancing the conductivity of $\mathrm{rGO}$ and the pseudocapacitance of $\mathrm{V}_{2} \mathrm{O}_{5}$. Li et al. emphasized the importance of carefully tuning the carbon content for improved electrochemical performance [70]. Different amounts of rGO were added during hydrothermal synthesis to yield VrG electrodes with 15, 22, and $26 \mathrm{wt} \%$ rGO. Even a relatively small difference of $4 \mathrm{wt} \%$ in the carbon content between VrG-22 and VrG-26 resulted in a significant increase in conductivity, with $\mathrm{VrG}-26$ retaining $46 \%$ of its charge capacity (compared to $26 \%$ capacity retention of $\mathrm{VrG}-22$ ) when the scan rate was increased from 1 to $20 \mathrm{mV} \mathrm{s}^{-1}$. As the orthorhombic $\mathrm{V}_{2} \mathrm{O}_{5}$ nanorods were wrapped by and intercalated between the crumpled rGO sheets, an increase in the rGO content resulted in few nanorod agglomerations and high conductivity, resulting in improved rate capability. An asymmetric capacitor with a VrG-26 anode and AC cathode exhibited a $\mathrm{C}_{\mathrm{sp}}$ of $37.2 \mathrm{~F} \mathrm{~g}^{-1}$ at a current density of $0.5 \mathrm{~A} \mathrm{~g}^{-1}$. The integrated, layered structure of $\mathrm{rGO}$ reduced the permanent dissolution of $\mathrm{V}_{2} \mathrm{O}_{5}$, leading to $90 \% \mathrm{C}_{\mathrm{sp}}$ retention after 1000 cycles at a current density of $2 \mathrm{~A} \mathrm{~g}^{-1}$. The maximum energy density exhibited was $54.3 \mathrm{Wh} \mathrm{kg}^{-1}$ at a power density of $136.4 \mathrm{~W} \mathrm{~kg}^{-1}$. Saravanakumar et al. physically mixed different ratios of already prepared $\mathrm{rGO}$ and $\mathrm{V}_{2} \mathrm{O}_{5}$ in disodium citrate and aged the solution for three days to yield a VrG composite [71]. All $\mathrm{VrG}$ compositions had an orthorhombic $\mathrm{V}_{2} \mathrm{O}_{5}$ crystal structure and produced a complex 
$\mathrm{V}_{2} \mathrm{O}_{5}$ network on the 2D rGO surface. However, among these, $\mathrm{VrG}-5(5 \mathrm{wt} \% \mathrm{rGO})$ and $\mathrm{VrG}-15$ (15 wt $\%$ rGO) resulted in more agglomeration of $\mathrm{V}_{2} \mathrm{O}_{5}$, whereas $\mathrm{VrG}-10$ (10 $\mathrm{wt} \%$ $\mathrm{rGO}$ ) had a more homogeneous spread of the $\mathrm{V}_{2} \mathrm{O}_{5}$ crystals. $\mathrm{V}_{2} \mathrm{O}_{5}$ agglomeration limited surface ion adsorption as the electrolyte could not intercalate deep into the bulk $\mathrm{V}_{2} \mathrm{O}_{5}$ crystal structure. Thus, well-spread VrG-10 exhibited the highest $\mathrm{C}_{\mathrm{sp}}$ of $519 \mathrm{~F} \mathrm{~g}^{-1}$ at a scan rate of $2 \mathrm{mV} \mathrm{s}^{-1}$, which was significantly greater than the $326 \mathrm{~F} \mathrm{~g}^{-1} \mathrm{C}_{\mathrm{sp}}$ for pristine $\mathrm{V}_{2} \mathrm{O}_{5}$. An increase in rGO content improved the electron mobility to balance the high pseudocapacitive charge capacity of $\mathrm{V}_{2} \mathrm{O}_{5}$. VrG-15 performed worse than bare $\mathrm{V}_{2} \mathrm{O}_{5}$ with a $\mathrm{C}_{\mathrm{sp}}$ of $210 \mathrm{~F} \mathrm{~g}^{-1}$ because of the lower $\mathrm{V}_{2} \mathrm{O}_{5}$ content and $\mathrm{V}_{2} \mathrm{O}_{5}$ agglomeration on rGO, which limited electron mobility and ion intercalation/de-intercalation. An increase in the rGO content enhanced the rate capability of the $\mathrm{VrG}$ electrodes, with $\mathrm{VrG}-5$ showing only $47 \% \mathrm{C}_{\mathrm{sp}}$ retention compared to $68 \%$ retained by $\mathrm{VrG}-15$ when the current density was increased from 0.5 to $10 \mathrm{~A} \mathrm{~g}^{-1}$. Increasing the rGO content decreased the internal resistance, as indicated by $0.4 \Omega$ resistance in $\mathrm{VrG}-10$ compared to $1.73 \Omega$ for pristine $\mathrm{V}_{2} \mathrm{O}_{5}$. The physical support provided by the rGO sheets further reduced the damage caused by repeated intercalation/de-intercalation, resulting in an $83 \% \mathrm{C}_{\mathrm{sp}}$ retention after 1000 cycles for $\mathrm{VrG}-10$. An appropriate $\mathrm{rGO}$ composition is required to decrease $\mathrm{V}_{2} \mathrm{O}_{5}$ agglomeration for maximum pseudocapacitive efficiency and improve the conductive pathways for higher rate capability.

Although a high carbon content is desirable, a high $\mathrm{V}_{2} \mathrm{O}_{5}$ composition is required for energy-dense supercapacitor electrodes. Ramadoss et al. examined the effect of varying rGO to $\mathrm{V}_{2} \mathrm{O}_{5}$ ratio by controlling the initial ratio of $\mathrm{GO}$ and $\mathrm{V}_{2} \mathrm{O}_{5}$ during microwave synthesis [72]. All three $\mathrm{VrG}$ variations, $\mathrm{V}_{1} \mathrm{rG}_{2}$ (1:2 $\mathrm{V}_{2} \mathrm{O}_{5}$ to GO), $\mathrm{V}_{1} \mathrm{rG}_{1}\left(1: 1 \mathrm{~V}_{2} \mathrm{O}_{5}\right.$ to $\left.\mathrm{GO}\right)$, and $\mathrm{V}_{2} \mathrm{rG}_{1}\left(2: 1 \mathrm{~V}_{2} \mathrm{O}_{5}\right.$ to $\left.\mathrm{GO}\right)$, possessed a pure orthorhombic crystal phase with uniform nanorods of 150-200 nm lengths. The $\mathrm{VrG}$ electrodes exhibited mixed pseudocapacitive and EDL contributions to the overall capacitance. An increase in the $\mathrm{V}_{2} \mathrm{O}_{5}$ content increased the $C_{s p}$ of the $\operatorname{VrG}$ electrode, as indicated by the higher $C_{s p}$ of $250 \mathrm{~F} \mathrm{~g}^{-1}$ for $V_{2} \mathrm{rG}_{1}$ than $103 \mathrm{~F} \mathrm{~g}^{-1}$ for $\mathrm{V}_{1} \mathrm{rG}_{2}$ at a scan rate of $5 \mathrm{mV} \mathrm{s}^{-1}$. As $\mathrm{V}_{2} \mathrm{O}_{5}$ contributed toward most of the capacitance via faradic reactions, increasing the proportion of $\mathrm{V}_{2} \mathrm{O}_{5}$ increased the total capacitance. A symmetric supercapacitor with $\mathrm{V}_{2} \mathrm{rG}_{1}$ electrodes had an energy density of $12.5 \mathrm{Wh} \mathrm{kg}^{-1}$ at a power density of 79,900 W kg-1, which decreased to $8.4 \mathrm{Wh} \mathrm{kg}^{-1}$ at 10 times the power density. Lee et al. also concluded that high $\mathrm{V}_{2} \mathrm{O}_{5}$ content increased the total capacitance [73]. $\mathrm{VrG}$ material was synthesized via a low-temperature hydrothermal process with different ratios of $\mathrm{V}_{2} \mathrm{O}_{5}$ powder and GO. $\mathrm{V}_{3} \mathrm{rG}_{1}$ (3:1 $\mathrm{V}_{2} \mathrm{O}_{5}$ to GO), $\mathrm{V}_{1} \mathrm{rG}_{1}$ (1:1 $\mathrm{V}_{2} \mathrm{O}_{5}$ to $\left.\mathrm{GO}\right)$, and $\mathrm{V}_{1} \mathrm{rG}_{3}\left(1: 3 \mathrm{~V}_{2} \mathrm{O}_{5}\right.$ to $\left.\mathrm{GO}\right)$ all yielded orthorhombic crystalline $\mathrm{V}_{2} \mathrm{O}_{5}$ nanobelts with uniform size. $\mathrm{V}_{2} \mathrm{O}_{5}$-rich $\mathrm{V}_{3} \mathrm{rG}_{1}$ outperformed the other two variations with a $C_{\mathrm{sp}}$ of $288 \mathrm{~F} \mathrm{~g}^{-1}$ at a scan rate of $10 \mathrm{mV} \mathrm{s}^{-1}$, doubling the $\mathrm{C}_{\mathrm{sp}}$ of $\mathrm{V}_{1} \mathrm{rG}_{3}$. Although an increase in the rGO content theoretically increased the conductivity, the low-temperature hydrothermal reduction led to only a partial reduction of GO to rGO, which limited the conversion to highly conductive rGO [73]. A large capacitance requires significant pseudocapacitive contributions, supporting the need for a $\mathrm{V}_{2} \mathrm{O}_{5}$-rich composite material. Many active sites were available for surface redox reactions because of the high surface area of the $\mathrm{V}_{2} \mathrm{O}_{5}$ nanobelts anchored to the rGO layers. However, excessive $\mathrm{V}_{2} \mathrm{O}_{5}$ content could lead to agglomeration that decreases the performance of the $\mathrm{VrG}$ composite. Fu et al. found a balance between the $\mathrm{rGO}$ and $\mathrm{V}_{2} \mathrm{O}_{5}$ contents by synthesizing $\mathrm{VrG}$ electrodes with different weight percentages of $\mathrm{V}_{2} \mathrm{O}_{5}$ [74]. The fabricated $\mathrm{VrG}$ composite synthesized via microwave synthesis method resulted in a uniform distribution of amorphous $\mathrm{V}_{2} \mathrm{O}_{5}$ nanoparticles on lamellar rGO sheets. Flaky rGO prevented the agglomeration of $\mathrm{V}_{2} \mathrm{O}_{5}$, which is a common problem that decreases the surface ion adsorption capability of the $\mathrm{V}_{2} \mathrm{O}_{5}$ nanostructure. More $\mathrm{V}_{2} \mathrm{O}_{5}$ crystals were formed on the $\mathrm{rGO}$ surface without agglomeration at a high initial $\mathrm{V}_{2} \mathrm{O}_{5}$ loading up to $34.1 \mathrm{wt} \%$. VrG-34 $\left(34.1 \mathrm{wt} \% \mathrm{~V}_{2} \mathrm{O}_{5}\right)$ exhibited excellent electrochemical performance with a $\mathrm{C}_{\mathrm{sp}}$ of $673.2 \mathrm{~F} \mathrm{~g}^{-1}$ at a current density of $1 \mathrm{~A} \mathrm{~g}^{-1}$. The high $\mathrm{rGO}$ content resulted in high rate capability, as indicated by a large $\mathrm{C}_{\mathrm{sp}}$ of $474.6 \mathrm{~F} \mathrm{~g}^{-1}$ at a high current density of $10 \mathrm{~A} \mathrm{~g}^{-1}$. A high $\mathrm{V}_{2} \mathrm{O}_{5}$ composition decreased the ion adsorption and number 
of interlayer rGO bridges, which are essential for fast electron transport. With an increase in current density, the high capacitance shifted from the redox dependence of $\mathrm{V}_{2} \mathrm{O}_{5}$ to the capacitive dependence provided by rGO. The porous and stable architecture of the composite allowed good cycling with a $96.8 \% \mathrm{C}_{\mathrm{sp}}$ retention after 10,000 cycles at a current density of $1 \mathrm{~A} \mathrm{~g}^{-1}$. A symmetric supercapacitor exhibited good performance with an energy density of $46.8 \mathrm{Wh} \mathrm{kg}^{-1}$ at a power density of $499.4 \mathrm{~W} \mathrm{~kg}^{-1}$. A high $\mathrm{V}_{2} \mathrm{O}_{5}$ content is necessary for high energy density through faradic energy storage; but ultimately, a balance between $\mathrm{V}_{2} \mathrm{O}_{5}$ and $\mathrm{rGO}$ is essential for maximizing the electrochemical performance.

A variation in the ratio of $\mathrm{rGO}$ to $\mathrm{V}_{2} \mathrm{O}_{5}$ also alters the porosity and surface area of the final VrG composite. Typically, a greater amount of rGO results in a larger surface area owing to its high surface area. Yao et al. found that decreasing $\mathrm{V}_{2} \mathrm{O}_{5}$ content increased the porosity of the composite [75]. A mixture of $\mathrm{V}_{2} \mathrm{O}_{5}$ powder with varying initial loading, $\mathrm{H}_{2} \mathrm{O}_{2}$, and $\mathrm{GO}$ sols was heated at $200{ }^{\circ} \mathrm{C}$ for $5 \mathrm{~h}$ to yield a $\mathrm{VrG}$ composite. The resulting $\mathrm{VrG}$ aerogel comprised $\mathrm{V}_{2} \mathrm{O}_{5}$ nanobelts with a pure orthorhombic crystal phase uniformly intercalated between the layers of rGO. $\mathrm{VrG}$ with $80.5 \mathrm{wt} \% \mathrm{~V}_{2} \mathrm{O}_{5}$ exhibited a small BET surface area of $20.5 \mathrm{~m}^{2} \mathrm{~g}^{-1}$, whereas $\mathrm{VrG}$ with $15.6 \mathrm{wt} \% \mathrm{~V}_{2} \mathrm{O}_{5}$ exhibited a large BET surface area of $103.4 \mathrm{~m}^{2} \mathrm{~g}^{-1}$. As rGO had a greater surface area than $\mathrm{V}_{2} \mathrm{O}_{5}$, the addition of higher amounts of $\mathrm{rGO}$ increased the overall surface area of the $\mathrm{VrG}$ material. Moreover, $\mathrm{V}_{2} \mathrm{O}_{5}$ tended to agglomerate at high concentrations. A decrease in the total $\mathrm{V}_{2} \mathrm{O}_{5}$ content resulted in a more homogeneous distribution of $\mathrm{V}_{2} \mathrm{O}_{5}$ throughout the $\mathrm{rGO}$ surface to provide more active sites. VrG-62 (61.6 wt $\left.\% \mathrm{~V}_{2} \mathrm{O}_{5}\right)$ outperformed other $\mathrm{VrG}$ electrodes owing to a good balance of EDLC and pseudocapacitance while maintaining a high pore volume of $0.008 \mathrm{~cm}^{3} \mathrm{~g}^{-1}$. The VrG-62 electrode exhibited a maximum $\mathrm{C}_{\mathrm{sp}}$ of $310.1 \mathrm{~F} \mathrm{~g}^{-1}$ at a current density of $1 \mathrm{~A} \mathrm{~g}^{-1}$. The $\mathrm{VrG}$ composite had good rate capability, as indicated by a high $\mathrm{C}_{\mathrm{sp}}$ of $195.2 \mathrm{~F} \mathrm{~g}^{-1}$ at a large current density of $10 \mathrm{~A} \mathrm{~g}^{-1}$. Choudhury et al. also reported that a lower $\mathrm{V}_{2} \mathrm{O}_{5}$ content of a $\mathrm{V}_{2} \mathrm{O}_{5}$ /graphene (VG) composite increased the specific surface area [76]. The VG material was synthesized via an in situ chemical reaction between $\mathrm{V}_{2} \mathrm{O}_{5}$ powder and exfoliated graphene with $\mathrm{H}_{2} \mathrm{O}_{2} \cdot \mathrm{V}_{4} \mathrm{G}_{1}\left(4: 1 \mathrm{~V}_{2} \mathrm{O}_{5}\right.$ to graphene) and $\mathrm{V}_{2} \mathrm{G}_{1}\left(2: 1 \mathrm{~V}_{2} \mathrm{O}_{5}\right.$ to graphene) exhibited a layered structure with $\mathrm{V}_{2} \mathrm{O}_{5}$ nanofibers anchored between the layers of rough graphene. The BET surface area of $\mathrm{V}_{2} \mathrm{G}_{1}$ was $142 \mathrm{~m}^{2} \mathrm{~g}^{-1}$, which decreased to $117 \mathrm{~m}^{2} \mathrm{~g}^{-1}$ for $\mathrm{V}_{4} \mathrm{G}_{1}$. A low amount of $\mathrm{V}_{2} \mathrm{O}_{5}$ produced a composite with a high surface area, resulting in more active redox sites and greater intercalation/deintercalation. Accordingly, $\mathrm{V}_{2} \mathrm{G}_{1}$ exhibited a higher $\mathrm{C}_{\mathrm{sp}}$ of $218 \mathrm{~F} \mathrm{~g}^{-1}$ compared to $112 \mathrm{~F} \mathrm{~g}^{-1}$ for $\mathrm{V}_{4} \mathrm{G}_{1}$ at a current density of $1 \mathrm{~A} \mathrm{~g}^{-1}$. A symmetric supercapacitor of $\mathrm{V}_{2} \mathrm{G}_{1}$ yielded an energy density of $22 \mathrm{Wh} \mathrm{kg}^{-1}$ at a power density of $3594 \mathrm{~W} \mathrm{~kg}^{-1}$.

However, a balance between $\mathrm{V}_{2} \mathrm{O}_{5}$ and $\mathrm{rGO}$ could increase the surface area to greater than that of pure rGO. Deng et al. found that a VrG composite yielded higher porosity than that of pure rGO because of the increased interlayer spacing of the rGO sheets caused by $\mathrm{V}_{2} \mathrm{O}_{5}$ intercalation [77]. A VrG monolith was synthesized via a hydrothermal method, resulting in a lamellar rGO structure with $\mathrm{V}_{2} \mathrm{O}_{5}$ nanowires embedded between the thin rGO sheets (22 $w \mathrm{t} \% \mathrm{rGO}$ ). The resulting BET surface area of the $\mathrm{VrG}$ monolith was $172.9 \mathrm{~m}^{2}$ $\mathrm{g}^{-1}$, which was $\sim 100 \mathrm{~m}^{2} \mathrm{~g}^{-1}$ larger than that of a pure rGO monolith and approximately five times larger than that of pure $\mathrm{V}_{2} \mathrm{O}_{5}$. The $\mathrm{VrG}$ monolith was also compressed into a thin film electrode. The $\mathrm{C}_{\mathrm{sp}}$ of $\mathrm{VrG}$ monolith and thin-film were 385 and $272 \mathrm{~F} \mathrm{~g}^{-1}$, respectively, at a current density of $0.25 \mathrm{~A} \mathrm{~g}^{-1}$. The $\mathrm{VrG}$ material exhibited enhanced ion diffusion rates owing to increased porosity, resulting in good rate capability, as indicated by a high $\mathrm{C}_{\mathrm{sp}}$ of $224 \mathrm{~F} \mathrm{~g}^{-1}$ at a current density of $10 \mathrm{~A} \mathrm{~g}^{-1}$. The energy density of the asymmetric supercapacitor with the $\mathrm{VrG}$ electrode was $26.22 \mathrm{Wh} \mathrm{kg}^{-1}$ at a power density of $425 \mathrm{~W} \mathrm{~kg}^{-1}$, which decreased to $7 \mathrm{Wh} \mathrm{kg}^{-1}$ at a power density of $8500 \mathrm{~W} \mathrm{~kg}^{-1}$. Ndiaye found that an increase in the graphene foam (GF) content only increased the porosity to a certain extent [78]. A $\mathrm{V}_{2} \mathrm{O}_{5} / \mathrm{GF}$ composite was synthesized with varying initial GF loading. The BET surface area increased from $4.9 \mathrm{~m}^{2} \mathrm{~g}^{-1}$ for pristine $\mathrm{V}_{2} \mathrm{O}_{5}$ nanosheets to $5.1 \mathrm{~m}^{2} \mathrm{~g}^{-1}$ when $50 \mathrm{mg}$ of GF was added. Because GF has a high specific surface area of $208.8 \mathrm{~m}^{2} \mathrm{~g}^{-1}$, the initial integration of GF increased the overall surface area. The low 
GF content also prevented the homogeneous integration of the $\mathrm{V}_{2} \mathrm{O}_{5}$ nanosheets with GF. An increase in the GF loading to $150 \mathrm{mg}(\mathrm{VrG}-150)$ resulted in a maximum surface area of $9.5 \mathrm{~m}^{2} \mathrm{~g}^{-1}$. However, further increase in the GF loading to $200 \mathrm{mg}$ resulted in the reduction of surface area to $6.2 \mathrm{~m}^{2} \mathrm{~g}^{-1}$. A high GF content caused GF and $\mathrm{V}_{2} \mathrm{O}_{5}$ to form separate agglomerations instead of a homogeneous composite. Consequently, the porous and homogeneous $\mathrm{VrG}-150$ outperformed the other electrodes, with a specific capacity of $73 \mathrm{mAh} \mathrm{g}^{-1}$ at a current density of $1 \mathrm{~A} \mathrm{~g}^{-1}$. An asymmetric capacitor assembled using a VrG-150 positive electrode and carbonized Fe-adsorbed polyaniline (C-FE-PANI) negative electrode yielded a specific capacity of $41 \mathrm{mAh} \mathrm{g}^{-1}$ at a current density of $1 \mathrm{~A} \mathrm{~g}^{-1}$. The energy density was $39 \mathrm{~W} \mathrm{~h} \mathrm{~kg}^{-1}$ at a power density of $947 \mathrm{~W} \mathrm{~kg}^{-1}$.

Determining the optimal ratio between $\mathrm{rGO}$ and $\mathrm{V}_{2} \mathrm{O}_{5}$ is essential for synthesizing a high-performance electrode material with a balance between the EDL and pseudocapacitive characteristics. An appropriate rGO content improves the conductivity and electrode cyclability, whereas a sufficient $\mathrm{V}_{2} \mathrm{O}_{5}$ content is necessary for high specific capacitance. The addition of rGO to bulk $\mathrm{V}_{2} \mathrm{O}_{5}$ increases the surface area of the composite material, and the intercalation of $\mathrm{V}_{2} \mathrm{O}_{5}$ into $\mathrm{rGO}$ layers can also increase the porosity of the composite material. However, a balance between the two components is necessary to prevent agglomeration.

\subsection{Effects of Physical Treatment}

Annealing newly fabricated $\mathrm{VrG}$ composites can alter oxidation states of vanadium oxides and improve their crystallinity, resulting in enhanced electrochemical performance. Control of the temperature during the heat treatment can increase the oxidation of $\mathrm{V}_{2} \mathrm{O}_{5}$ and the formation of a homogeneous composite. Following a hydrothermal synthesis procedure, $\mathrm{Li}$ et al. synthesized $\mathrm{V}_{\mathrm{x}} \mathrm{O}_{\mathrm{y}}$ nanoflowers anchored to $\mathrm{rGO}$ sheets [79]. Annealing of the resulting composite caused the nanoflowers to morph into $\mathrm{V}_{2} \mathrm{O}_{5}$ nanorods with varying lengths and diameters depending on the annealing temperature. Moreover, an increase in the annealing temperature converted amorphous vanadium oxides into orthorhombic $\mathrm{V}_{2} \mathrm{O}_{5}$ crystals through the oxidation of $\mathrm{V}^{4+}$ to $\mathrm{V}^{5+}$. $\mathrm{VrG}$ annealed at $350{ }^{\circ} \mathrm{C}$ under nitrogen atmosphere exhibited the maximum $\mathrm{C}_{\mathrm{sp}}$ of $537 \mathrm{~F} \mathrm{~g}^{-1}$ at a current density of $1 \mathrm{~A} \mathrm{~g}^{-1}$ due to short ion diffusion pathways in the organized $\mathrm{V}_{2} \mathrm{O}_{5}$ crystal lattice. Because the nanorods were uniformly anchored to the mesoporous $\mathrm{rGO}$ surface, the high conductivity and porosity afforded by the rGO resulted in a good rate capability, indicated by the $60 \%$ $\mathrm{C}_{\mathrm{sp}}$ retention at a high current density of $20 \mathrm{~A} \mathrm{~g}^{-1}$. Improved cyclic performance of the $\mathrm{VrG}$ material was also observed, with $84 \% \mathrm{C}_{\mathrm{sp}}$ retention after 1000 cycles at a current density of $1 \mathrm{~A} \mathrm{~g}^{-1}$. The $\mathrm{VrG}$ electrode exhibited a high energy density of $74.58 \mathrm{Wh} \mathrm{kg}^{-1}$ at a power density of $500 \mathrm{~W} \mathrm{~kg}^{-1}$, which decreased slightly to $29.33 \mathrm{Wh} \mathrm{kg}^{-1}$ at a power density of $10,000 \mathrm{~W} \mathrm{~kg}^{-1}$. In a similar study, Liu et al. fabricated a VrG composite via a hydrothermal method using an $\mathrm{NH}_{4} \mathrm{VO}_{3}$ precursor followed by annealing at different temperatures in air [80]. Without annealing, $\mathrm{V}_{2} \mathrm{O}_{5}$ nanospheres of inconsistent sizes and incomplete formation were observed, whereas $\operatorname{VrG}$ annealed at a high temperature of $350{ }^{\circ} \mathrm{C}(\mathrm{VrG}-350)$ exhibited a degraded $\mathrm{rGO}$ support without distinct $\mathrm{V}_{2} \mathrm{O}_{5}$ nanospheres. However, $\mathrm{VrG}$ annealed at $300{ }^{\circ} \mathrm{C}$ (VrG-300) had uniformly sized $\mathrm{V}_{2} \mathrm{O}_{5}$ nanospheres homogeneously embedded on the surface of the rGO. VrG-300 exhibited greater GO reduction and an increase in $\mathrm{V}_{2} \mathrm{O}_{5}$ composition from 12 to $30 \mathrm{wt} \%$, owing to greater $\mathrm{V}^{4+}$ oxidation to $\mathrm{V}^{5+}$. With fewer defects in the carbon lattice and a higher $\mathrm{V}_{2} \mathrm{O}_{5}$ content, $\mathrm{VrG}-300$ exhibited the largest $\mathrm{C}_{\mathrm{sp}}$ of $386 \mathrm{~F} \mathrm{~g}^{-1}$ at a current density of $0.5 \mathrm{~A} \mathrm{~g}^{-1}$. An asymmetric supercapacitor with the VrG-300 electrode had a maximum energy density of $80.4 \mathrm{Wh} \mathrm{kg}^{-1}$ at a power density of $275 \mathrm{~W} \mathrm{~kg}^{-1}$, which decreased to $32 \mathrm{Wh} \mathrm{kg}^{-1}$ at a power density of $1374 \mathrm{~W} \mathrm{~kg}^{-1}$. Thangappan et al. electro-spun a mixture of vanadium acetylacetonate, GO, polyvinyl pyrrolidone, dimethylformamide (DMF), and ethanol, and subsequently annealed the composite at 350 or $550{ }^{\circ} \mathrm{C}$ in air [81]. Non-annealed $\operatorname{VrG}$ and $\mathrm{VrG}$ annealed at $350{ }^{\circ} \mathrm{C}$ resulted in a web of uniformly thin and straight nanowires. $\operatorname{VrG}$ annealed at $550{ }^{\circ} \mathrm{C}$ resulted in a twisted and aggregated structure with arched webs that were half the diameter of the 
non-annealed $\mathrm{VrG}$ due to the decomposition of the organic binder material. Annealing at $550{ }^{\circ} \mathrm{C}$ completely reduced GO, resulting in a more conductive composite fiber. However, high temperature disintegrated the carbon material, resulting in a low carbon content of $0.3 \mathrm{wt} \%$. Non-annealed and low-temperature annealed $\operatorname{VrG}$ had amorphous crystal structures, whereas the $\mathrm{VrG}$ annealed at $550{ }^{\circ} \mathrm{C}$ possessed an orthorhombic crystal structure, as indicated by the formation of large $\mathrm{V}_{2} \mathrm{O}_{5}$ crystals. The stable crystals and mesoporous, web-like structure of $\mathrm{VrG}$ annealed at $550{ }^{\circ} \mathrm{C}$ allowed a large amount of ion diffusion into the electrode for high energy storage. The $C_{\mathrm{sp}}$ was $453.8 \mathrm{~F} \mathrm{~g}^{-1}$ at a scan rate of $10 \mathrm{mV} \mathrm{s}^{-1}$ because of the slow ion intercalation at low scan rates. The $\mathrm{C}_{\mathrm{sp}}$ decreased to $111.01 \mathrm{~F} \mathrm{~g}^{-1}$ at a scan rate of $100 \mathrm{mV} \mathrm{s}^{-1}$. Therefore, the control of the annealing temperature is essential for both the reduction of GO to rGO and improving the crystallinity of $\mathrm{V}_{2} \mathrm{O}_{5}$.

Despite the previously mentioned benefits of heat treatment, the annealing of $\mathrm{VrG}$ electrodes may decrease the electrical performance. Lee et al. analyzed the discrepancy in the electrochemical performance of a non-annealed $\mathrm{V}_{2} \mathrm{O}_{5}$ composite in comparison with an annealed composite, where an rGO thin film was fabricated from $\mathrm{GO}$ using $\mathrm{CO}_{2}$ laser reduction, and $\mathrm{V}_{2} \mathrm{O}_{5}$ was deposited on the film via atomic layer deposition [82]. The $\mathrm{CO}_{2}$ laser changed the porosity of the compact $\mathrm{GO}$ by increasing the interstitial gap between the rGO sheets while creating pores that penetrated multiple rGO sheets. The spacing between the rGO sheets increased with $\mathrm{V}_{2} \mathrm{O}_{5}$ infiltration. The $\mathrm{V}_{2} \mathrm{O}_{5}$ deposition left the rGO template intact, and further annealing the composite in an argon atmosphere did not significantly change the surface morphology of the electrode. However, annealing converted the amorphous $\mathrm{V}_{2} \mathrm{O}_{5}$ crystal structure into a more crystalline $\mathrm{V}_{2} \mathrm{O}_{5}$ with varying oxidation states of vanadium oxide. The amorphous crystal characteristics of $\mathrm{V}_{2} \mathrm{O}_{5}$ before annealing allowed deeper ion diffusion through the distorted lattices, resulting in a greater faradic character. In contrast, the annealed VrG exhibited higher crystallinity and greater EDL contribution. Considering the lamellar structure of the rGO sheets, the diffusion-based faradic capacitance of the non-annealed $\mathrm{VrG}$ resulted in a higher $\mathrm{C}_{\mathrm{sp}}$ of $189 \mathrm{~F} \mathrm{~g}^{-1}$ at a current density of $1 \mathrm{~A} \mathrm{~g}^{-1}$. The charge transfer resistance was also lower for the nonannealed $\operatorname{VrG}$. Initial cycling increased the $\mathrm{C}_{\mathrm{sp}}$ to $108 \%$ for the non-annealed $\operatorname{VrG}$ material owing to electro-activation caused by the initial intercalation of electrolyte ions. However, this did not occur for annealed $\operatorname{VrG}$ because of the more rigid crystallized structure of the annealed $\mathrm{VrG}$ (Figure 4).

In addition to heat treatment, the morphology and crystallinity of a $\mathrm{VrG}$ composite can be altered by laser irradiation. Lazauskas et al. first synthesized a $\mathrm{V}_{2} \mathrm{O}_{5} / \mathrm{GO}$ nanoribbon composite using a melt-quenching process and further applied laser treatment to reduce $\mathrm{GO}$ to $\mathrm{rGO}$ [83]. A 405-nm laser was used to irradiate specific regions of the $\mathrm{V}_{2} \mathrm{O}_{5} / \mathrm{GO}$ composite, resulting in a $\mathrm{VrG}$ composite with surface protrusions. The laser treatment resulted in pillar-like $\mathrm{V}_{2} \mathrm{O}_{5}$ protrusions that uniformly extruded from the rGO base. These protrusions increased the surface area by four times to $17.27 \mathrm{~m}^{2} \mathrm{~g}^{-1}$. An increase in the laser power output from 1.69 to $2.03 \mathrm{~W} \mathrm{~cm}^{-2}$ to $2.37 \mathrm{~W} \mathrm{~cm}^{-2}$ resulted in more protrusions. However, further increase in power to $2.71 \mathrm{~W} \mathrm{~cm}^{-2}$ led to larger $\mathrm{V}_{2} \mathrm{O}_{5}$ agglomerations, thereby decreasing the surface area of the composite material. The laser treatment also decreased the amount of intercalated $\mathrm{H}_{2} \mathrm{O}$ molecules in the $\mathrm{V}_{2} \mathrm{O}_{5}$ crystal lattice while further reducing $\mathrm{GO}$ to $\mathrm{rGO}$. The laser treatment resulted in a $\mathrm{VrG}$ composite with a more organized $\mathrm{V}_{2} \mathrm{O}_{5}$ crystal structure and high conductivity of $6.8 \mathrm{~S} \mathrm{~m}^{-1}$.

Physical treatment of $\mathrm{V}_{2} \mathrm{O}_{5}$ with heat or laser can alter the crystallinity of $\mathrm{V}_{2} \mathrm{O}_{5}$, oxidize $\mathrm{V}^{4+}$ to $\mathrm{V}^{5+}$ and reduce GO to $\mathrm{rGO}$. Highly crystalline $\mathrm{V}_{2} \mathrm{O}_{5}$ is more conductive than amorphous $\mathrm{V}_{2} \mathrm{O}_{5}$, allowing for greater rate capability, but it is less efficient for ion diffusion than the latter. The reduction of GO to rGO improves the conductivity of the carbon backbone in the VrG composite. Physical treatment can also be used to control the formation of agglomerations, and excessive heat exposure can destroy the carbon content of the hybrid material. 


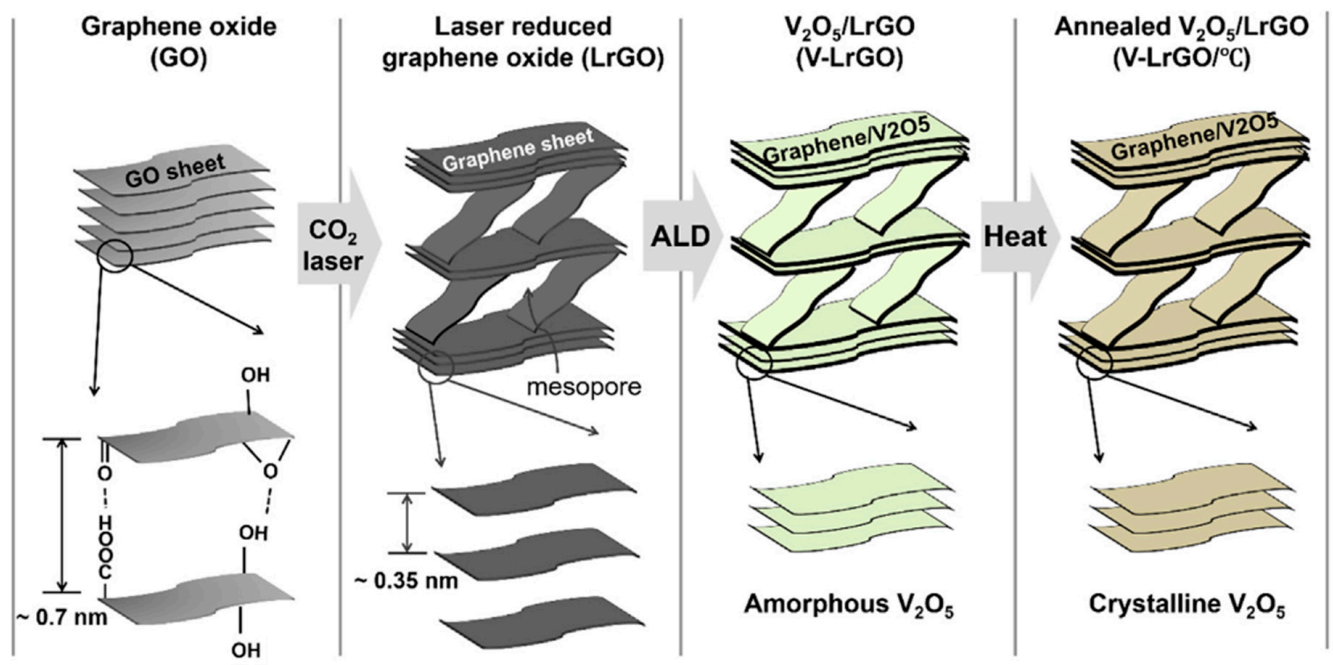

Figure 4. Schematic illustration for the fabrication process of the multilayered graphene (i.e., LrGO) and amorphous or crystalline $\mathrm{V}_{2} \mathrm{O}_{5}$ coated LrGO. Firstly, the prepared $\mathrm{GO}$ was reduced by a home engraver equipped with a $\mathrm{CO}_{2}$ laser. Then, the $\mathrm{LrGO}$ was coated with amorphous $\mathrm{V}_{2} \mathrm{O}_{5}$ by a lowtemperature ALD process, followed by annealing at high temperatures. Reprinted with permission from Ref. [82]. Copyright 2020 Elsevier.

\section{3. $\mathrm{V}_{2} \mathrm{O}_{5} / \mathrm{CNT}$}

CNTs have received considerable attention owing to their high conductivities, large surface areas, mechanical stability, and unique $1 \mathrm{D}$ tubular structures $[84,85]$. The ability of CNTs to be functionalized allows precise control of their properties to meet the needs of specific supercapacitor applications [86]. Single-walled CNTs (SWCNTs) and multi-walled CNTs (MWCNTs) have been utilized in conjunction with vanadium oxides to yield highperformance hybrid materials for supercapacitor applications [87]. Herein, the effects of different synthesis pathways, $\mathrm{V}_{2} \mathrm{O}_{5} / \mathrm{CNT}$ compositions, and physical treatments on the morphology and electrochemical performances of $\mathrm{V}_{2} \mathrm{O}_{5} / \mathrm{CNT}$ (VCNT) composite materials are discussed. The morphology and electrochemical performances of $\mathrm{V}_{2} \mathrm{O}_{5} / \mathrm{CNT}$ electrodes for supercapacitor applications reported in the literature are summarized in Table 2.

Table 2. $\mathrm{V}_{2} \mathrm{O}_{5}$ morphology and electrochemical performances of $\mathrm{V}_{2} \mathrm{O}_{5}$ / carbon nanotube composite electrodes for supercapacitor applications.

\begin{tabular}{|c|c|c|c|c|c|}
\hline Morphology & $\begin{array}{l}\operatorname{Maximum} \mathrm{C}_{\mathrm{sp}} \\
\quad\left(\mathrm{Fg}^{-1}\right)\end{array}$ & $\begin{array}{l}\text { Cycling } \mathrm{C}_{\mathrm{sp}} \\
\text { Retention }(\%)\end{array}$ & Cycle Number & $\begin{array}{l}\text { Energy Density } \\
\quad\left(\mathrm{Wh} \mathrm{kg}^{-1}\right)\end{array}$ & $\begin{array}{l}\text { Power Density } \\
\quad\left(\mathrm{W} \mathrm{kg}^{-1}\right)\end{array}$ \\
\hline Nanostars & 1016 & $64 *$ & $5000 *$ & 13.24 & 710 \\
\hline Nanospheres & 125 & - & 400 & 25 & 100 \\
\hline Nanobelts & 685 & 99.7 & 10,000 & 34.3 & 150 \\
\hline Amorphous & 410 & 86 & 600 & 57 & 250 \\
\hline Nanoflakes & 629 & 93 & 4000 & 72 & 2300 \\
\hline Nanosheets & 207.7 & $75^{*}$ & $10,000 *$ & 7300 & 42.6 \\
\hline Nanospheres & 284 & $76^{*}$ & $5000 *$ & 32.3 & 118 \\
\hline Nanosheets & 357.5 & 99.5 & 1000 & - & - \\
\hline CNT Coating & 510 & 96 & 5000 & 16 & 800 \\
\hline
\end{tabular}

* Cycling performance was determined using a two-electrode configuration.

\subsection{Effects of Synthesis Method}

A common procedure for fabricating VCNT composites is the hydro/solvothermal method. Jiang et al. grew $\mathrm{V}_{2} \mathrm{O}_{5}$ crystals on a GF/CNT substrate by employing a hydrothermal process [88]. Subsequently, PEDOT coating was deposited via a chronoamperometry technique, yielding a VCNT/GF/PEDOT composite (Figure 5). 


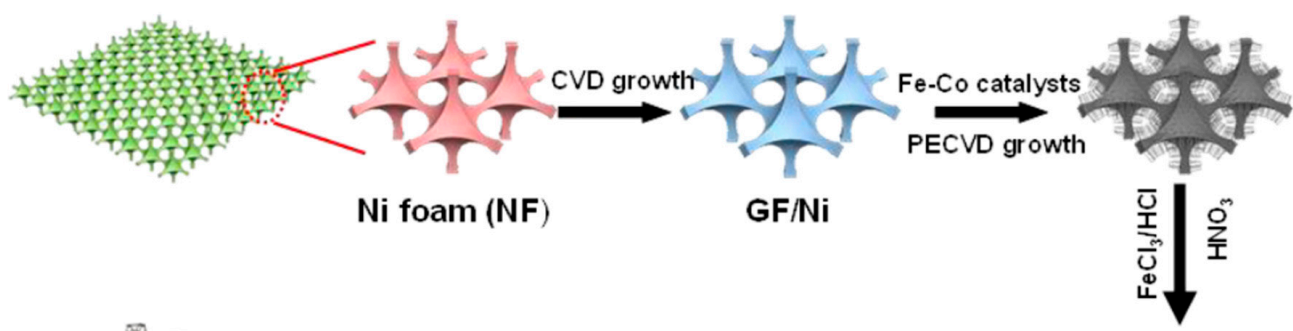

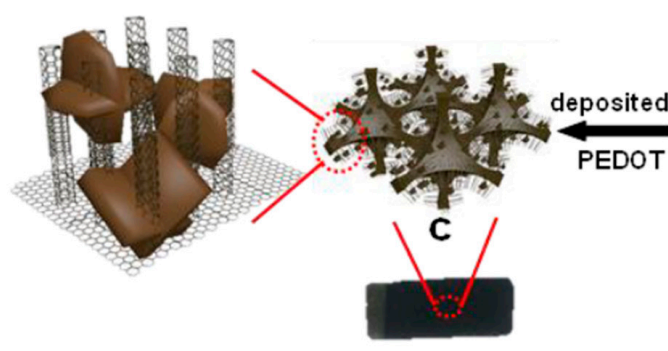

C

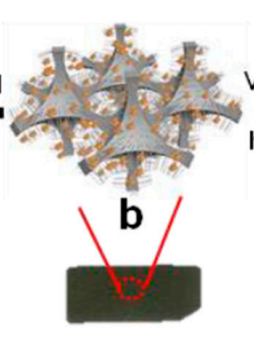

B

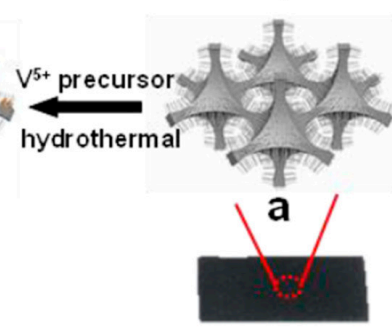

A

Figure 5. Schematic of the synthesis of (A) CNT/GF, (B) VCNT/GF, (C) VCNT/GF/PEDOT. Reprinted with permission from Ref. [88]. Copyright 2017 Royal Society of Chemistry.

Orthorhombic crystal phase $\mathrm{V}_{2} \mathrm{O}_{5}$ nanostars were intercalated into the interstitial space between the vertically aligned CNTs. The addition of the PEDOT coating reduced the $\mathrm{V}_{2} \mathrm{O}_{5}$ dissolution during synthesis and increased the size of the $\mathrm{V}_{2} \mathrm{O}_{5}$ nanostars by $\sim 15 \%$. The high surface area of the enlarged $\mathrm{V}_{2} \mathrm{O}_{5}$ nanostars increased the pseudocapacitive surface reactions. The composite electrode was tested in a three-electrode configuration with a Pt counter electrode and an $\mathrm{Ag} / \mathrm{AgCl}$ reference electrode in $5 \mathrm{M} \mathrm{LiNO}_{3}$ electrolyte, yielding a high $\mathrm{C}_{\mathrm{sp}}$ of $1016 \mathrm{~F} \mathrm{~g}^{-1}$ at a current density of $1 \mathrm{~A} \mathrm{~g} \mathrm{~g}^{-1}$. The direct growth of $\mathrm{V}_{2} \mathrm{O}_{5}$ on the vertically aligned CNTs enabled good surface contact for efficient electrical conduction. The porous Ni foam/CNT frame also provided structural stability to the overall electrode. The result indicated good rate capability with an excellent $\mathrm{C}_{\mathrm{sp}}$ of $484 \mathrm{~F} \mathrm{~g}^{-1}$ at a high current density of $20 \mathrm{~A} \mathrm{~g}^{-1}$ and high coulombic efficiency of $97.8 \%$. The asymmetric supercapacitor with a VCNT electrode exhibited a maximum energy density of $13.24 \mathrm{Wh} \mathrm{kg}^{-1}$ at a power density of $710 \mathrm{~W} \mathrm{~kg}^{-1}$, which decreased to $10.34 \mathrm{Wh} \mathrm{kg}^{-1}$ at a power density of $2659 \mathrm{~W} \mathrm{~kg}^{-1}$. The energy density decreased slightly at high power owing to the absence of an insulating binder material and the high conductivity provided by the Ni/CNT frame. Wang et al. synthesized a VCNT composite by adding CNTs to the $\mathrm{V}_{2} \mathrm{O}_{5}$ nanosheets that were synthesized via a hydrothermal reaction between bulk $\mathrm{V}_{2} \mathrm{O}_{5}$ and $\mathrm{H}_{2} \mathrm{O}$ [89]. CNTs were subsequently added to a solution of $\mathrm{V}_{2} \mathrm{O}_{5}$ nanosheets and aged for two days. This fabrication method resulted in a lamellar nanostructure with $\mathrm{V}_{2} \mathrm{O}_{5}$ layers intercalated with CNTs, corresponding to $13.7 \mathrm{wt} \%$ of the total composition. The CNTs increased the interstitial spacing between the $\mathrm{V}_{2} \mathrm{O}_{5}$ nanosheets, preventing $\mathrm{V}_{2} \mathrm{O}_{5}$ agglomeration and increasing the porosity, yielding a large specific surface area of 102.05 $\mathrm{m}^{2} \mathrm{~g}^{-1}$. The $C_{\mathrm{sp}}$ of the VCNTs was $553.33 \mathrm{~F} \mathrm{~g}^{-1}$ at a current density of $5 \mathrm{~mA} \mathrm{~cm}{ }^{-2}$. The increased interlayer spacing between the $\mathrm{V}_{2} \mathrm{O}_{5}$ planes allowed greater ion intercalation/deintercalation, which promoted faradic redox reactions. Furthermore, the CNTs increased the overall conductivity of the device, resulting in a low series resistance of $0.95 \Omega$ and a charge transfer resistance of $0.6 \Omega$ for enhanced rate capability. Owing to the structural stability provided by the CNTs, the charge/discharge stability increased, as indicated by a high $C_{\mathrm{sp}}$ retention of $83 \%$ after 1000 cycles at a current density of $10 \mathrm{~mA} \mathrm{~cm}{ }^{-2}$.

Deposition techniques have also been used to grow vertically aligned CNTs and $\mathrm{V}_{2} \mathrm{O}_{5}$ composites directly on conductive substrates such as $\mathrm{Ni}$, yielding a binderless electrode material. Jampani et al. used CVD to synthesize an array of vertically aligned CNTs on flat $\mathrm{Ni}$ disks that formed a forest-like microstructure. Atmospheric pressure CVD was used to deposit Ti-doped $\mathrm{V}_{2} \mathrm{O}_{5}$ on the CNTs [90]. The resulting composite had an amorphous 
crystal phase with $\mathrm{V}_{2} \mathrm{O}_{5}$ globules anchored to the vertically aligned CNT forest; a $\mathrm{C}_{\mathrm{sp}}$ of $313 \mathrm{~F} \mathrm{~g}^{-1}$ was observed at a scan rate of $2 \mathrm{mV} \mathrm{s}^{-1}$. The amorphous crystal structure of the Ti-doped $\mathrm{V}_{2} \mathrm{O}_{5}$ decreased the $\mathrm{V}_{2} \mathrm{O}_{5}$ dissolution during charge/discharge, resulting in nearly perfect $C_{\mathrm{sp}}$ retention even after 400 cycles at a high scan rate of $100 \mathrm{mV} \mathrm{s}^{-1}$. The areal capacitance was $350 \mathrm{mF} \mathrm{cm}{ }^{-2}$ at a scan rate of $2 \mathrm{mV} \mathrm{s}^{-1}$, which decreased to $20 \mathrm{mF} \mathrm{cm}{ }^{-2}$ at a scan rate of $200 \mathrm{mV} \mathrm{s}^{-1}$. The decent rate capability was due to the low resistance of the binderless composite at $0.0182 \Omega \mathrm{cm}^{2}$, which was two orders of magnitude more conductive than pristine $\mathrm{V}_{2} \mathrm{O}_{5}$. The electrodes had a maximum energy density of $25 \mathrm{Wh} \mathrm{kg}^{-1}$ at a power density of $100 \mathrm{~W} \mathrm{~kg}^{-1}$, which decreased to $11 \mathrm{Wh} \mathrm{kg}^{-1}$ at a power density of $4500 \mathrm{~W} \mathrm{~kg}^{-1}$. Shakir et al. used spray coating to prepare a layered $\mathrm{V}_{2} \mathrm{O}_{5} / \mathrm{MWCNT}$ (VMWCNT) composite electrode on a Ni/Cu/Ni/Au electroplated substrate [91]. A polyester fiber fabric was first plated with $\mathrm{Ni} / \mathrm{Cu} / \mathrm{Ni} / \mathrm{Au}$ layers sequentially via electroless plating. The MWCNT/ $\mathrm{V}_{2} \mathrm{O}_{5}$ core/shell nanotubes were synthesized via a bottom-up assembly method using pre-functionalized MWCNTs and $\mathrm{NH}_{4} \mathrm{VO}_{3}$. A layer of graphene was then deposited on the conductive fabric. Subsequently, a mixture of $\mathrm{V}_{2} \mathrm{O}_{5}$-coated MWCNTs was spray-coated on the top graphene layer. Alternating graphene and VMWCNT layers were applied repeatedly to yield a binderless VMWCNT/graphene composite electrode. The electrode comprised a thick orthorhombic $\mathrm{V}_{2} \mathrm{O}_{5}$ shell coating the MWCNTs. The $\mathrm{C}_{\mathrm{sp}}$ of the VMWCNT/graphene electrode with 3-nm-thick $\mathrm{V}_{2} \mathrm{O}_{5}$ layers had an excellent $C_{\text {sp }}$ of $2590 \mathrm{~F} \mathrm{~g}^{-1}$ at a scan rate of $1 \mathrm{mV} \mathrm{s}^{-1}$. Increasing the $\mathrm{V}_{2} \mathrm{O}_{5}$ coating thickness to $20 \mathrm{~nm}$ decreased the $C_{\mathrm{sp}}$ to $510 \mathrm{~F} \mathrm{~g}^{-1}$ because of inefficient ion penetration into the inner layers of the VMWCNTs. The 3-nm-thick VMWCNT/graphene electrode retained $96 \%$ of its initial $C_{\text {sp }}$ after 5000 cycles at a scan rate of $20 \mathrm{mV} \mathrm{s}^{-1}$ because of the effective conductive MWCNT bridge linking electron transport from $\mathrm{V}_{2} \mathrm{O}_{5}$ to graphene. The energy density was $96 \mathrm{Wh} \mathrm{kg}^{-1}$ at a power density of $800 \mathrm{~W} \mathrm{~kg}^{-1}$, which decreased to $28 \mathrm{Wh} \mathrm{kg}^{-1}$ at a power density of $9000 \mathrm{~W} \mathrm{~kg}^{-1}$.

One major advantage of CNTs is their easy functionalization to yield high-performance VCNT electrodes through various synthesis methods. Modifying CNTs with specific functional groups such as hydroxyl or carboxyl groups can improve the conductivity of the $\mathrm{CNTs}$ and promote the nucleation of $\mathrm{V}_{2} \mathrm{O}_{5}$ crystals. Hu et al. used a one-step hydrothermal method to synthesize a vanadium oxide composite with functionalized CNTs [92]. The CNTs were functionalized with hydroxyl and carbonyl groups using concentrated sulfuric and nitric acids, which acted as the activation centers for coordinate bond formation with VO. Vanadium oxide nanoribbons were formed at the nucleation sites via a hydrothermal reaction and were bonded to the CNTs via hydroxyl functional groups. By adding GO to a mixture of $\mathrm{V}_{2} \mathrm{O}_{5}$ and CNTs, Hu et al. fabricated a $\mathrm{V}_{3} \mathrm{O}_{7} / \mathrm{CNT} / \mathrm{rGO}$ composite (rGO-VCNT) comprised of rGO sheets uniformly coated with large $\mathrm{V}_{3} \mathrm{O}_{7}$ nanobelts and thin CNTs. The rGO-VCNT composite with $40 \mathrm{wt} \% \mathrm{rGO}$ exhibited a maximum $\mathrm{C}_{\mathrm{sp}}$ of $685 \mathrm{~F} \mathrm{~g}^{-1}$ at a current density of $0.5 \mathrm{~A} \mathrm{~g}^{-1}$, which decreased to $\sim 375 \mathrm{~F} \mathrm{~g}^{-1}$ at a high current density of $10 \mathrm{~A} \mathrm{~g}^{-1}$. The high porosity of rGO and improved conductivity because of well-distributed CNTs resulted in an excellent rate capability. With a primarily carbon-based composition and strong bonds between $\mathrm{V}_{2} \mathrm{O}_{5}$ and CNTs, the rGO-VCNT (40 $\mathrm{wt} \% \mathrm{rGO}$ ) electrode retained $99.7 \%$ of its initial $C_{\mathrm{sp}}$ after 10,000 cycles at a high scan rate of $100 \mathrm{mV} \mathrm{s}^{-1}$. The maximum energy density of the symmetric supercapacitor was $34.3 \mathrm{Wh} \mathrm{kg}^{-1}$ at a power density of $150 \mathrm{~W} \mathrm{~kg}^{-1}$, which decreased to $18.8 \mathrm{Wh} \mathrm{kg}^{-1}$ at a power density of $3000 \mathrm{~W} \mathrm{~kg}^{-1}$. MtzEnriquez et al. reported an improved discharge time of a VCNT electrode by functionalizing the CNTs to promote $\mathrm{V}_{2} \mathrm{O}_{5}$ defects [93]. The CNTs were first deposited on a flexible graphene electrode and activated with strong acids. A $\mathrm{V}_{2} \mathrm{O}_{5}$ slurry was then applied to the CNT-coated graphene electrode and hot-pressed at 0.1 ton for physical binding. The resulting composite was comprised of rectangular $\mathrm{V}_{2} \mathrm{O}_{5}$ orthorhombic nanoribbons intercalated into a fibrous CNT structure. Oxygen vacancies formed in the $\mathrm{V}_{2} \mathrm{O}_{5}$ crystal structure due to the reduction of $\mathrm{V}^{5+}$ to $\mathrm{V}^{4+}$, which acted as redox centers for delayed current discharge. The functionalization of CNTs with carboxylic groups also created oxygen vacancies in the carbon lattice, promoting the formation of additional $\mathrm{V}_{2} \mathrm{O}_{5}$ defects. 
The CNTs also provided a secondary layer for ion storage and a large surface area for $\mathrm{V}_{2} \mathrm{O}_{5}$ contact, resulting in a high capacity and rate capability. The asymmetric supercapacitor with a graphene/VCNT anode had an energy density of $369.6 \mathrm{Wh} \mathrm{kg}^{-1}$.

MWCNTs can also be functionalized to achieve an increase in conductivity and homogeneous $\mathrm{V}_{2} \mathrm{O}_{5}$ formation. Saravanakumar et al. functionalized MWCNTs with hydroxyl, carboxyl, and keto-carbonyl groups using concentrated $\mathrm{H}_{2} \mathrm{SO}_{4}$ and $\mathrm{HNO}_{3}$ [94]. A mixture of functionalized MWCNTs and $\mathrm{V}_{2} \mathrm{O}_{5}$ crystals was aged for three days at room temperature to yield a $\mathrm{V}_{2} \mathrm{O}_{5}$ /MWCNT (VMWCNT) composite. The orthorhombic $\mathrm{V}_{2} \mathrm{O}_{5}$ crystals formed the cores surrounded by MWCNTs, resulting in a highly porous network. Even with a relatively low carbon content of $8.73 \mathrm{wt} \%$, the surface area was large $\left(14.4 \mathrm{~m}^{2} \mathrm{~g}^{-1}\right)$ because of the mesoporous web-like architecture of the MWCNTs. The VMWCNT electrode exhibited a maximum $\mathrm{C}_{\mathrm{sp}}$ of $410 \mathrm{~F} \mathrm{~g}^{-1}$ at a current density of $0.5 \mathrm{~A} \mathrm{~g}^{-1}$, which decreased to $280 \mathrm{~F} \mathrm{~g}^{-1}$ at a current density of $10 \mathrm{~A} \mathrm{~g}^{-1}$. The high rate capability was because of the porous structure that allowed the fast intercalation/de-intercalation of ions and high conductivity of the functionalized CNT web. The functionalized CNTs improved the cyclability of the VMWCNT electrode, as indicated by $86 \% \mathrm{C}_{\mathrm{sp}}$ retention after 600 cycles at a high current density of $10 \mathrm{~A} \mathrm{~g}^{-1}$. The symmetric supercapacitor with functionalized VMWCNT electrodes exhibited an energy density of $8.9 \mathrm{Wh} \mathrm{kg}^{-1}$ at a power density of $121 \mathrm{~W} \mathrm{~kg}^{-1}$. Pandit et al. functionalized MWCNTs with carboxyl groups using $\mathrm{H}_{2} \mathrm{O}_{2}$ [95]. A stainless-steel current collector was first dip coated with the MWCNTs, and the resulting MWCNT/stainless-steel electrode was dip coated with a solution of $\mathrm{VOSO}_{4}$ and $\mathrm{NaOH}$. After repeated dipping and drying, the resulting VMWCNT/stainless-steel electrode had a layered structure of orthorhombic $\mathrm{V}_{2} \mathrm{O}_{5}$ flakes intercalated in a web of long MWCNTs. A $C_{\mathrm{sp}}$ of $629 \mathrm{~F} \mathrm{~g}^{-1}$ was observed at a current density of $2 \mathrm{~A} \mathrm{~g}^{-1}$, which decreased to $\sim 320 \mathrm{~F} \mathrm{~g}^{-1}$ at a current density of $8 \mathrm{~A} \mathrm{~g} \mathrm{~g}^{-1}$. The $\mathrm{C}_{\mathrm{sp}}$ of the composite electrode was high because the porous structure formed by the web-like MWCNTs allowed large volumes of counterion intercalation/de-intercalation deep in the $\mathrm{V}_{2} \mathrm{O}_{5}$ crystals. The VMWCNT electrode retained $93 \%$ of its $C_{\text {sp }}$ after 4000 cycles at a high scan rate of $100 \mathrm{mV} \mathrm{s}^{-1}$, showing good reversibility and stability. A symmetric supercapacitor with VMWCNT electrodes yielded an energy density of $72 \mathrm{Wh} \mathrm{kg}^{-1}$ at a power density of $2300 \mathrm{~W} \mathrm{~kg}^{-1}$ that decreased to $18.66 \mathrm{Wh} \mathrm{kg}^{-1}$ at a power density of $8400 \mathrm{~W} \mathrm{~kg}^{-1}$ and current density of $4 \mathrm{~A} \mathrm{~g}^{-1}$.

Different synthesis strategies, including hydro/solvothermal and deposition methods, can result in VCNT composites with different nanostructures. The hydrothermal method is a facile technique that involves the nucleation of $\mathrm{V}_{2} \mathrm{O}_{5}$ crystals from vanadium precursors on CNTs at high temperatures. Deposition techniques such as CVD allow the direct layering of $\mathrm{V}_{2} \mathrm{O}_{5}$ on CNTs with a controllable thickness. Functionalizing the CNTs with hydroxyl and carbonyl groups before synthesis with $\mathrm{V}_{2} \mathrm{O}_{5}$ can improve the overall conductivity, porosity, and stability of the hybrid material.

\subsection{Effects of Composition}

The ratio of $\mathrm{V}_{2} \mathrm{O}_{5}$ to $\mathrm{CNTs}$ affects the electrochemical performance of VCNT electrodes via changes in their morphologies, conductivities, porosities, and pseudocapacitive potentials. Guo et al. reported increases in the conductivity and rate capability with high CNT content [96]. The $\mathrm{V}_{2} \mathrm{O}_{5} \cdot n \mathrm{H}_{2} \mathrm{O}$ aerogel and CNTs were dispersed in DI water, vacuum filtered with a cellulose membrane, and dried at $60^{\circ} \mathrm{C}$. The film was comprised of densely packed $\mathrm{V}_{2} \mathrm{O}_{5}$ nanosheets with homogeneously intercalated CNTs between the $\mathrm{V}_{2} \mathrm{O}_{5}$ layers, preventing $\mathrm{V}_{2} \mathrm{O}_{5}$ self-stacking. An increase in the CNT content increased the thickness of the VCNT film by increasing the interstitial space between the $\mathrm{V}_{2} \mathrm{O}_{5}$ sheets. The increased thickness prevented deep ion infiltration into the inner $\mathrm{V}_{2} \mathrm{O}_{5}$ layers near the center of the electrode. However, an increase in the CNT content increased the conductivity of the overall electrode by introducing more interlayer CNT connections, as indicated by the low square resistance of $128 \Omega \mathrm{sq}^{-1}$ for VCNT-10 (10 $\mathrm{wt} \%$ CNT). VCNT-10 exhibited the highest $\mathrm{C}_{\mathrm{sp}}$ of $207.7 \mathrm{~F} \mathrm{~g}^{-1}\left(521 \mathrm{~F} \mathrm{~cm}^{-3}\right)$ at a current density of $0.5 \mathrm{~A} \mathrm{~g}^{-1}$. An increase in the CNT content increased the rate capability, with VCNT-15 (15 wt\% CNT) exhibiting the 
highest $C_{\text {sp }}$ retention of $49.5 \%$ compared to the $42 \%$ retention of the VCNT-10 electrode at a high current density of $20 \mathrm{~A} \mathrm{~g}^{-1}$. The flexible symmetric supercapacitor exhibited good performance in both bent and unbent states with a high energy density of $7300 \mathrm{Wh}$ $\mathrm{kg}^{-1}$ at a power density of $42.6 \mathrm{~W} \mathrm{~kg}^{-1}$. Yilmaz et al. reported similar improvements with fewer $\mathrm{V}_{2} \mathrm{O}_{5}$ nanosheets intercalated with $\mathrm{CNT}$ [97]. $\mathrm{V}_{2} \mathrm{O}_{5}$ gel was rigorously mixed in solutions with different amounts of CNTs, yielding free-standing electrodes consisting of $\mathrm{V}_{2} \mathrm{O}_{5}$ nanosheets with an orthorhombic crystal structure. The CNTs were homogeneously intercalated between the $\mathrm{V}_{2} \mathrm{O}_{5}$ nanosheets. An increase in the $\mathrm{V}_{2} \mathrm{O}_{5}$ content decreased the porosity of the $\mathrm{V}_{2} \mathrm{O}_{5}$ nanosheets, decreasing the overall surface area of the VCNT composite. The composite gel was printed on a $1 \mathrm{~cm} \times 1 \mathrm{~cm}$ ITO glass plate and dried before use as an electrode. $\mathrm{V}_{1} \mathrm{CNT}_{2}\left(1: 2\right.$ ratio of $\mathrm{V}_{2} \mathrm{O}_{5}$ to $\mathrm{CNT}$ ) yielded the highest $\mathrm{C}_{\mathrm{sp}}$ of $116 \mathrm{~F} \mathrm{~g}^{-1}$ at a current density of $0.1 \mathrm{~A} \mathrm{~g}^{-1}$. An increase in the $\mathrm{V}_{2} \mathrm{O}_{5}$ loading to $1: 1$ ratio $\left(\mathrm{V}_{1} \mathrm{CNT}_{1}\right)$ resulted in a lower $\mathrm{C}_{\mathrm{sp}}$ value of $32 \mathrm{~F} \mathrm{~g}^{-1}$ at a current density of $0.1 \mathrm{~A} \mathrm{~g}^{-1}$ because of a decrease in the number of active sites on $\mathrm{V}_{2} \mathrm{O}_{5}$ nanosheets. Further addition of $\mathrm{V}_{2} \mathrm{O}_{5}$ decreased the $\mathrm{C}_{\mathrm{sp}}$ due to $\mathrm{V}_{2} \mathrm{O}_{5}$ agglomeration, which decreased surface ion adsorption. Because of the highly conductive $\mathrm{CNT}$ linkages, the carbon-dominant $\mathrm{V}_{1} \mathrm{CNT}_{2}$ electrode exhibited a good cycling capability, with $91.2 \%$ capacitance retention after 5000 cycles at a current density of $5 \mathrm{~A} \mathrm{~g}^{-1}$. A symmetric supercapacitor with $\mathrm{V}_{1} \mathrm{CNT}_{2}$ electrode yielded a volumetric energy density of $0.67 \mathrm{mWh} \mathrm{cm}^{-3}$ at a power density of $0.27 \mathrm{~W} \mathrm{~cm}^{-3}$. Wu et al. fabricated a thin-film electrode with varying $\mathrm{V}_{2} \mathrm{O}_{5}$ content using a sol-gel method [98]. $\mathrm{V}_{2} \mathrm{O}_{5}$ nanobelts, CNTs, ethanol, terpilneol, and ethyl cellulose were mixed at $80^{\circ} \mathrm{C}$ to yield a gel that was then doctor bladed onto a ceramic plate and annealed at $350{ }^{\circ} \mathrm{C}$ in air. The thin film was peeled off the ceramic to yield a free-standing VCNT thin film. The $\mathrm{V}_{2} \mathrm{O}_{5}$ nanobelts were highly uniform with an orthorhombic crystal phase, resulting in uniformly thick (20-100 nm) and long $(>100 \mathrm{~nm})$ nanobelts. A conductive current collector was added by compressing the thin-film electrode between Ti foils at 4000 psi. The VCNT-75 (75 wt $\% \mathrm{~V}_{2} \mathrm{O}_{5}$ composition) thin-film exhibited the highest $\mathrm{C}_{\mathrm{sp}}$ of $216 \mathrm{~F} \mathrm{~g}^{-1}$ at a scan rate of $5 \mathrm{mV} \mathrm{s}^{-1}$, which was five times greater than that of the bare CNTs. VCNT-75 also exhibited the highest volumetric capacitance of $540 \mathrm{~F} \mathrm{~cm}^{-3}$ at a scan rate of $5 \mathrm{mV} \mathrm{s}^{-1}$, which decreased by $79 \%$ at a scan rate of $100 \mathrm{mV} \mathrm{s}^{-1}$. The poor rate capability was due to an inefficient electron transfer caused by the low carbon composition. VCNT-61 $\left(60.5 \mathrm{wt} \% \mathrm{~V}_{2} \mathrm{O}_{5}\right)$ exhibited the best balance between maximum capacitance and electrode stability with a $\mathrm{C}_{\mathrm{sp}}$ of $192 \mathrm{~F} \mathrm{~g}^{-1}$ at a scan rate of $5 \mathrm{mV} \mathrm{s}^{-1}$ and a $64 \% \mathrm{C}_{\mathrm{sp}}$ retention at a scan rate of $100 \mathrm{mV} \mathrm{s}^{-1}$. Moreover, the higher CNT content increased the electron conduction, resulting in $79.8 \% \mathrm{C}_{\mathrm{sp}}$ retention after 5000 cycles at a scan rate of $50 \mathrm{mV} \mathrm{s}^{-1}$. A symmetric supercapacitor with VCNT-61 electrodes yielded a maximum volumetric energy density of $41 \mathrm{Wh} \mathrm{L}^{-1}$ at a volumetric power density of $\sim 400 \mathrm{~W} \mathrm{~L}^{-1}$, which decreased to $29.1 \mathrm{Wh} \mathrm{L}^{-1}$ at a volumetric power density of $6500 \mathrm{~W} \mathrm{~L}^{-1}$. A balance between conductive CNTs and energy-dense $\mathrm{V}_{2} \mathrm{O}_{5}$ is necessary for achieving the maximum electrochemical performance.

The $\mathrm{CNT}$ to $\mathrm{V}_{2} \mathrm{O}_{5}$ ratio changes the extent of the EDL and pseudocapacitive characteristics of the hybrid material. Perera et al. found that altering the $\mathrm{V}_{2} \mathrm{O}_{5}$ to CNT ratio can also affect the physical properties of the composite thin film [99]. A free-standing VCNT electrode was fabricated by filtering a suspension of $C N T s$ and $\mathrm{V}_{2} \mathrm{O}_{5}$ through nylon filter paper. The VCNT-covered filter papers were dried, yielding a highly flexible thin-film supercapacitor electrode. The hybrid material was comprised of long $\mathrm{V}_{2} \mathrm{O}_{5}$ nanowires that formed a web-like structure. Short and curly CNTs were uniformly intercalated into the $\mathrm{V}_{2} \mathrm{O}_{5}$ web. Increasing $\mathrm{V}_{2} \mathrm{O}_{5}$ content decreased the porosity of the composite while increasing the CNT content increased the brittleness of the thin-film electrode. A 1:1 ratio of $\mathrm{V}_{2} \mathrm{O}_{5}$ and $\mathrm{CNTs}\left(\mathrm{V}_{1} \mathrm{CNT}_{1}\right)$ exhibited the greatest structural integrity and optimal electrochemical performance with a $\mathrm{C}_{\mathrm{sp}}$ of $57.3 \mathrm{~F} \mathrm{~g}^{-1}$ at a current density of $0.5 \mathrm{~A} \mathrm{~g}^{-1}$. The $\mathrm{V}_{1} \mathrm{CNT}_{1}$ electrode exhibited good rate capability with a $\mathrm{C}_{\mathrm{sp}}$ of $42.9 \mathrm{~F} \mathrm{~g}^{-1}$ at a current density of $10 \mathrm{~A} \mathrm{~g}^{-1}$. A coin-cell type supercapacitor with a $\mathrm{V}_{1} \mathrm{CNT}_{1}$ anode exhibited an energy density of $46.3 \mathrm{Wh} \mathrm{kg}^{-1}$ at a power density of $5260 \mathrm{~W} \mathrm{~kg}^{-1}$. In comparison, the VCNTs with a 1:5 ratio of $\mathrm{V}_{2} \mathrm{O}_{5}$ to $\mathrm{CNTs}$ had a lower energy density of $6 \mathrm{Wh} \mathrm{kg}^{-1}$ because of the decreased 
pseudocapacitive energy storage capacity. A good balance of $\mathrm{V}_{2} \mathrm{O}_{5}$ content for maximum pseudocapacitive capacity and increased CNT content for improved porosity is essential for optimized VCNT electrode performance. Such flexible, high-performance electrodes allow the development of more powerful portable and bendable technologies. Sathiya et al. reported different contributions of intercalative and capacitive charge capacities by varying the $\mathrm{V}_{2} \mathrm{O}_{5}$ content [100]. VTIP was dispersed in a suspension of pre-functionalized CNTs and stirred for one day to allow slow hydrolysis. The resulting VCNT composite gel was aged for a week, washed with acetone, dried at room temperature, and further dried at $200{ }^{\circ} \mathrm{C}$. Long CNTs were uniformly coated with a layer of $\mathrm{V}_{2} \mathrm{O}_{5}$ crystals, resulting in a web-like structure of long $\mathrm{V}_{2} \mathrm{O}_{5} / \mathrm{CNT}$ core/shell nanotubes. Pristine CNTs relied purely on nonfaradic mechanisms for charge storage, whereas pure $\mathrm{V}_{2} \mathrm{O}_{5}$ mainly used faradic ion intercalation for charge storage. An increase in the $\mathrm{V}_{2} \mathrm{O}_{5}$ content from 0 to $25 \mathrm{wt} \%$ increased both faradic and nonfaradic contributions owing to the synergistic effect between the CNTs and $\mathrm{V}_{2} \mathrm{O}_{5}$. However, further increase in the $\mathrm{V}_{2} \mathrm{O}_{5}$ content decreased the faradic contribution due to increased $\mathrm{V}_{2} \mathrm{O}_{5}$ coating thickness. With a $\mathrm{V}_{2} \mathrm{O}_{5}$ loading of $25 \mathrm{wt} \%$, $67 \%$ of the total stored charge was from pseudocapacitive redox reactions and surface ion adsorption. The maximum specific capacity was $850 \mathrm{mAh} \mathrm{g}^{-1}$, which was more than twice the capacity of purely pseudocapacitive pristine $\mathrm{V}_{2} \mathrm{O}_{5}$.

Because essential factors, including conductivity, porosity, and the charge storage method, are dependent on the ratio of $\mathrm{V}_{2} \mathrm{O}_{5}$ to $\mathrm{CNT}$, it is important to optimize each type of VCNT composite. In general, a higher CNT content increases the EDL contribution, conductivity, and rate capability. In contrast, a large $\mathrm{V}_{2} \mathrm{O}_{5}$ content results in a higher faradic contribution, energy storage potential, and flexibility.

\subsection{Effects of Physical Treatment}

Heat treatment is often used as the final step in VCNT synthesis because annealing the composite material improves the crystallinity and morphology of the composite. Sun et al. found an increased conversion of amorphous vanadium oxide to $\mathrm{V}_{2} \mathrm{O}_{5}$ after heat treatment [101]. Vertically aligned CNTs were deposited on a Si substrate via CVD and reacted with vanadium(III) acetylacetonate. Upon annealing at $350{ }^{\circ} \mathrm{C}$ in air, $\mathrm{V}_{2} \mathrm{O}_{5}$ microspheres were uniformly grown on the CNT surface. Annealing the composite converted the vanadium precursor to $\mathrm{V}_{2} \mathrm{O}_{5}$ and improved the crystallinity of the vanadium oxide precursor. Even after high-temperature annealing, the composite contained mixed valence states of vanadium oxide, which enhanced the ion diffusion. The $\mathrm{C}_{\mathrm{sp}}$ of the VCNT composite was $284 \mathrm{~F} \mathrm{~g}^{-1}$ at a current density of $2 \mathrm{~A} \mathrm{~g}^{-1}$, which decreased by $\sim 50 \%$ at a high current density of $15 \mathrm{~A} \mathrm{~g}^{-1}$. The direct growth of $\mathrm{V}_{2} \mathrm{O}_{5}$ on the CNTs improved the surface contact, thereby decreasing the charge transfer resistance to $1.2 \Omega$ and resulting in good rate performance. Moreover, interstitial spacing between the vertically aligned CNTs provided a spacious environment that decreased the internal strain during charge/discharge, resulting in a high $\mathrm{C}_{\mathrm{sp}}$ retention of $89.3 \%$ after 2500 cycles at a high current density of $10 \mathrm{~A} \mathrm{~g}^{-1}$. An asymmetric supercapacitor with the VCNT electrode had an energy density of $32.3 \mathrm{Wh}$ $\mathrm{kg}^{-1}$ at a power density of $118 \mathrm{~W} \mathrm{~kg}-1$. Similarly, Wang et al. reported increased $\mathrm{V}_{2} \mathrm{O}_{5}$ formation after calcination [102]. A solution of $\mathrm{NH}_{4} \mathrm{VO}_{3}, \mathrm{CNTs}$, super $\mathrm{AC}$ (SAC), and DI water was reacted in an autoclave at $180^{\circ} \mathrm{C}$ for one day and subsequently calcinated in a muffle furnace at $250{ }^{\circ} \mathrm{C}$ for $6 \mathrm{~h}$ in air. The resulting VCNT material had orthorhombic $\mathrm{V}_{2} \mathrm{O}_{5}$ sheets interspaced with thick CNTs and SAC bundles. The addition of CNTs increased the BET surface area from 14 to $19 \mathrm{~m}^{2} \mathrm{~g}^{-1}$, and the addition of both CNTs and SAC further increased the surface area to $78 \mathrm{~m}^{2} \mathrm{~g}^{-1}$ because of the increased mesopore volume. The VCNT electrode without SAC outperformed pristine $\mathrm{V}_{2} \mathrm{O}_{5}$ with a $\mathrm{C}_{\mathrm{sp}}$ of $231.8 \mathrm{~F} \mathrm{~g}^{-1}$ at a high current density of $10 \mathrm{~A} \mathrm{~g}^{-1}$. A high $\mathrm{C}_{\mathrm{sp}}$ was observed even at a high current density because of the improved conductivity provided by the intercalated CNTs and short ion diffusion pathways to the crystalline $\mathrm{V}_{2} \mathrm{O}_{5}$ sheets. Moreover, the VCNT electrode with SAC yielded a maximum $\mathrm{C}_{\mathrm{sp}}$ of $357.5 \mathrm{~F} \mathrm{~g}^{-1}$ because of the increased surface area that provided more activation sites. Shakir et al. synthesized a VMWCNT material through a 
heat-induced reaction and further annealed the composite at $350{ }^{\circ} \mathrm{C}$ for $2 \mathrm{~h}$ under ambient conditions [103]. The resulting VMWCNT thin film had layers of highly orthorhombic $\mathrm{V}_{2} \mathrm{O}_{5}$ crystals surrounded by long and curly MWCNTs. VMWCNTs that were $3 \mathrm{~nm}$ thick exhibited the highest $\mathrm{C}_{\mathrm{sp}}$ of $510 \mathrm{~F} \mathrm{~g}^{-1}$ at a scan rate of $1 \mathrm{mV} \mathrm{s}^{-1}$ because the thickness maximized the surface area-to-volume ratio of $\mathrm{V}_{2} \mathrm{O}_{5}$. The $\mathrm{C}_{\mathrm{sp}}$ of the composite was significantly higher than that of bare MWCNTs at $80 \mathrm{~F} \mathrm{~g}^{-1}$ because of the pseudocapacitive reactions enabled by the $\mathrm{V}_{2} \mathrm{O}_{5}$ crystals. The VMWCNT electrode exhibited good stability with $96 \%$ of its initial $C_{\mathrm{sp}}$ retained after 5000 cycles at a high scan rate of $20 \mathrm{mV} \mathrm{s}^{-1}$ because of the improved conductivity of the MWCNTs and structural stability of the web-like nanostructure. The energy density of the electrode was $16 \mathrm{Wh} \mathrm{kg}^{-1}$ at a power density of $800 \mathrm{~W} \mathrm{~kg}^{-1}$. Physical treatment is a key component of VCNT synthesis because it promotes the conversion of amorphous vanadium oxides to a more crystalline $\mathrm{V}_{2} \mathrm{O}_{5}$.

\section{4. $\mathrm{V}_{2} \mathrm{O}_{5} / \mathrm{CNFs}$}

CNFs have attracted significant attention as a substrate material for $\mathrm{V}_{2} \mathrm{O}_{5}$ growth because of their ease of synthesis, pore size controllability, and high conductivity [104]. Moreover, their stable 3D structures allow them to be used as free-standing electrodes for decreased internal resistance, high porosity, and flexible electrode applications [105]. $\mathrm{V}_{2} \mathrm{O}_{5} / \mathrm{CNF}$ (VCNF) composites often comprise either a $\mathrm{CNF} / \mathrm{V}_{2} \mathrm{O}_{5}$ core/shell structure, $\mathrm{V}_{2} \mathrm{O}_{5}$ crystal growth on long $\mathrm{CNFs}$, or $\mathrm{V}_{2} \mathrm{O}_{5}$ crystals intercalated in the CNF pores. The effects of the synthesis method, $\mathrm{V}_{2} \mathrm{O}_{5}$ content, and physical treatment on the electrochemical performances of the VCNF composite electrodes are reviewed. The morphology and electrochemical performances of $\mathrm{V}_{2} \mathrm{O}_{5} / \mathrm{CNF}$ electrodes for supercapacitor applications reported in the literature are summarized in Table 3.

\subsection{Effects of Synthesis Method}

Electrodeposition is a common technique used to form a $\mathrm{V}_{2} \mathrm{O}_{5}$ coating on long carbon fibers, resulting in a $\mathrm{CNF} / \mathrm{V}_{2} \mathrm{O}_{5}$ core/shell structure. Song et al. used electrodeposition to coat the nanofibers of exfoliated carbon cloth (CC) with $\mathrm{V}_{2} \mathrm{O}_{5}$ [106]. The architecture of the fibrous structure was preserved, and two additional layers, an exfoliated carbon middle layer and a $\mathrm{V}_{2} \mathrm{O}_{5}$ outer layer, were added to the preexisting nanofibers. Due to a lack of heat or catalyst during electrodeposition, only half of the initial $\mathrm{V}_{2} \mathrm{O}_{5}$ precursor was oxidized, resulting in amorphous, mixed-valence $\mathrm{V}_{2} \mathrm{O}_{5}$. The areal capacitance of the device was $106 \mathrm{~F} \mathrm{~cm}^{-2}$ at a current density of $2 \mathrm{~mA} \mathrm{~cm}^{-2}$, which decreased by $24 \%$ at a current density of $20 \mathrm{~mA} \mathrm{~cm}^{-2}$. The good rate capability was attributed to the conductive carbon skeleton and improved electron mobility through the $\mathrm{V}-\mathrm{O}-\mathrm{C}$ bonds in the exfoliated carbon middle layer. Unlike most electrodes that degrade with repeated cycling, a $40 \%$ increase in the $C_{\mathrm{sp}}$ of the exfoliated VCNF electrode was observed after 10,000 cycles at a current density of $60 \mathrm{~mA} \mathrm{~cm}^{-2}$ because of the activation of the material via ion intercalation/de-intercalation. Repeated cycling introduced more intercalated water molecules, which expanded the interlayer distance for additional active sites. Water also shuttled the electrolyte ions during intercalation/de-intercalation. A similar $\mathrm{V}^{4+}$ to $\mathrm{V}^{5+}$ ratio decreased the dissolution of the $\mathrm{V}_{2} \mathrm{O}_{5}$ crystals during charge/discharge for improved stability.

Table 3. $\mathrm{V}_{2} \mathrm{O}_{5}$ morphology and electrochemical performances of $\mathrm{V}_{2} \mathrm{O}_{5}$ /carbon nanofiber composite electrodes for supercapacitor applications.

\begin{tabular}{|c|c|c|c|c|c|}
\hline Morphology & $\begin{array}{l}\operatorname{Maximum} C_{s p} \\
\quad\left(F g^{-1}\right)\end{array}$ & $\begin{array}{c}\text { Cycling } \mathrm{C}_{\mathrm{sp}} \\
\text { Retention (\%) }\end{array}$ & Cycle Number & $\begin{array}{l}\text { Energy Density } \\
\quad\left(\mathrm{Wh} \mathrm{kg}^{-1}\right)\end{array}$ & $\begin{array}{l}\text { Power Density } \\
\quad\left(\mathrm{W} \mathrm{kg}^{-1}\right)\end{array}$ \\
\hline Nanorods & 535.3 & 91.1 & 5000 & 38.7 & 900 \\
\hline CNF Coating & - & - & - & 101 & 27,370 \\
\hline Nanosheets & - & 89.3 & 10,000 & 40.2 & 800 \\
\hline CNF Coating & 227 & 89 & 2000 & 63.6 & 400 \\
\hline CNF Coating & - & $94 *$ & 10,000 * & 17.7 & 2728 \\
\hline Nanospheres & 475.5 & $89.7 *$ & $6000 *$ & - & - \\
\hline Nanohairs & 460.8 & $92 *$ & 10,000 * & 48.32 & 490 \\
\hline
\end{tabular}

${ }^{*}$ Cycling performance was determined using a two-electrode configuration. 
Crystallization can be used to coat CNFs with $\mathrm{V}_{2} \mathrm{O}_{5}$. Zhou et al. synthesized a highperformance $\mathrm{V}_{2} \mathrm{O}_{5}$ /polyindole/ ACC (VPIAC) composite electrode via crystallization [107]. Activated carbon cloth (ACC) was synthesized via $\mathrm{CC}$ activation with $\mathrm{HNO}_{3}, \mathrm{H}_{2} \mathrm{SO}_{4}$, and $\mathrm{KMnO}_{4}$, followed by heat-induced reduction in $\mathrm{N}_{2} / \mathrm{H}_{2}(95 \% / 5 \%)$ atmosphere at $1000{ }^{\circ} \mathrm{C}$. Sodium metavanadate was dripped onto the ACC and crystallized at $400{ }^{\circ} \mathrm{C}$. Subsequently, a solution of $\mathrm{H}_{2} \mathrm{O}_{2}$, indole, and DI water was dripped onto $\mathrm{V}_{2} \mathrm{O}_{5} / \mathrm{ACC}$ to promote $\mathrm{V}^{4+}$ oxidation to $\mathrm{V}^{5+}$. The resulting composite exhibited a bamboo-like structure with $\mathrm{V}_{2} \mathrm{O}_{5}$ and polyindole anchored to the surface of the long nanofibers. The electrochemical performance of the composite electrode was determined using a three-electrode configuration with a $\mathrm{Pt}$ counter electrode, $\mathrm{Ag} / \mathrm{AgCl}$ reference electrode, and $5 \mathrm{M} \mathrm{LiNO}_{3}$ electrolyte. The VPIAC hybrid material exhibited a high $C_{\mathrm{sp}}$ of $535.3 \mathrm{~F} \mathrm{~g}^{-1}$ at a current density of $1 \mathrm{~A} \mathrm{~g}^{-1}$ because of the increased conductivity of the polyindole. The VPIAC electrode had a low series resistance and charge transfer resistance of 1.1 and $7.6 \Omega$, respectively. The hybrid material exhibited excellent $91.1 \% \mathrm{C}_{\mathrm{sp}}$ retention after 5000 cycles at a high current density of $10 \mathrm{~A} \mathrm{~g}^{-1}$ because the polyindole decreased the dissolution of $\mathrm{V}_{2} \mathrm{O}_{5}$ during charge/discharge and increased adhesion between the CNFs and $\mathrm{V}_{2} \mathrm{O}_{5}$. The energy density of an asymmetric supercapacitor with the VPIAC electrode was $38.7 \mathrm{Wh} \mathrm{kg}^{-1}$ at a power density of $900 \mathrm{~W} \mathrm{~kg}^{-1}$, which decreased to $32.6 \mathrm{Wh} \mathrm{kg}^{-1}$ at a power density of $18,000 \mathrm{~W} \mathrm{~kg}^{-1}$.

The sol-dipping method can also allow the uniform coating of CNFs with a $\mathrm{V}_{2} \mathrm{O}_{5}$ shell. Azadian et al. employed a sol-dipping method involving the repeated dipping and drying of polyacrylonitrile-based carbon paper into a $\mathrm{V}_{2} \mathrm{O}_{5}$ sol [108]. The dip-dry process was performed multiple times to promote the growth of a thick layer of $\mathrm{V}_{2} \mathrm{O}_{5}$ crystals on the carbon paper nanofibers. The $\mathrm{V}_{2} \mathrm{O}_{5}$ grown on the $\mathrm{CNF}$ exhibited a high $\mathrm{C}_{\mathrm{sp}}$ of $800 \mathrm{~F} \mathrm{~g}^{-1}$. Because of the porous architecture of the carbon fibers, the intercalation/de-intercalation was highly reversible, yielding a high Coulombic efficiency of $92 \%$. The energy density of the electrode was $101 \mathrm{Wh} \mathrm{kg}^{-1}$ at a power density of $27370 \mathrm{~W} \mathrm{~kg}^{-1}$.

In addition to the formation of a CNF/ $\mathrm{V}_{2} \mathrm{O}_{5}$ core/shell nanostructure, small $\mathrm{V}_{2} \mathrm{O}_{5}$ nanoparticles can be intercalated within the porous CNFs. Zhou et al. fabricated a CC-based electrode with $\mathrm{V}_{2} \mathrm{O}_{5}$ nanosheets embedded within the CNF webs [109]. CC/graphene foam/CoMoS 4 was mixed with a $\mathrm{V}_{2} \mathrm{O}_{5}$ supernatant for $12 \mathrm{~h}$. The $\mathrm{CoMoS}_{4}$ bound to $\mathrm{CC} /$ graphene resulted in the uniform coating of thin $\mathrm{CoMoS}_{4}$ nanowires on the smooth $\mathrm{CNFs}$, and the nanowires hosted the $\mathrm{V}_{2} \mathrm{O}_{5}$ nanosheets. The cyclic voltammetry $(\mathrm{CV})$ curves of the hybrid material exhibited a distinct peak, indicating a large pseudocapacitive contribution. The CV curves retained their shape upon increasing scan rates from 5 to $50 \mathrm{mV} \mathrm{s}^{-1}$, indicating good rate capability owing to the conductive carbon matrix (Figure 6a). The composite behaved more like a battery instead of a capacitor, based on the large IR drop shown in the galvanostatic charge-discharge (GCD) plot in Figure 6b. The specific capacity of the electrode was $158.6 \mathrm{mAh} \mathrm{g}^{-1}$ at a current density of $1 \mathrm{~A} \mathrm{~g}^{-1}$ (Figure 6c).

Vanadium promoted faradic redox reactions, which increased the charge storage potential of the electrode. The addition of graphene to the carbon fibers enhanced the charge transfer from $\mathrm{V}_{2} \mathrm{O}_{5}$ to the current collector and functioned as a buffer to prevent physical deformation during intercalation/de-intercalation. Thus, the hybrid material was highly cyclable with a $>90 \% \mathrm{C}_{\mathrm{sp}}$ retention after 5000 cycles (Figure $6 \mathrm{~d}$ ). An asymmetric supercapacitor with a $\mathrm{V}_{2} \mathrm{O}_{5} / \mathrm{CoMoS}_{4} / \mathrm{CC} /$ graphene positive electrode exhibited an energy density of $40.2 \mathrm{Wh} \mathrm{kg}^{-1}$ at a power density of $800 \mathrm{~W} \mathrm{~kg}^{-1}$.

Unlike other synthesis strategies for growing $\mathrm{V}_{2} \mathrm{O}_{5}$ on a carbon nanofiber substrate, the electrospinning technique can directly produce VCNF composite materials [110]. The placement of a solution of a carbonaceous material such as polyacrylonitrile (PAN) and $\mathrm{V}_{2} \mathrm{O}_{5}$ in an electrospinning apparatus resulted in a flexible nanofiber composite material with controllable porosity and composition [111]. Kim et al. electrospun VCNF fibers using a dispersion of PAN and different amounts of $\mathrm{V}_{2} \mathrm{O}_{5}$ in a DMF solution [112]. The resulting nanofibers were heat treated at $800{ }^{\circ} \mathrm{C}$ under a nitrogen atmosphere for further oxidation and stabilization. The resulting nanofiber structure was primarily composed of 
carbon with small, amorphous $\mathrm{V}_{2} \mathrm{O}_{5}$ agglomerations anchored on the CNF surface. The size of the agglomerations increased from 20 to $80 \mathrm{~nm}$ with an increase in the $\mathrm{V}_{2} \mathrm{O}_{5}$ content. Increasing the $\mathrm{V}_{2} \mathrm{O}_{5}$ content also increased the surface area of the electrode by introducing more pores into the nanofiber structure. The BET surface area of VCNF-20 $\left(20 \mathrm{wt} \% \mathrm{~V}_{2} \mathrm{O}_{5}\right)$ was $595.21 \mathrm{~m}^{2} \mathrm{~g}^{-1}$ compared to $510.45 \mathrm{~m}^{2} \mathrm{~g}^{-1}$ for VCNF-5 $\left(5 \mathrm{wt} \% \mathrm{~V}_{2} \mathrm{O}_{5}\right)$. In a symmetric electrode setup, the VCNF-20 electrode exhibited a $\mathrm{C}_{\mathrm{sp}}$ of $150.0 \mathrm{~F} \mathrm{~g}^{-1}$ at a current density of $1 \mathrm{~mA} \mathrm{~cm}^{-2}$, which was three times greater than that of the bare CNF because of the faradic contributions from the $\mathrm{V}_{2} \mathrm{O}_{5}$ crystals.
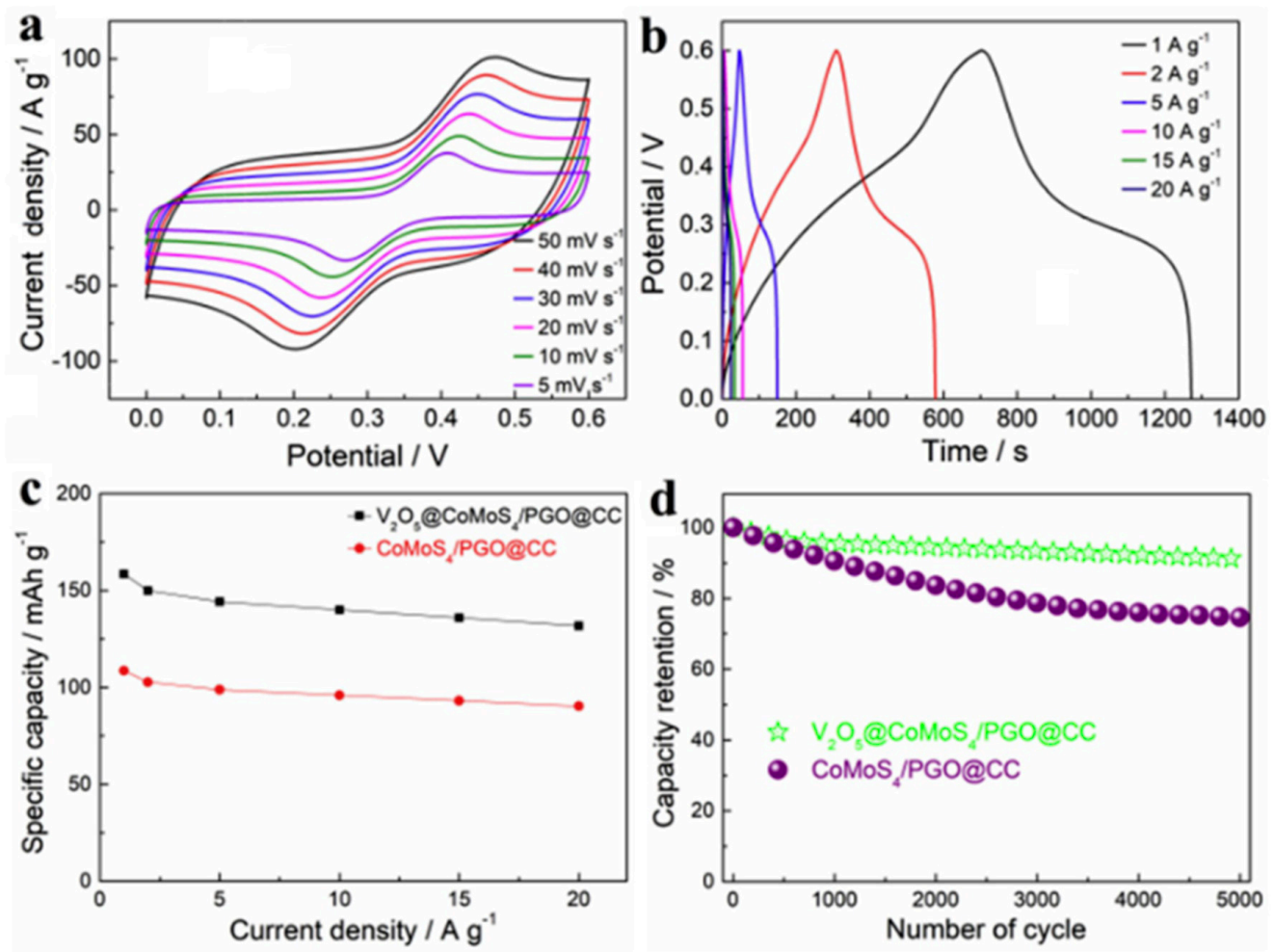

Figure 6. (a) $\mathrm{CV}$ and (b) GCD curves of $\mathrm{V}_{2} \mathrm{O}_{5} / \mathrm{CoMoS}_{4} / \mathrm{CC} /$ graphene at different scan rates and current densities, respectively. (c) $\mathrm{C}_{\mathrm{sp}}$ values of $\mathrm{V}_{2} \mathrm{O}_{5} / \mathrm{CoMoS}_{4} / \mathrm{CC} /$ graphene and $\mathrm{CoMoS}_{4} / \mathrm{CC} /$ graphene at different current densities and (d) cycling performances of $\mathrm{V}_{2} \mathrm{O}_{5} / \mathrm{CoMoS}_{4} / \mathrm{CC} /$ graphene and $\mathrm{CoMoS}_{4} / \mathrm{CC} /$ graphene. Reprinted with permission from Ref. [109]. Copyright 2020 Elsevier.

Various synthesis methods are available for the fabrication of VCNF hybrid materials. Strategies that involve the coating of nanofibers on a CC substrate, such as electrodeposition, sol dipping, and crystallization, utilize the porous architecture and high conductivity of $\mathrm{CNFs}$ for improved electrochemical performance. Alternatively, $\mathrm{V}_{2} \mathrm{O}_{5}$ nanocrystals can be intercalated into the CNFs for similar benefits. Electrospinning can be used to synthesize a VCNF material without any dependence on the CNF substrate. Instead, $\mathrm{V}_{2} \mathrm{O}_{5}$ and the carbon precursor can be electrospun into a fibrous product, allowing easily controllable composition and porosity.

\subsection{Effects of Composition}

The ratio between $\mathrm{CNF}$ and $\mathrm{V}_{2} \mathrm{O}_{5}$ plays a vital role in determining the electrochemical properties of a VCNF composite by altering its conductivity, porosity, and morphology. $\mathrm{Kim}$ et al. electrospun a solution with varying $\mathrm{V}_{2} \mathrm{O}_{5}$ loading and PA [113]. The mixture was subsequently heat treated and steamed under a nitrogen atmosphere at $800{ }^{\circ} \mathrm{C}$ for $1 \mathrm{~h}$ for carbon activation. The activated VCNF material had a fibrous structure with $\mathrm{V}_{2} \mathrm{O}_{5}$ agglomerations of 15 to $60 \mathrm{~nm}$ in diameter. The size of the agglomerations increased with increasing $\mathrm{V}_{2} \mathrm{O}_{5}$ loading owing to a change in the viscosity and conductivity of the 
electrospun solution. The activation of the nanofibers increased the diameter from 108 to $200 \mathrm{~nm}$. A lower $\mathrm{V}_{2} \mathrm{O}_{5}$ content increased the surface area of the composite with a maximum BET surface area of $1113.5 \mathrm{~m}^{2} \mathrm{~g}^{-1}$ for activated VCNF-5 $\left(5 \mathrm{wt} \% \mathrm{~V}_{2} \mathrm{O}_{5}\right)$ because more carbon was accessible for activation by the steam. Activated VCNF- 5 had the greatest $\mathrm{C}_{\mathrm{sp}}\left(73.85 \mathrm{~F} \mathrm{~g}^{-1}\right)$ at a current density of $1 \mathrm{~mA} \mathrm{~cm}^{-2}$, which decreased slightly to $58.02 \mathrm{~F} \mathrm{~g}^{-1}$ at a large current density of $20 \mathrm{~mA} \mathrm{~cm}^{-1}$ because of its low charge transfer resistance of $1.20 \Omega$. The symmetric supercapacitor with activated VCNF-5 electrodes had an energy density of $68.84 \mathrm{Wh} \mathrm{kg}^{-1}$ at a power density of $20,000 \mathrm{~W} \mathrm{~kg}^{-1}$.

The composition of $\mathrm{V}_{2} \mathrm{O}_{5}$ and $\mathrm{CNF}$ can be altered by changing the duration of $\mathrm{V}_{2} \mathrm{O}_{5}$ exposure to the CNF substrate. Choudhury et al. submerged CNF paper in a solution of $\mathrm{V}_{2} \mathrm{O}_{5}$ and $\mathrm{H}_{2} \mathrm{O}_{2}$ for five and seven days [114]. The resulting free-standing paper electrode was dried at $100{ }^{\circ} \mathrm{C}$ for one day in an oven. Increased exposure to $\mathrm{V}_{2} \mathrm{O}_{5}$ resulted in more $\mathrm{V}_{2} \mathrm{O}_{5}$ crystallization on the CNFs. VCNF-5 (five days) had a $\mathrm{V}_{2} \mathrm{O}_{5}$ layer thickness of $\sim 8 \mathrm{~nm}$, whereas VCNF-7 (seven days) had a thickness of $\sim 17 \mathrm{~nm}$. Although both VCNF variants were limited by the incomplete oxidation of $\mathrm{V}_{2} \mathrm{O}_{5}, \mathrm{VCNF}-5$ exhibited higher crystallinity and decreased water intercalation because of the shorter exposure to the $\mathrm{V}_{2} \mathrm{O}_{5}$ solution. VCNF-5 also had a larger BET surface area of $573.65 \mathrm{~m}^{2} \mathrm{~g}^{-1}$ compared to the surface area of $442.16 \mathrm{~m}^{2} \mathrm{~g}^{-1}$ for VCNF-7 because each nanofiber in VCNF-5 was thinner, resulting in larger pore sizes. VCNF-5 exhibited larger EDL characteristics than VCNF-7 because VCNF5 had a higher amount of accessible carbon content. VCNF- 5 yielded a $\mathrm{C}_{\mathrm{sp}}$ of $227 \mathrm{~F} \mathrm{~g}^{-1}$ at a current density of $1 \mathrm{~A} \mathrm{~g}^{-1}$. The $\mathrm{C}_{\mathrm{sp}}$ decreased slightly to $154 \mathrm{~F} \mathrm{~g}^{-1}$ at a current density of $10 \mathrm{~A} \mathrm{~g}^{-1}$ because of its low $5.49 \Omega$ charge transfer resistance. The VCNF-5 electrode had a maximum energy density of $63.6 \mathrm{Wh} \mathrm{kg}^{-1}$ at a power density of $\sim 400 \mathrm{~W} \mathrm{~kg}^{-1}$, which decreased to $18.8 \mathrm{Wh} \mathrm{kg}^{-1}$ at a power density of $4555 \mathrm{~W} \mathrm{~kg}^{-1}$. Velayutham et al. examined the importance of electrodeposition duration on the composition of binderless VCNF electrodes [115]. Rope-like $\mathrm{V}_{2} \mathrm{O}_{5}$ with a pure orthorhombic crystal phase was evenly deposited onto the carbon fibers, resulting in $\mathrm{V}_{2} \mathrm{O}_{5}$ surface extrusions. The wrinkled surface from the $\mathrm{V}_{2} \mathrm{O}_{5}$ crystal growths resulted in a greater surface area for faradic redox reactions. Increasing the deposition time beyond $40 \mathrm{~min}$ resulted in a smoother surface because of the increased $\mathrm{V}_{2} \mathrm{O}_{5}$ growth, leading to a smaller surface area. VCNF-40 (40 min deposition) exhibited the highest areal capacitance of $394 \mathrm{mF} \mathrm{cm}^{-2}$ at a current density of $1 \mathrm{~mA} \mathrm{~cm}^{-2}$. A 40 min deposition time had a large $\mathrm{V}_{2} \mathrm{O}_{5}$ composition for higher energy storage potential while creating a rough $\mathrm{CNF}$ coating for more surface redox reactions. At higher scan rates, VCNF-30 performed better than VCNF-40 with an areal capacitance of $143 \mathrm{mF} \mathrm{cm}^{-2}$ at a current density of $15 \mathrm{~mA} \mathrm{~cm}^{-2}$ because the higher carbon composition improved the electron mobility. An asymmetric supercapacitor with a VCNF-30 positive electrode yielded an energy density of $17.7 \mathrm{Wh} \mathrm{kg}^{-1}$ at a power density of $2728 \mathrm{~W} \mathrm{~kg}^{-1}$.

The composition of VCNF composites can be altered by controlling the initial loading of $\mathrm{V}_{2} \mathrm{O}_{5}$ during synthesis or exposing a CNF substrate to $\mathrm{V}_{2} \mathrm{O}_{5}$ for different durations of time. Optimizing the composition of the VCNF material is essential for maximizing the faradic energy storage potential while maintaining high porosity and conductivity for the hybrid material.

\subsection{Effects of Physical Treatment}

The heat treatment of the VCNF composites improves their stability and increases $\mathrm{V}_{2} \mathrm{O}_{5}$ oxidation for better electrochemical performance. Chen et al. formed arrays of thin $\mathrm{V}_{2} \mathrm{O}_{5}$ nanosheets on a CC template via a hydrothermal synthesis route and subsequently annealed the composite at different temperatures in an $\mathrm{H}_{2}$ /argon atmosphere [116]. An increase in the annealing temperatures created more defects in the $\mathrm{V}_{2} \mathrm{O}_{5}$ crystal structure, and the non-uniform crystal structure resulted in high ion diffusion and fast redox reactions. The VCNF material contained amorphous $\mathrm{V}_{2} \mathrm{O}_{5}$ nanosheets with more metallic than semiconductor characteristics due to the oxygen defects. Figure 7 summarizes the effects of annealing on the formation of defects for enhanced electrochemical performance. The VCNF annealed at the highest temperature of $500{ }^{\circ} \mathrm{C}$ yielded the highest areal capacitance 
of $554 \mathrm{mF} \mathrm{cm}^{-2}$ at a current density of $0.63 \mathrm{~A} \mathrm{~g}^{-1}$. An asymmetric supercapacitor with the VCNF electrode exhibited an energy density of $161.8 \mu \mathrm{Wh} \mathrm{cm}{ }^{-2}$ at a power density of $500 \mu \mathrm{W} \mathrm{cm}{ }^{-2}$. You et al. found that annealing a VCNF composite at different temperatures affected the formation of $\mathrm{V}_{2} \mathrm{O}_{5}$ agglomeration [117]. A VCNF composite was synthesized via a hydrothermal process and subsequently annealed at $500{ }^{\circ} \mathrm{C}$ in a nitrogen atmosphere for different durations. $\mathrm{V}_{2} \mathrm{O}_{5}$ had a partial orthorhombic crystal structure owing to the incomplete oxidation of $\mathrm{V}_{2} \mathrm{O}_{5}$ during the hydrothermal process. Long annealing durations increased the size of the $\mathrm{V}_{2} \mathrm{O}_{5}$ agglomeration on the CNF surface. VCNF-24 (24 h annealing) contained a uniform distribution of $\mathrm{V}_{2} \mathrm{O}_{5}$ nanospheres coating the CNFs. However, an increase in the annealing time to $48 \mathrm{~h}$ resulted in large agglomerations of $\mathrm{V}_{2} \mathrm{O}_{5}$, decreasing the number of $\mathrm{V}_{2} \mathrm{O}_{5}$ active sites for surface redox reactions. With a homogeneous distribution of $\mathrm{V}_{2} \mathrm{O}_{5}$ crystals on the CNFs, VCNT-24 outperformed the other electrodes. VCNT-24 yielded a high $\mathrm{C}_{\mathrm{sp}}$ of $475.5 \mathrm{~F} \mathrm{~g}^{-1}$ at a current density of $1 \mathrm{~A} \mathrm{~g}^{-1}$, more than three times that of pristine $\mathrm{V}_{2} \mathrm{O}_{5}$. With many $\mathrm{V}_{2} \mathrm{O}_{5}$ nanospheres, most of the capacitance was attributed to ion diffusion instead of surface capacitance. A flexible asymmetric supercapacitor with a VCNT-24 positive electrode exhibited a volumetric energy density of $0.928 \mathrm{mWh} \mathrm{cm}^{-3}$ at a power density of $17.5 \mathrm{~mW} \mathrm{~cm}^{-3}$.

Annealing the composite material also allowed the formation of doped VCNF composites. Guo et al. doped a VCNF composite with additional carbon to form carbon $/ \mathrm{V}_{2} \mathrm{O}_{5}$ core/shell nanowires on a CNF substrate [118]. First, the VCNF electrode was fabricated via a hydrothermal technique. The VCNF was then dipped in a glucose solution and heat-treated at $500{ }^{\circ} \mathrm{C}$ under a nitrogen atmosphere, resulting in C-doped VCNF. The overall nanofibrous macrostructure of $\mathrm{CC}$ was preserved after heat treatment. The long $\mathrm{CNFs}$ were uniformly coated with thin strands of long $\mathrm{V}_{2} \mathrm{O}_{5}$ nanowires. The annealed glucose coated the thin $\mathrm{V}_{2} \mathrm{O}_{5}$ strands with an outer layer of carbon. The C-doped VCNF electrode exhibited an areal capacitance of $128.5 \mathrm{mF} \mathrm{cm}^{-2}$ at a scan rate of $10 \mathrm{mV} \mathrm{s}^{-1}$, which decreased by $60 \%$ at a scan rate of $400 \mathrm{mV} \mathrm{s}^{-1}$. The good rate capability was because of the additional carbon coating that increased the conductivity. The areal capacitance was $164.2 \mathrm{~F} \mathrm{~cm}^{-2}$ at a current density of $0.5 \mathrm{~A} \mathrm{~cm}^{-2}$, with major contributions from both faradic and EDL characteristics. The charge transfer resistance $(3.8 \Omega)$ was low because of the conductive contact between the CNFs on the CC and the outer carbon layer on the $\mathrm{V}_{2} \mathrm{O}_{5}$ nanowires. The carbon coating also reduced vanadium dissolution, resulting in high cyclic stability, as indicated by a high $94.4 \% \mathrm{C}_{\mathrm{sp}}$ retention after 10,000 cycles at a high scan rate of $100 \mathrm{mV} \mathrm{s}^{-1}$, which was significantly higher than that of pure $\mathrm{V}_{2} \mathrm{O}_{5}(13.3 \%)$. Sun et al. doped CNFs with nitrogen by first preparing a solution of $\mathrm{CNF}$, pyrrole monomer, and ammonium persulfate and subsequently heating the mixture to $900{ }^{\circ} \mathrm{C}$ under argon atmosphere for $2 \mathrm{~h}$, yielding an $\mathrm{N}$-doped $\mathrm{CNF}\left(\mathrm{N}-\mathrm{CNF}\right.$ ) composite [119]. A $\mathrm{V}_{2} \mathrm{O}_{5}$ sol was added dropwise into the $\mathrm{N}-\mathrm{CNF}$ material to yield a sol-gel that was subsequently cured for two days in an oven at $50{ }^{\circ} \mathrm{C}$. The resulting aerogel was freeze dried and annealed at $350{ }^{\circ} \mathrm{C}$ in air, yielding a free-standing N-VCNF electrode. The N-CNFs were coated with a 20-nm-thick layer of $\mathrm{V}_{2} \mathrm{O}_{5}$. The $\mathrm{V}_{2} \mathrm{O}_{5}$ layer constituted a pure orthorhombic crystal phase, suggesting the complete oxidation of $\mathrm{V}^{4+}$ to $\mathrm{V}^{5+}$ due to the annealing procedure. The addition of the $\mathrm{V}_{2} \mathrm{O}_{5}$ layer to the N-CNFs decreased the BET surface area to $334.2 \mathrm{~m}^{2} \mathrm{~g}^{-1}$. The $\mathrm{C}_{\mathrm{sp}}$ of N-VCNF was $595.1 \mathrm{~F} \mathrm{~g}^{-1}$ at a current density of $0.5 \mathrm{~A} \mathrm{~g}^{-1}$, which was almost twice that of the non-doped VCNF. The nitrogen substitutions in the CNF lattice functioned as nucleation sites for additional $\mathrm{V}_{2} \mathrm{O}_{5}$ crystal growth, allowing a more uniform formation of the core/shell microstructure. The homogeneous $\mathrm{V}_{2} \mathrm{O}_{5}$ coating decreased the charge transfer resistance to $1.04 \Omega$. The N-VCNF electrode exhibited good reversibility with almost no change in $C_{\mathrm{sp}}$ after 10,000 cycles at a current density of $0.5 \mathrm{~A} \mathrm{~g} \mathrm{~g}^{-1}$ and only a $3 \%$ decrease after 12,000 cycles because of the stable core/shell nanostructure. The symmetrical supercapacitor with N-VCNF electrodes had a maximum energy density of $82.65 \mathrm{Wh} \mathrm{kg}^{-1}$ at a power density of $250 \mathrm{~W} \mathrm{~kg}^{-1}$ which decreased to $26.83 \mathrm{Wh} \mathrm{kg}^{-1}$ at a power density of $5000 \mathrm{~W} \mathrm{~kg}^{-1}$. 


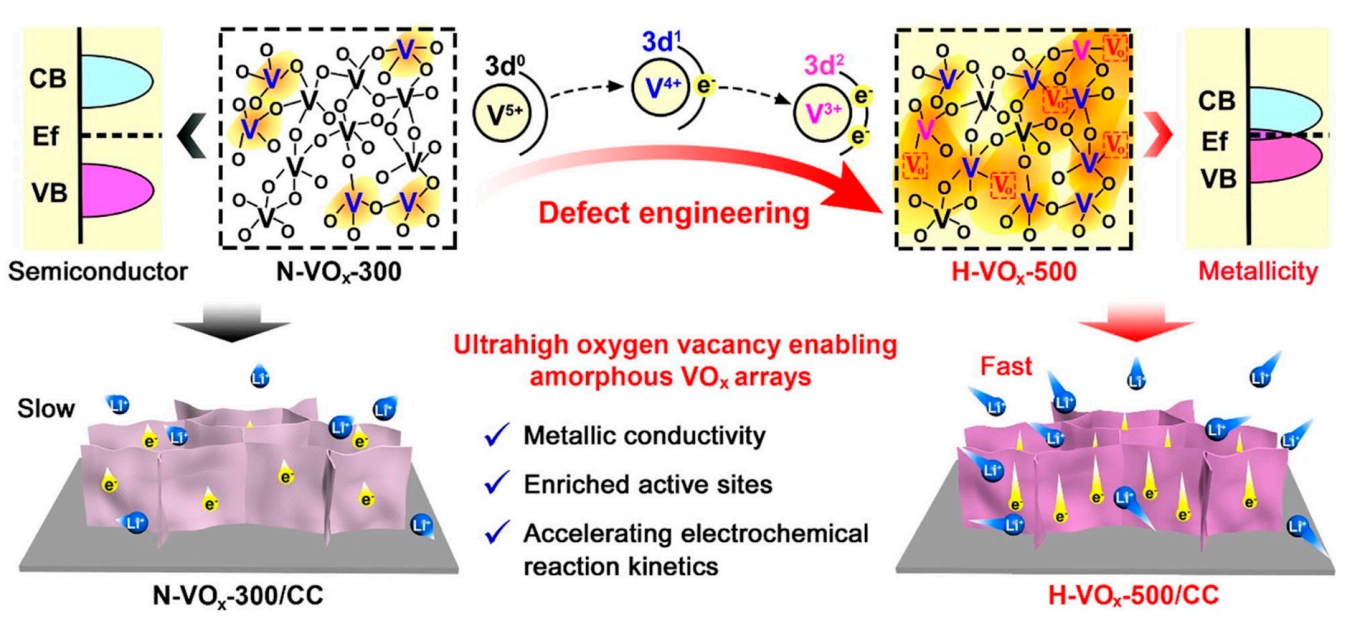

Figure 7. Schematic of the regulation of the V $3 \mathrm{~d}$ band edge with high electrical conductivity by defect engineering and electrochemical advantages of the as-formed metallic amorphous $\mathrm{VO}_{\mathrm{x}}$ nanosheet arrays. Reprinted with permission from Ref. [116]. Copyright 2021 Elsevier.

In addition to the heat treatment, other physical treatments can alter the morphology of the VCNF electrodes. Parmar et al. further modified the $\mathrm{V}_{2} \mathrm{O}_{5}$ crystals grown on carbon fiber surfaces using lasers to dehydrate amorphous $\mathrm{V}_{2} \mathrm{O}_{5}$ crystals [120]. A VCNF material with intercalated water molecules was synthesized via electrodeposition. Pristine $\mathrm{V}_{2} \mathrm{O}_{5}$ had an interstitial spacing of $\sim 4.4 \AA$ with an alternating $\mathrm{VO}_{5}-\mathrm{VO}_{5}$ pyramid structure, whereas hydrated $\mathrm{V}_{2} \mathrm{O}_{5}$ had a spacing that was two to three times greater than that of the atomic pyramids facing the same direction. De-intercalating water from the crystal structure of $\mathrm{V}_{2} \mathrm{O}_{5}$ decreased the interlayer gap to $\sim 4 \AA$, reverting the atomic structure to the alternating pyramid form. Panigrahi et al. grew hair-like $\mathrm{V}_{2} \mathrm{O}_{5}$ crystals on $A C$ felt but restrained one side of the $\mathrm{AC}$ felt to a glass slide [121]. Thus, $\mathrm{V}_{2} \mathrm{O}_{5}$ formation occurred only on the exposed side, allowing better electrical contact on the uncoated side. The acid-activated carbon felt acted as a porous template, resulting in a large BET surface area of $76.434 \mathrm{~m}^{2} \mathrm{~g}^{-1}$ for better ion diffusion. The porous architecture of the hair-like $\mathrm{V}_{2} \mathrm{O}_{5}$ resulted in a greater pseudocapacitive contributions than EDL contributions, resulting in a high $\mathrm{C}_{\mathrm{sp}}$ of $460.8 \mathrm{~F} \mathrm{~g}^{-1}$ at a current density of $2 \mathrm{~A} \mathrm{~g}^{-1}$. The highly interconnected CNF structure increased the rate capability such that $C_{\text {sp }}$ only decreased to $81.25 \%$ at 10 times the current density. The good electron mobility of the hybrid material was further supported by a low series resistance of $2.7 \Omega$ and charge transfer resistance of $1.1 \Omega$. A symmetric supercapacitor with the VCNF electrode exhibited an energy density of $48.32 \mathrm{Wh} \mathrm{kg}^{-1}$ at a power density of $490 \mathrm{~W} \mathrm{~kg}^{-1}$.

\section{Other $\mathrm{V}_{2} \mathrm{O}_{5} /$ Carbon Composites}

Many studies have been conducted on other $\mathrm{V}_{2} \mathrm{O}_{5}$ / carbon (VC) composites based on carbon moieties such as carbon quantum dots (CQDs) or bio-based carbon materials. As a stable, green, and conductive material, carbon can be added as supplementary materials to enhance the pseudocapacitive performance of $\mathrm{V}_{2} \mathrm{O}_{5}$ for supercapacitor applications [122]. These VC hybrid materials can be synthesized with carbon obtained from both inorganic and organic sources for diverse composite nanostructures. Herein, the effects of the synthesis process, $\mathrm{V}_{2} \mathrm{O}_{5}$ / carbon composition, and physical treatment on the electrochemical performances of other carbon-based $\mathrm{V}_{2} \mathrm{O}_{5}$ composites are discussed. The morphology and electrochemical performances of other $\mathrm{V}_{2} \mathrm{O}_{5}$ / carbon composite electrodes for supercapacitor applications reported in the literature are summarized in Table 4. 
Table 4. $\mathrm{V}_{2} \mathrm{O}_{5}$ morphology and electrochemical performances of other $\mathrm{V}_{2} \mathrm{O}_{5}$ / carbon composite electrodes for supercapacitor applications.

\begin{tabular}{|c|c|c|c|c|c|}
\hline Morphology & $\begin{array}{l}\underset{\left(F g^{-1}\right)}{\operatorname{Maximum} C_{s p}} \\
\quad\end{array}$ & $\begin{array}{c}\text { Cycling } \mathrm{C}_{\mathrm{sp}} \\
\text { Retention (\%) }\end{array}$ & Cycle Number & $\begin{array}{l}\text { Energy Density } \\
\quad\left(\mathrm{Wh} \mathrm{kg}^{-1}\right)\end{array}$ & $\begin{array}{l}\text { Power Density } \\
\left(\mathrm{W} \mathrm{kg}^{-1}\right)\end{array}$ \\
\hline Amorphous & 120 & 89 & 10,000 & - & - \\
\hline Nanorods & 300 & $87^{*}$ & 5000 * & - & - \\
\hline Nanoflowers & 417 & 92.3 & 2250 & 47 & 224 \\
\hline Nanoflowers & - & $88 *$ & 25,000 * & 33.4 & 670 \\
\hline Nanobelts & 281 & 87 & 2000 & - & - \\
\hline Nanorods & 313 & 81 & 4000 & - & - \\
\hline Amorphous & 157.7 & $93 *$ & 10,000 * & 87.6 & 497 \\
\hline Nanosheets & 487 & 84 & 2000 & 12.8 & 317 \\
\hline Nanobelts & 406 & 13.8 & 100 & 245.7 & 396 \\
\hline Nanobelts & 260 & 92 & 5000 & - & - \\
\hline
\end{tabular}

* Cycling performance was determined using a two-electrode configuration.

\subsection{Effects of Synthesis Method}

The final nanostructure of the VC composite material depends significantly on the initial carbon precursor. Daubert et al. compared the morphologies of the VC electrodes synthesized using either microporous Supra 50 or mesoporous G60 carbon powders [123]. Both carbon powders were activated with concentrated acid and pasted on Ni foil with an acetylene black filler and PVDF binder. $\mathrm{V}_{2} \mathrm{O}_{5}$ was subsequently coated on the carbon-coated $\mathrm{Ni}$ foam using atomic layer deposition (ALD). The resulting hybrid material had a layer of amorphous $\mathrm{V}_{2} \mathrm{O}_{5}$ crystals covering the carbon surface. Additional $\mathrm{V}_{2} \mathrm{O}_{5}$ deposition cycles resulted in increasingly uneven $\mathrm{V}_{2} \mathrm{O}_{5}$ coatings. For mesoporous $\mathrm{G} 60$, the maximum $\mathrm{C}_{\mathrm{sp}}$ was $540 \mathrm{~F} \mathrm{~g}^{-1}$ with 25 ALD cycles and $120 \mathrm{~F} \mathrm{~g}^{-1}$ for 75 ALD cycles. The high capacitance was due to the even $\mathrm{V}_{2} \mathrm{O}_{5}$ surface coating, thereby providing a large surface area for more ion adsorption. Because the micropores of Supra 50 matched the size of the atomic layer deposition precursor, the deposition process could not effectively coat Supra 50. Moreover, the coating process blocked the formation of micropores and decreased the number of active sites for faradic redox reactions. Thus, carefully selecting the carbon precursor is essential in maximizing the VC hybrid material's electrochemical performance.

Bio-based carbon sources have also been utilized for the synthesis of VC materials. Glucose is a promising carbon precursor for VC materials because it can act as an oxidizing agent at high temperatures and function as a conductive carbon additive [124]. Narayanan employed a facile hydrothermal synthesis method using $\mathrm{V}_{2} \mathrm{O}_{5}$ powder and glucose as precursors to yield $\mathrm{VC}$ [125]. The $\mathrm{VC}$ material was composed of $\mathrm{V}_{2} \mathrm{O}_{5}$ nanorods with glucose-derived carbon quantum dots (CQDs) uniformly scattered on the nanorod surface. Incomplete oxidation of $\mathrm{V}^{4+}$ to $\mathrm{V}^{5+}$ was observed due to partial reduction by glucose; however, the $\mathrm{V}_{2} \mathrm{O}_{5}$ rods still exhibited an orthorhombic crystal structure. The electrochemical performance of the $\mathrm{VC}$ material was tested using a three-electrode configuration with a $\mathrm{CQD}$ counter electrode and an $\mathrm{Ag} / \mathrm{AgCl}$ reference electrode in $3 \mathrm{M} \mathrm{KCl}$ electrolyte. The $\mathrm{C}_{\mathrm{sp}}$ of VC was $300 \mathrm{~F} \mathrm{~g}^{-1}$ at a current density of $0.5 \mathrm{~A} \mathrm{~g}^{-1}$, which decreased slightly to $250 \mathrm{~F} \mathrm{~g}^{-1}$ at a current density of $2 \mathrm{~A} \mathrm{~g}^{-1}$. The intercalated CQDs improved the conductivity of the device, as indicated by a low charge transfer resistance of $14.5 \Omega$. Moreover, the layered crystal structure of the $\mathrm{V}_{2} \mathrm{O}_{5}$ nanorods allowed better electron mobility via the attached CQDs. An asymmetric cell with a VC working electrode yielded a $\mathrm{C}_{\mathrm{sp}}$ of $119 \mathrm{~F} \mathrm{~g}^{-1}$ at a current density of $1 \mathrm{~A} \mathrm{~g}^{-1}$. The energy density was $60 \mathrm{Wh} \mathrm{kg}^{-1}$ at a current density of $1 \mathrm{~A} \mathrm{~g}^{-1}$. The maximum power density was $4200 \mathrm{~W} \mathrm{~kg}^{-1}$ at a current density of $5 \mathrm{~A} \mathrm{~g}^{-1}$. Balasubramanian et al. used dextran, a naturally occurring polysaccharide, as the carbon precursor [126]. Dextran was slowly added to a solution of $\mathrm{V}_{2} \mathrm{O}_{5}$ and $\mathrm{H}_{2} \mathrm{O}_{2}$ and stirred for $4 \mathrm{~h}$ to allow precipitation. The precipitate was subsequently annealed at $400{ }^{\circ} \mathrm{C}$ for $2 \mathrm{~h}$ to yield a VC hybrid material. The composite exhibited a flower-like macrostructure with urchin-like protrusions. The soft dextran decomposed and covered $\mathrm{V}_{2} \mathrm{O}_{5}$ in a sharp 
urchin-like structure after annealing. The amorphous carbon layer increased the conductivity of $\mathrm{VC}$ and reduced $\mathrm{V}_{2} \mathrm{O}_{5}$ dissolution during charge/discharge. The flower-like architecture increased the surface area of the composite, resulting in more active sites for ion intercalation/de-intercalation, increasing the $C_{s p}$ value to a maximum of $417 \mathrm{~F} \mathrm{~g}^{-1}$ at a current density of $0.5 \mathrm{~A} \mathrm{~g}^{-1}$. The energy density of the $\mathrm{VC}$ composite was $47 \mathrm{Wh} \mathrm{kg}^{-1}$ at a power density of $224 \mathrm{~W} \mathrm{~kg}^{-1}$.

The carbon sources used for VC synthesis can also be derived from once-living organisms. Ngom et al. fabricated VC electrodes from different strains of hibiscus flower: light red (LR), dark red (DR), and white (W) [127]. The flowers were dried in sunlight and crushed into powder. The powder was dissolved in DI water and filtered to remove the large organic residue. The $\mathrm{V}_{2} \mathrm{O}_{5}$ powder was added to the solution with $\mathrm{H}_{2} \mathrm{O}_{2}$ and subsequently heated in an autoclave for one day at $180{ }^{\circ} \mathrm{C}$. The hibiscus-derived graphitic flakes were used as the template for $\mathrm{V}_{2} \mathrm{O}_{5}$ growth, resulting in the nucleation of flowerlike $\mathrm{V}_{2} \mathrm{O}_{5}$ nanosheets. $\mathrm{H}_{2} \mathrm{O}_{2}$ promoted the exfoliation of the carbon flakes, resulting in a more porous structure that allowed better ion diffusion. DR-VC exhibited the largest orthorhombic crystal size, with the largest specific surface area of $3.3 \mathrm{~m}^{2} \mathrm{~g}^{-1}$. Due to the increased surface area and organized crystal structure, DR-VC exhibited the highest specific capacity of $99.1 \mathrm{mAh} \mathrm{g}^{-1}$. An asymmetric supercapacitor with DR-VC and AC electrodes yielded an energy density of $33.4 \mathrm{Wh} \mathrm{kg}^{-1}$ at a power density of $670 \mathrm{~W} \mathrm{~kg}^{-1}$. Mei et al. pyrolyzed bacterial cellulose to yield carbonized bacterial cellulose (CBC), which was reacted with $\mathrm{V}_{2} \mathrm{O}_{5}$ powder via a hydrothermal method [128]. The resulting composite comprised web-like carbon strands coated with thick $\mathrm{V}_{2} \mathrm{O}_{5}$ nanobelts with a width of $\sim 70 \mathrm{~nm}$ and length of $\sim 600 \mathrm{~nm}$. The amorphous carbon strands formed a highly conductive web that prevented $\mathrm{V}_{2} \mathrm{O}_{5}$ aggregation. The orthorhombic crystal phase $\mathrm{V}_{2} \mathrm{O}_{5}$ supported the faradic redox reactions, and both EDL and pseudocapacitive characteristics contributed to charge storage. The $\mathrm{C}_{\mathrm{sp}}$ was $198 \mathrm{~F} \mathrm{~g}^{-1}$ at a scan rate of $10 \mathrm{mV} \mathrm{s}^{-1}$, which decreased to $\sim 75 \mathrm{~F} \mathrm{~g}^{-1}$ at a scan rate of $200 \mathrm{mV} \mathrm{s}^{-1}$. The $\mathrm{CBC} / \mathrm{V}_{2} \mathrm{O}_{5}$ composite had a maximum $\mathrm{C}_{\mathrm{sp}}$ of $281 \mathrm{~F} \mathrm{~g}^{-1}$ at a current density of $0.25 \mathrm{~A} \mathrm{~g}^{-1}$, which decreased to $65 \mathrm{~F} \mathrm{~g}^{-1}$ at a current density of $5 \mathrm{~A} \mathrm{~g}^{-1}$. The high $\mathrm{C}_{\mathrm{sp}}$ at a lower current density was due to the increased pseudocapacitive contribution from $\mathrm{V}_{2} \mathrm{O}_{5}$. The $\mathrm{CBC} / \mathrm{V}_{2} \mathrm{O}_{5}$ electrode exhibited a high cyclic stability with $97 \% \mathrm{C}_{\mathrm{sp}}$ retention after 1000 cycles and $87 \%$ of its initial $\mathrm{C}_{\mathrm{sp}}$ after 2000 cycles at a high scan rate of $100 \mathrm{mV} \mathrm{s}^{-1}$ because of the highly conductive carbon network. The $\mathrm{V}_{2} \mathrm{O}_{5} / \mathrm{CBC}$ electrode was highly reversible because the carbon webs stabilized the $\mathrm{V}_{2} \mathrm{O}_{5}$ nanobelts.

The initial carbon precursor is vital for determining the final morphology of the $\mathrm{VC}$ composite. A carbon source with large pores provides a large surface area for $\mathrm{V}_{2} \mathrm{O}_{5}$ nucleation and more active sites for faradic redox reactions. Bio-derived carbon materials from various sources such as glucose, plants, and bacteria have organized carbon structures that can be carbonized and combined with $\mathrm{V}_{2} \mathrm{O}_{5}$ to improve conductivity and structural stability.

\subsection{Effects of Composition}

The ratio of the carbon component to $\mathrm{V}_{2} \mathrm{O}_{5}$ affects the synergetic balance between conductivity and charge capacity and can also alter the morphology of the resulting composite. Fleischmann et al. varied the ratio of $\mathrm{V}_{2} \mathrm{O}_{5}$ to carbon onion precursors for hydrothermal synthesis [129]. Figure 8 shows the SEM micrographs of $\mathrm{V}_{2} \mathrm{C}_{7}\left(2: 7 \mathrm{~V}_{2} \mathrm{O}_{5}\right.$ to carbon onion), $\mathrm{V}_{3} \mathrm{C}_{6}\left(3: 6 \mathrm{~V}_{2} \mathrm{O}_{5}\right.$ to carbon onion), and $\mathrm{V}_{4} \mathrm{C}_{5}$ (4:5 $\mathrm{V}_{2} \mathrm{O}_{5}$ to carbon onion). Fleischmann et al. also physically combined the carbon onions and $\mathrm{V}_{2} \mathrm{O}_{5}$ crystals after synthesizing each of these individually $\left(\mathrm{C}_{5} \mathrm{~V}_{4}\right.$-COMP).

Quasi-spherical $\mathrm{V}_{2} \mathrm{O}_{5}$ nanoflowers were grown at the nucleation sites on the carbon onions. Thus, an increase in the initial carbon content also increased the $\mathrm{V}_{2} \mathrm{O}_{5}$ growth An increase in the carbon onion content resulted in a larger surface area for additional surface reactions. $\mathrm{V}_{2} \mathrm{C}_{7}$ (Figure $8 \mathrm{~A}$ ) was more spread out with smaller agglomerations than $\mathrm{V}_{3} \mathrm{C}_{6}$ (Figure 8B). Increasing $\mathrm{V}_{2} \mathrm{O}_{5}$ content to $\mathrm{V}_{4} \mathrm{C}_{5}$ (Figure $8 \mathrm{C}$ ) produced larger $\mathrm{V}_{2} \mathrm{O}_{5}$ agglomerations, as indicated by the dark coloring. Physical mixing of carbon onions and 
$\mathrm{V}_{2} \mathrm{O}_{5}$ resulted in large agglomerations of vanadium oxide and carbon onions (Figure 8D), which prevented the synergy between the two materials. The various VC composites were analyzed using a two-electrode configuration with a PTFE-bound AC counter electrode and a $\mathrm{VC}$ working electrode with $\mathrm{LiClO}_{4}$ in acetonitrile electrolyte. $\mathrm{V}_{3} \mathrm{C}_{6}$ outperformed the other three composites because of well-integrated conductive carbon with a large surface area and sizable $\mathrm{V}_{2} \mathrm{O}_{5}$ growth. Zhang et al. reported an increase in conductivity with an increase in the carbon content [130]. $\mathrm{V}_{2} \mathrm{O}_{5}$ was combined with mesoporous carbon hollow spheres (MCHSs) in different ratios to form a suspension that was rigorously stirred and subsequently freeze dried to yield a macroporous VC composite. The hybrid material comprised a web-like $\mathrm{V}_{2} \mathrm{O}_{5}$ maze with sporadic MCHS nanospheres anchored to the webs. Increasing the weight percentage of MCHSs from 33\% (VC-33) to 67\% (VC-67) increased the number of spherical carbon agglomerations. VC-33 had sparse carbon nanospheres, whereas VC-67 formed grape-like bundles on the $\mathrm{V}_{2} \mathrm{O}_{5}$ webs. VC-50 (50 wt $\%$ MCHS) contained a uniform spread of graphitic carbon nanospheres on the $\mathrm{V}_{2} \mathrm{O}_{5}$ web. A low carbon content reduced agglomerations that allowed ion adsorption into $\mathrm{V}_{2} \mathrm{O}_{5}$. However, an increase in the carbon content increased the conductivity of the material. Thus, VC-50 with a uniform distribution of carbon nanospheres exhibited the highest $C_{\mathrm{sp}}$ of $313 \mathrm{~F} \mathrm{~g}^{-1}$ at a current density of $0.25 \mathrm{~A} \mathrm{~g}^{-1}$. The macroporous web structure decreased the stress due to repeated ion insertion/de-insertion, resulting in an increase in cyclability from $43 \%$ for bare $\mathrm{V}_{2} \mathrm{O}_{5}$ to $81 \%$ for $\mathrm{VC}-50$ after 4000 cycles at a current density of $5 \mathrm{~A} \mathrm{~g}^{-1}$.
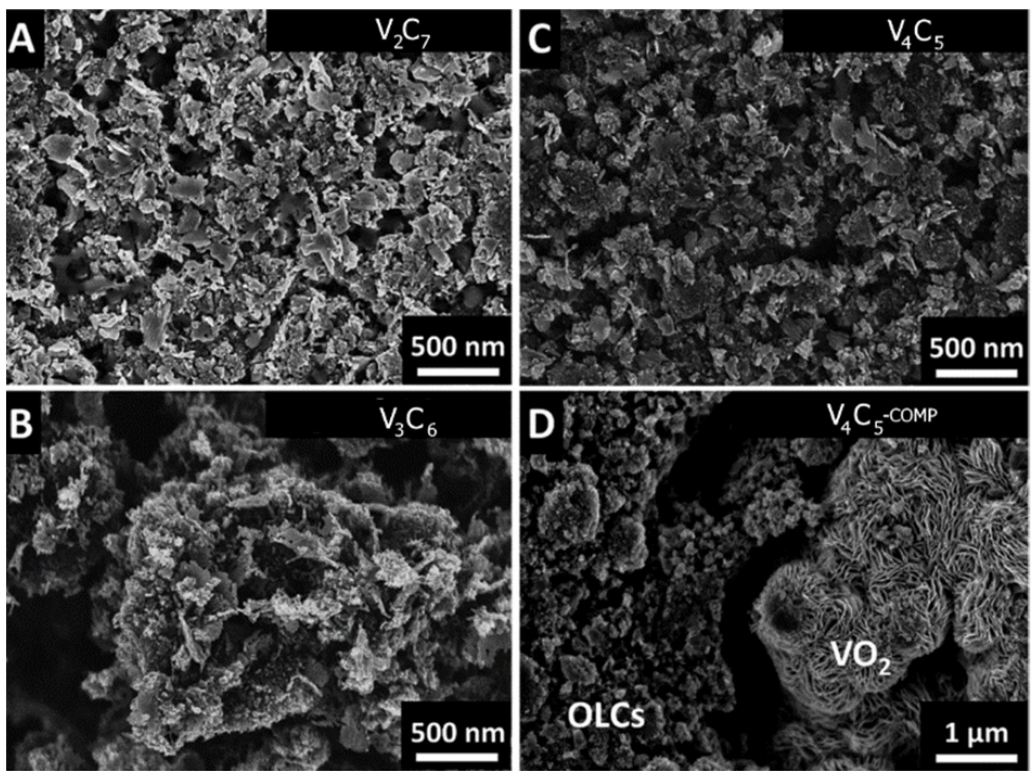

Figure 8. SEM micrographs of (A) $\mathrm{V}_{2} \mathrm{C}_{7}$, (B) $\mathrm{V}_{3} \mathrm{C}_{6}$, (C) $\mathrm{V}_{4} \mathrm{C}_{5}$, and (D) $\mathrm{V}_{4} \mathrm{C}_{5}$-COMP. Reprinted with permission from Ref. [129]. Copyright 2017 Royal Society of Chemistry.

Control of the carbon to $\mathrm{V}_{2} \mathrm{O}_{5}$ ratio can also change the porosity of the VC material, thereby altering the ion diffusion capability and number of active sites for faradic redox reactions. Zhu et al. determined the effects of $\mathrm{V}_{2} \mathrm{O}_{5}$ loading on the porosity and performance of a VC electrode [131]. The VC composite was synthesized using a liquid-phase impregnation technique, yielding a hierarchically porous $\mathrm{VC}$ material. The VC material had a macroporous carbon frame with $\mathrm{V}_{2} \mathrm{O}_{5}$ intercalated through the pores. At a low $17.6 \mathrm{wt} \%$ of $\mathrm{V}_{2} \mathrm{O}_{5}$ (VC-18), the pores in the carbon were small and tightly packed, resulting in a BET surface area of $622 \mathrm{~m}^{2} \mathrm{~g}^{-1}$. At a high $\mathrm{V}_{2} \mathrm{O}_{5}$ loading of $52 \mathrm{wt} \%$ (VC-52), the sheets were covered with large micropores with tiny gaps between the layers, resulting in a smaller BET surface area of $487 \mathrm{~m}^{2} \mathrm{~g}^{-1}$. The VC material with a $38.7 \mathrm{wt} \% \mathrm{~V}_{2} \mathrm{O}_{5}$ (VC-39) had the greatest BET surface area of $645 \mathrm{~m}^{2} \mathrm{~g}^{-1}$ because of its larger pores. Thus, VC-39 yielded the highest $C_{\text {sp }}$ of $492.1 \mathrm{~F} \mathrm{~g}^{-1}$ at a scan rate of $5 \mathrm{mV} \mathrm{s}^{-1}$ because of the numerous active 
sites provided by the micropores and ease of ion diffusion through the high volume of macropores. The $\mathrm{C}_{\mathrm{sp}}$ value decreased slightly to $\sim 400 \mathrm{~F} \mathrm{~g}^{-1}$ at a scan rate of $100 \mathrm{mV} \mathrm{s}^{-1}$, indicating good rate capability because the amorphous carbon dispersion enabled good electron mobility with low series and charge transfer resistances of 0.54 and $1.05 \Omega$, respectively. A symmetric supercapacitor assembled with VC-39 had an energy density of $87.6 \mathrm{Wh} \mathrm{kg}^{-1}$ at a power density of $497 \mathrm{~W} \mathrm{~kg}^{-1}$ that decreased to $20.4 \mathrm{Wh} \mathrm{kg}^{-1}$ at a power density of $3272 \mathrm{~W} \mathrm{~kg}^{-1}$. Saravanakumar et al. controlled the ratio of $\mathrm{N}$-doped mesoporous carbon (N-MPC) nanospheres to $\mathrm{V}_{2} \mathrm{O}_{5}$ to obtain a superior supercapacitor electrode with maximum porosity [132]. The $\mathrm{VC}$ material comprised $\mathrm{V}_{2} \mathrm{O}_{5}$ flakes anchored onto the spherical N-MPC. These $\mathrm{V}_{2} \mathrm{O}_{5}$ covered carbon spheres formed agglomerations with other $\mathrm{VC}$ nanospheres. The hydrothermal method oxidized $\mathrm{V}_{2} \mathrm{O}_{5}$ to form pure orthorhombic crystals, while reducing the carbon into a graphitic crystal phase. A low N-MPC loading of $10 \%$ (VC-10) resulted in many uncoated carbon spheres due to $\mathrm{V}_{2} \mathrm{O}_{5}$ agglomeration. This decreased the accessibility to $\mathrm{V}_{2} \mathrm{O}_{5}$ for surface ion intercalation. At $5 \mathrm{wt} \% \mathrm{~N}-\mathrm{MPC}$, the carbon nanospheres were homogeneously covered to maximize the pseudocapacitive capacity of $\mathrm{V}_{2} \mathrm{O}_{5}$ with an optimal surface area of $8.77 \mathrm{~m}^{2} \mathrm{~g}^{-1}$. The addition of $15 \mathrm{wt} \% \mathrm{~N}-\mathrm{MPC}$ resulted in nanospheres that were completely coated by $\mathrm{V}_{2} \mathrm{O}_{5}$, decreasing the accessibility to N-MPC for a suboptimal surface area of $10.35 \mathrm{~m}^{2} \mathrm{~g}^{-1}$. At $10 \mathrm{wt} \% \mathrm{~N}-\mathrm{MPC}$, the carbon nanospheres were effectively covered to maximize the pseudocapacitive capacity of $\mathrm{V}_{2} \mathrm{O}_{5}$ with an optimal surface area of $8.77 \mathrm{~m}^{2} \mathrm{~g}^{-1}$. VC-10 exhibited the highest $\mathrm{C}_{\mathrm{sp}}$ of $487 \mathrm{~F} \mathrm{~g}^{-1}$ at a current density of $0.5 \mathrm{~A} \mathrm{~g}^{-1}$, which was $34 \%$ higher than that of bare $\mathrm{V}_{2} \mathrm{O}_{5}$. The increase in capacitance was caused by a significant increase in surface area from 5.64 to $8.77 \mathrm{~m}^{2} \mathrm{~g}^{-1}$ and increased conductivity because of N-MPC. An asymmetric supercapacitor with the VC10 electrode had an energy density of $12.8 \mathrm{Wh} \mathrm{kg}^{1}$ at a power density of $317 \mathrm{~W} \mathrm{~kg}^{-1}$. Kudo et al. added varying amounts of acetylene black to a $\mathrm{V}_{2} \mathrm{O}_{5}$ sol to create a suspension with acetone surfactant [133]. The $\mathrm{Ni}$ foam was subsequently submerged in the suspension and heated at $120^{\circ} \mathrm{C}$ for $5 \mathrm{~h}$. The resulting VC was comprised of spherical carbon cores with an uneven $\mathrm{V}_{2} \mathrm{O}_{5}$ outer layer coating. These nanospheres formed bumpy agglomerations, yielding a BET surface area of $30 \mathrm{~m}^{2} \mathrm{~g}^{-1}$. With a large carbon content (30 wt \% acetylene black), the VC exhibited good rate capability, maintaining a charge capacity of $340 \mathrm{mAh} \mathrm{g}^{-1}$ at a high current density of $54 \mathrm{~A} \mathrm{~g}^{-1}$. The VC electrode maintained $100 \%$ of its capacity even after 2000 cycles at a charge rate of $20 \mathrm{C}$ because the porosity of the VC material allowed unobstructed Li ion insertion/de-insertion. The maximum energy density was $80 \mathrm{Wh} \mathrm{kg}^{-1}$ at a power density of $26,000 \mathrm{~W} \mathrm{~kg}^{-1}$ with an average working voltage of $2 \mathrm{~V}$, which rapidly deteriorated with repeated cycles. The average energy density was $15-20 \mathrm{Wh} \mathrm{kg}^{-1}$. Peng et al. followed a similar synthesis route using Ketjen black powder and a $\mathrm{V}_{2} \mathrm{O}_{5}$ sol [134]. Ni foam was used as a template for $\mathrm{VC}$ coating. The VC material comprised $\mathrm{V}_{2} \mathrm{O}_{5}$ nanosheets covered with carbon nanospheres uniformly distributed on the hydrated $\mathrm{V}_{2} \mathrm{O}_{5}$ surface. An increase in the initial Ketjen black loading increased the final surface area of VC, with a maximum BET surface area of $264.72 \mathrm{~m}^{2} \mathrm{~g}^{-1}$ for $\mathrm{VC}_{1}$ ( $1 \mathrm{~g}$ Ketjen black loading). $\mathrm{VC}_{0.5}$ ( $0.5 \mathrm{~g}$ Ketjen black loading) exhibited the highest $C_{\mathrm{sp}}$ of $1634 \mathrm{~F} \mathrm{~g}^{-1}$ at a current density of $5 \mathrm{~mA} \mathrm{~cm}^{-2}$ because of effective synergy between carbon for fast electron mobility and $\mathrm{V}_{2} \mathrm{O}_{5}$ nanosheets for high pseudocapacitance. A symmetric supercapacitor with the $\mathrm{VC}_{0.5}$ electrodes had an energy density of $56.83 \mathrm{Wh} \mathrm{kg}^{-1}$ at a power density of $303 \mathrm{~W} \mathrm{~kg}^{-1}$, which decreased slightly to $30.86 \mathrm{Wh} \mathrm{kg}^{-1}$ at a power density of $2433 \mathrm{~W} \mathrm{~kg}^{-1}$. Despite not having a lower surface area and containing less conductive carbon content than $\mathrm{VC}_{1}, \mathrm{VC}_{0.5}$ retained a good rate capability while sustaining a high energy storage capacity.

\subsection{Effects of Physical Treatment}

Heat treatment of a VC composite can alter the morphology of the hybrid material [135]. Kim et al. synthesized VC by heating a mixture of vanadium trichloride, terephthalic acid, and DI water in an autoclave at $200^{\circ} \mathrm{C}$ for four days. Subsequently, the VC powder was calcinated at $400{ }^{\circ} \mathrm{C}$ for $6 \mathrm{~h}$ in an argon atmosphere [136]. Prior to calcination, the VC exhibited a rectangular structure with large crystals that were 1-4 $\mu \mathrm{m}$ in length. 
The heat-treated VC had a highly orthorhombic crystal structure with thinner nanorods that were $0.5-3 \mu \mathrm{m}$ in length. A 4-6-nm-thick layer of graphitic carbon coated the $\mathrm{V}_{2} \mathrm{O}_{5}$ nanorods. The annealed VC exhibited an initial discharge rate of $286 \mathrm{mAh} \mathrm{g}^{-1}$ at $0.1 \mathrm{C}$, which was close to the theoretical limit of $294 \mathrm{mAh} \mathrm{g}^{-1}$. Zhang et al. also analyzed the effects of annealing temperature and duration on the morphology of the VC material [137]. The VC composite was synthesized via a hydrothermal method and was further heat treated in a muffle furnace at varying temperatures of 300 to $500{ }^{\circ} \mathrm{C}$ for different durations in air. The hydrothermal synthesis yielded smooth prism-like monoclinic $\mathrm{V}_{2} \mathrm{O}_{5}$ protrusions with amorphous carbon nanospheres embedded between the $\mathrm{V}_{2} \mathrm{O}_{5}$ crystals. Calcination under air resulted in porous $\mathrm{V}_{2} \mathrm{O}_{5}$ nanoparticles with uneven surfaces due to combustion reactions with air. At a low calcination temperature of $300^{\circ} \mathrm{C}$, many carbon nanospheres remained scattered within the $\mathrm{V}_{2} \mathrm{O}_{5}$ nanorods, whereas no nanospheres were present in the VC that was heat treated at $500{ }^{\circ} \mathrm{C}$. The presence of carbon nanospheres indicated the incomplete oxidation of $\mathrm{V}_{2} \mathrm{O}_{5}$, resulting in a lower $\mathrm{C}_{\mathrm{sp}}$ of $151 \mathrm{~F} \mathrm{~g}^{-1}$ at a current density of $1 \mathrm{~A} \mathrm{~g}^{-1}$ for VC-300 compared to $367 \mathrm{~F} \mathrm{~g}^{-1}$ for VC-500. An increase in the calcination duration up to $8 \mathrm{~h}$ increased the $\mathrm{C}_{\mathrm{sp}}$ of the VC composite because $\mathrm{V}_{2} \mathrm{O}_{5}$ had more time to nucleate. However, further increasing the calcination time to $12 \mathrm{~h}$ decreased the $\mathrm{C}_{\mathrm{sp}}$ because the agglomeration of $\mathrm{V}_{2} \mathrm{O}_{5}$ resulted in limited surface ion diffusion.

Heat treatment can also promote the oxidation of $\mathrm{V}^{4+}$ to $\mathrm{V}^{5+}$ for a more crystalline $\mathrm{V}_{2} \mathrm{O}_{5}$. Zeiger et al. fabricated vanadium carbide/carbide core/shell composites (VC-C) by reacting vanadium carbide with $\mathrm{NiCl}_{2}$ in a graphite crucible at $700{ }^{\circ} \mathrm{C}$ in chlorine gas followed by calcination at $450{ }^{\circ} \mathrm{C}$ in synthetic air to promote further oxidation of $\mathrm{V}^{4+}$ [138]. The resulting VC-C nanostructure was composed of a $\mathrm{V}_{2} \mathrm{O}_{5}$ core and carbide-derived carbon shell. Increasing the calcination temperature to $600{ }^{\circ} \mathrm{C}$ increased $\mathrm{V}_{2} \mathrm{O}_{5}$ oxidation but burned off most of the carbon shell. VC-C- 90 (90\% theoretically converted) exhibited the highest specific capacity of $415 \mathrm{mAh} \mathrm{g}^{-1}$ at a current density of $0.01 \mathrm{~A} \mathrm{~g}^{-1}$ with almost $100 \%$ coulombic efficiency. The partial conversion of the $\mathrm{V}_{2} \mathrm{O}_{5}$ core from vanadium carbide provided a large storage capacity, while the outer carbon shell increased the conductivity of the composite. A decrease in the annealing temperature to decrease the carbide shell burnoff while effectively oxidizing the vanadium carbide core was essential for maximum yield. An asymmetric supercapacitor setup with the VC-C-90 negative electrode yielded an energy density of $90 \mathrm{Wh} \mathrm{kg}{ }^{-1}$ for charging and $50 \mathrm{Wh} \mathrm{kg}^{-1}$ for discharging at a power density of $166 \mathrm{~W} \mathrm{~kg}^{-1}$. The energy density decreased to $27 \mathrm{Wh} \mathrm{kg}^{-1}$ at a high-power density of $6700 \mathrm{~W} \mathrm{~kg}^{-1}$, retaining $80 \%$ of its energy density after 10,000 cycles at a current density of $1 \mathrm{~A} \mathrm{~g}^{-1}$. Narayanan et al. annealed glucose-based VC at temperatures of $250-400{ }^{\circ} \mathrm{C}$ in air [139]. The composite contained thin $\mathrm{V}_{2} \mathrm{O}_{5}$ nanorods with CQDs anchored to the nanorods; the $\mathrm{V}_{2} \mathrm{O}_{5}$ nanorods also had a thin carbon coating. Increasing the annealing temperature decreased the thickness of the $\mathrm{V}_{2} \mathrm{O}_{5}$ nanorods and promoted $\mathrm{V}_{2} \mathrm{O}_{5}$ oxidation using oxygen from the atmosphere, resulting in more orthorhombic $\mathrm{V}_{2} \mathrm{O}_{5}$ crystals. VC annealed at $250{ }^{\circ} \mathrm{C}(\mathrm{VC} 250)$ exhibited the highest $\mathrm{C}_{\mathrm{sp}}$ of $260 \mathrm{~F} \mathrm{~g}^{-1}$ at a current density of $1 \mathrm{~A} \mathrm{~g} \mathrm{~g}^{-1}$. The layered $\mathrm{V}_{2} \mathrm{O}_{5}$ crystal structure improved electron propagation, and the high surface area of the VC material increased the surface adsorption. VC250 also exhibited the lowest charge transfer resistance of $11.4 \Omega$. The VC250 electrode exhibited high cycling capability, retaining $92 \%$ of its $\mathrm{C}_{\mathrm{sp}}$ after 5000 cycles at a current density of $5 \mathrm{~A} \mathrm{~g}^{-1}$ because the carbon coating decreased vanadium dissolution. The imperfections in the $\mathrm{V}_{2} \mathrm{O}_{5}$ lattice caused by $\mathrm{V}^{4+}$ enhanced the Li-ion intercalation capability and decreased $\mathrm{V}_{2} \mathrm{O}_{5}$ dissolution.

The heat treatment of VC composites can change the morphology of the composite and promote the oxidation of vanadium oxide to $\mathrm{V}_{2} \mathrm{O}_{5}$. Thus, controlling the annealing temperature and duration allows the formation of partially oxidized VC materials for increased stability and surface ion intercalation. However, excessive annealing temperatures and durations disintegrate the carbon content, resulting in a low conductivity. Therefore, it is essential to optimize both the annealing temperature and duration. 


\section{Conclusions}

The synthesis of various metal oxide and carbon composites as supercapacitor electrode materials has attracted significant attention because of the increasing demand for high energy and power-dense energy storage devices used in portable electronics and electric vehicles. The development of stable vanadium oxide-based electrode materials has been extensively investigated due to the high energy storage potential and natural abundance of vanadium oxide. Common carbon nanostructures such as rGO, CNTs, CNFs, and CQDs have been combined with $\mathrm{V}_{2} \mathrm{O}_{5}$ to yield high-performance supercapacitor electrode materials.

$\mathrm{V}_{2} \mathrm{O}_{5} / \mathrm{rGO}$ composites can be synthesized using many methods, including hydro/ solvothermal, sol-gel, filtration, and chemical deposition methods. These strategies often yield a lamellar rGO nanostructure with $\mathrm{V}_{2} \mathrm{O}_{5}$ intercalated between the nanosheets. $\mathrm{V}_{2} \mathrm{O}_{5} / \mathrm{CNT}$ hybrid materials are frequently synthesized as vertically aligned nanotubes infiltrated by $\mathrm{V}_{2} \mathrm{O}_{5}$ crystals or long nanotubes with $\mathrm{V}_{2} \mathrm{O}_{5}$ growth using various synthesis methods. The CNTs have the advantage of facile functionalization with hydroxyl or carboxyl groups to increase $\mathrm{V}_{2} \mathrm{O}_{5}$ nucleation and conductivity. The $\mathrm{V}_{2} \mathrm{O}_{5} / \mathrm{CNF}$ composites offer the unique advantage of having a highly stable 3D macrostructure that can be used as a template for the fabrication of free-standing and binderless electrodes. Using electrodeposition, crystallization, sol-dipping, or electrospinning methods, a fibrous structure with a CNF $/ \mathrm{V}_{2} \mathrm{O}_{5}$ core/shell nanostructure or $\mathrm{V}_{2} \mathrm{O}_{5}$ crystals intercalated into web-like CNFs can be synthesized. Other $\mathrm{V}_{2} \mathrm{O}_{5}$ /carbon materials such as CQD-based and amorphous carbon-flake-based composites can be easily synthesized via facile strategies such as the hydro/solvothermal method. Carbon precursors can be sourced from both artificially synthesized and bio-based carbonaceous materials.

In most cases, an increase in the $\mathrm{V}_{2} \mathrm{O}_{5}$ content in the $\mathrm{V}_{2} \mathrm{O}_{5}$ /carbon hybrid materials increases the total energy storage potential because of faradic redox reactions. However, a high $\mathrm{V}_{2} \mathrm{O}_{5}$ content results in agglomerations that hinder surface ion adsorption. An increase in the carbon content leads to increased EDL contributions and conductivity for improved rate capability and cyclic stability. However, the low energy storage potential of carbon nanomaterials limits high carbon content for energy-dense electrode materials. An optimal balance of $\mathrm{V}_{2} \mathrm{O}_{5}$ and carbon can increase the surface area and porosity beyond that of solely the carbon material alone, enabling more activation sites for greater ion intercalation/deintercalation. The synergy between $\mathrm{V}_{2} \mathrm{O}_{5}$ and carbon can also inhibit vanadium ion dissolution, resulting in a more stable charge/discharge. Physical treatment via annealing, calcination, and laser treatment can promote vanadium oxide oxidation to $\mathrm{V}_{2} \mathrm{O}_{5}$, altering the crystallinity of the hybrid material for improved electrochemical performance.

This review discusses the effects of different synthesis methods, $\mathrm{V}_{2} \mathrm{O}_{5} /$ carbon compositions, and physical treatment strategies on the morphology and electrochemical performances of $\mathrm{V}_{2} \mathrm{O}_{5}$ / carbon composites. This review is expected to serve as a catalyst for further research for the development of an ideal supercapacitor electrode material with high power and energy properties. Furthermore, light, solid-state supercapacitors based on $\mathrm{V}_{2} \mathrm{O}_{5}$ /carbon nanomaterials have potential applications for portable, stretchable and wearable electronics. Continued research efforts in this area could make great contribution to developing supercapacitor technologies.

Author Contributions: Conceptualization, A.K., J.H.K. and R.P.; methodology, A.K., R.P.; writingoriginal draft preparation, A.K.; writing - review and editing, A.K., G.K., J.H.K. and R.P. All authors have read and agreed to the published version of the manuscript.

Funding: This work was supported by the National Research Foundation (NRF) of South Korea, funded by the Ministry of Science and ICT, Republic of Korea (NRF-2017R1D1A1B06028030 and NRF-2018M3A7B4071535).

Data Availability Statement: Not applicable.

Conflicts of Interest: The authors declare no conflict of interest. 


\section{References}

1. Najib, S.; Erdem, E. Current progress achieved in novel materials for supercapacitor electrodes: Mini review. Nanoscale Adv. 2019, 1, 2817-2827. [CrossRef]

2. Zhang, S.; Pan, N. Supercapacitors Performance Evaluation. Adv. Energy Mater. 2015, 5, 1401401. [CrossRef]

3. Simon, P.; Gogotsi, Y.; Dunn, B. Where do batteries end and supercapacitors begin? Science 2014, 343, 1210-1211. [CrossRef]

4. Lin, T.; Chen, I.W.; Liu, F.; Yang, C.; Bi, H.; Xu, F.; Huang, F. Nitrogen-doped mesoporous carbon of extraordinary capacitance for electrochemical energy storage. Science 2015, 350, 1508-1513. [CrossRef]

5. Vlad, A.; Singh, N.; Rolland, J.; Melinte, S.; Ajayan, P.M.; Gohy, J.F. Hybrid supercapacitor-battery materials for fast electrochemical charge storage. Sci. Rep. 2014, 4, 4315. [CrossRef]

6. Suganya, B.; Maruthamuthu, S.; Chandrasekaran, J.; Saravanakumar, B.; Vijayakumar, E.; Marnadu, R.; Al-Enizi, A.M.; Ubaidullah, M. Design of zinc vanadate $\left(\mathrm{Zn}_{3} \mathrm{~V}_{2} \mathrm{O}_{8}\right) /$ nitrogen doped multiwall carbon nanotubes (N-MWCNT) towards supercapacitor electrode applications. J. Electroanal. Chem. 2021, 881, 114936. [CrossRef]

7. Patel, R.; Inamdar, A.I.; Hou, B.; Cha, S.N.; Ansari, A.T.; Gunjakar, J.L.; Im, H.; Kim, H. Solvothermal synthesis of highperformance Ni-Co layered double hydroxide nanofoam electrode for electrochemical energy storage. Curr. Appl. Phys. 2017, 17, 501-506. [CrossRef]

8. Zhu, J.; Chen, S.; Zhou, H.; Wang, X. Fabrication of a low defect density graphene-nickel hydroxide nanosheet hybrid with enhanced electrochemical performance. Nano Res. 2012, 5, 11-19. [CrossRef]

9. Nandi, D.; Mohan, V.B.; Bhowmick, A.K.; Bhattacharyya, D. Metal/metal oxide decorated graphene synthesis and application as supercapacitor: A review. J. Mater. Sci. 2020, 55, 6375-6400. [CrossRef]

10. Mathis, T.S.; Kurra, N.; Wang, X.; Pinto, D.; Simon, P.; Gogotsi, Y. Energy Storage Data Reporting in Perspective-Guidelines for Interpreting the Performance of Electrochemical Energy Storage Systems. Adv. Energy Mater. 2019, 9, 1902007. [CrossRef]

11. Iro, Z.S.; Subramani, C.; Dash, S.S. Electrochemical science: A brief review on electrode materials for supercapacitor. Int. J. Electrochem. Sci. 2016, 11, 10628-10643. [CrossRef]

12. Majumdar, D.; Mandal, M.; Bhattacharya, S.K. $\mathrm{V}_{2} \mathrm{O}_{5}$ and its Carbon-Based Nanocomposites for Supercapacitor Applications. ChemElectroChem 2019, 6, 1623-1648. [CrossRef]

13. Borenstein, A.; Hanna, O.; Attias, R.; Luski, S.; Brousse, T.; Aurbach, D. Carbon-based composite materials for supercapacitor electrodes: A review. J. Mater. Chem. A 2017, 5, 12653-12672. [CrossRef]

14. Ho, M.Y.; Khiew, P.S.; Isa, D.; Tan, T.K.; Chiu, W.S.; Chia, C.H. A review of metal oxide composite electrode materials for electrochemical capacitors. Nano 2014, 9, 1430002. [CrossRef]

15. Zhu, J.; Cao, L.; Wu, Y.; Gong, Y.; Liu, Z.; Hoster, H.E.; Zhang, Y.; Zhang, S.; Yang, S.; Yan, Q.; et al. Building 3D structures of vanadium pentoxide nanosheets and application as electrodes in supercapacitors. Nano Lett. 2013, 13, 5408-5413. [CrossRef] [PubMed]

16. Qian, A.; Pang, Y.; Wang, G.; Hao, Y.; Liu, Y.; Shi, H.; Chung, C.H.; Du, Z.; Cheng, F. Pseudocapacitive Charge Storage in MXene- $\mathrm{V}_{2} \mathrm{O}_{5}$ for Asymmetric Flexible Energy Storage Devices. ACS Appl. Mater. Interfaces 2020, 12, 54791-54797. [CrossRef] [PubMed]

17. Zhi, M.; Xiang, C.; Li, J.; Li, M.; Wu, N. Nanostructured carbon-metal oxide composite electrodes for supercapacitors: A review. Nanoscale 2013, 5, 72-88. [CrossRef] [PubMed]

18. Qu, Q.; Zhu, Y.; Gao, X.; Wu, Y. Core-Shell Structure of Polypyrrole Grown on $\mathrm{V}_{2} \mathrm{O}_{5}$ Nanoribbon as High Performance Anode Material for Supercapacitors. Adv. Energy Mater. 2012, 2, 950-955. [CrossRef]

19. Augustyn, V.; Simon, P.; Dunn, B. Pseudocapacitive oxide materials for high-rate electrochemical energy storage. Energy Environ. Sci. 2014, 7, 1597-1614. [CrossRef]

20. Chalker, C.J.; An, H.; Zavala, J.; Parija, A.; Banerjee, S.; Lutkenhaus, J.L.; Batteas, J.D. Fabrication and Electrochemical Performance of Structured Mesoscale Open Shell $\mathrm{V}_{2} \mathrm{O}_{5}$ Networks. Langmuir 2017, 33, 5975-5981. [CrossRef]

21. Gerbaldi, C.; Destro, M.; Nair, J.R.; Ferrari, S.; Quinzeni, I.; Quartarone, E. High-rate $\mathrm{V}_{2} \mathrm{O}_{5}$-based Li-ion thin film polymer cell with outstanding long-term cyclability. Nano Energy 2013, 2, 1279-1286. [CrossRef]

22. Mjejri, I.; Manceriu, L.M.; Gaudon, M.; Rougier, A.; Sediri, F. Nano-vanadium pentoxide films for electrochromic displays. Solid State Ionics 2016, 292, 8-14. [CrossRef]

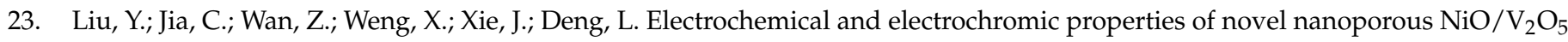
hybrid film. Sol. Energy Mater. Sol. Cells 2015, 132, 467-475. [CrossRef]

24. Karade, S.S.; Lalwani, S.; Eum, J.H.; Kim, H. Coin cell fabricated symmetric supercapacitor device of two-steps synthesized $\mathrm{V}_{2} \mathrm{O}_{5}$ Nanorods. J. Electroanal. Chem. 2020, 864, 114080. [CrossRef]

25. Zhang, H.; Han, X.; Gan, R.; Guo, Z.; Ni, Y.; Zhang, L. A facile biotemplate-assisted synthesis of mesoporous $\mathrm{V}_{2} \mathrm{O}_{5}$ microtubules for high performance asymmetric supercapacitors. Appl. Surf. Sci. 2020, 511, 145527. [CrossRef]

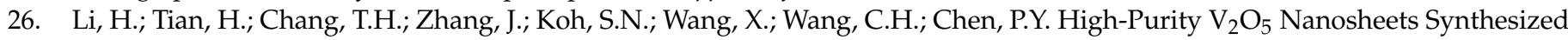
from Gasification Waste: Flexible Energy Storage Devices and Environmental Assessment. ACS Sustain. Chem. Eng. 2019, 7, 12474-12484. [CrossRef]

27. Zhang, S.; Chen, S.; Luo, Y.; Yan, B.; Gu, Y.; Yang, F.; Cao, Y. Large-scale preparation of solution-processable one-dimensional $\mathrm{V}_{2} \mathrm{O}_{5}$ nanobelts with ultrahigh aspect ratio for bifunctional multicolor electrochromic and supercapacitor applications. J. Alloys Compd. 2020, 842, 155882. [CrossRef] 
28. Lee, H.; Kumbhar, V.S.; Lee, J.; Choi, Y.; Lee, K. Highly reversible crystal transformation of anodized porous $\mathrm{V}_{2} \mathrm{O}_{5}$ nanostructures for wide potential window high-performance supercapacitors. Electrochim. Acta 2020, 334, 135618. [CrossRef]

29. Uma Shankar, V.; Govindarajan, D.; Christuraj, P.; Salethraj, M.J.; Johanson, F.J.; Raja, M.D. Enhanced the electrochemical properties of $\mathrm{Ni}$ doped $\mathrm{V}_{2} \mathrm{O}_{5}$ as a electrode material for supercapacitor applications. In Materials Today: Proceedings; Elsevier BV: Amsterdam, The Netherlands, 2020.

30. Hsiao, Y.S.; Chang-Jian, C.W.; Syu, W.L.; Yen, S.C.; Huang, J.H.; Weng, H.C.; Lu, C.Z.; Hsu, S.C. Enhanced electrochromic performance of carbon-coated $\mathrm{V}_{2} \mathrm{O}_{5}$ derived from a metal-organic framework. Appl. Surf. Sci. 2021, 542, 148498. [CrossRef]

31. Ke, Q.; Wang, J. Graphene-based materials for supercapacitor electrodes-A review. J. Mater. 2016, 2, 37-54. [CrossRef]

32. Thalji, M.R.; Ali, G.A.M.; Lee, S.P.; Chong, K.F. Solvothermal Synthesis of Reduced Graphene Oxide as Electrode Material for Supercapacitor Application. Chem. Adv. Mater. 2019, 4, 17-26.

33. Yang, Z.; Tian, J.; Yin, Z.; Cui, C.; Qian, W.; Wei, F. Carbon nanotube- and graphene-based nanomaterials and applications in high-voltage supercapacitor: A review. Carbon 2019, 141, 467-480. [CrossRef]

34. Faraji, S.; Ani, F.N. The development supercapacitor from activated carbon by electroless plating-A review. Renew. Sustain. Energy Rev. 2015, 42, 823-834. [CrossRef]

35. Cottineau, T.; Toupin, M.; Delahaye, T.; Brousse, T.; Bélanger, D. Nanostructured transition metal oxides for aqueous hybrid electrochemical supercapacitors. Appl. Phys. A Mater. Sci. Process. 2006, 82, 599-606. [CrossRef]

36. Patel, R.; Park, J.T.; Patel, M.; Dash, J.K.; Gowd, E.B.; Karpoormath, R.; Mishra, A.; Kwak, J.; Kim, J.H. Transition-metal-based layered double hydroxides tailored for energy conversion and storage. J. Mater. Chem. A 2017, 6, 12-29. [CrossRef]

37. Noked, M.; Avraham, E.; Bohadana, Y.; Soffer, A.; Aurbach, D. Development of anion stereoselective, activated carbon molecular sieve electrodes prepared by chemical vapor deposition. J. Phys. Chem. C 2009, 113, 7316-7321. [CrossRef]

38. Xu, Y.; Lin, Z.; Zhong, X.; Huang, X.; Weiss, N.O.; Huang, Y.; Duan, X. Holey graphene frameworks for highly efficient capacitive energy storage. Nat. Commun. 2014, 5, 4554. [CrossRef]

39. Cheng, J.; Gu, G.; Guan, Q.; Razal, J.M.; Wang, Z.; Li, X.; Wang, B. Synthesis of a porous sheet-like $\mathrm{V}_{2} \mathrm{O}_{5}-\mathrm{CNT}$ nanocomposite using an ice-templating "bricks-and-mortar" assembly approach as a high-capacity, long cyclelife cathode material for lithium-ion batteries. J. Mater. Chem. A 2016, 4, 2729-2737. [CrossRef]

40. Mohd Abdah, M.A.A.; Azman, N.H.N.; Kulandaivalu, S.; Sulaiman, Y. Review of the use of transition-metal-oxide and conducting polymer-based fibres for high-performance supercapacitors. Mater. Des. 2020, 186, 108199. [CrossRef]

41. González, A.; Goikolea, E.; Barrena, J.A.; Mysyk, R. Review on supercapacitors: Technologies and materials. Renew. Sustain. Energy Rev. 2016, 58, 1189-1206. [CrossRef]

42. Delbari, S.A.; Ghadimi, L.S.; Hadi, R.; Farhoudian, S.; Nedaei, M.; Babapoor, A.; Sabahi Namini, A.; Van Le, Q.; Shokouhimehr, M.; Shahedi Asl, M.; et al. Transition metal oxide-based electrode materials for flexible supercapacitors: A review. J. Alloys Compd. 2021, 857, 158281. [CrossRef]

43. Kumar, K.S.; Choudhary, N.; Jung, Y.; Thomas, J. Recent Advances in Two-Dimensional Nanomaterials for Supercapacitor Electrode Applications. ACS Energy Lett. 2018, 3, 482-495. [CrossRef]

44. Raghavendra, K.V.G.; Vinoth, R.; Zeb, K.; Muralee Gopi, C.V.V.; Sambasivam, S.; Kummara, M.R.; Obaidat, I.M.; Kim, H.J. An intuitive review of supercapacitors with recent progress and novel device applications. J. Energy Storage 2020, $31,101652$. [CrossRef]

45. Lokhande, V.C.; Lokhande, A.C.; Lokhande, C.D.; Kim, J.H.; Ji, T. Supercapacitive composite metal oxide electrodes formed with carbon, metal oxides and conducting polymers. J. Alloys Compd. 2016, 682, 381-403. [CrossRef]

46. Dubey, R.; Guruviah, V. Review of carbon-based electrode materials for supercapacitor energy storage. Ionics 2019, 25, 1419-1445. [CrossRef]

47. Fisher, R.A.; Watt, M.R.; Jud Ready, W. Functionalized Carbon Nanotube Supercapacitor Electrodes: A Review on Pseudocapacitive Materials. ECS J. Solid State Sci. Technol. 2013, 2, M3170-M3177. [CrossRef]

48. Bose, S.; Kuila, T.; Mishra, A.K.; Rajasekar, R.; Kim, N.H.; Lee, J.H. Carbon-based nanostructured materials and their composites as supercapacitor electrodes. J. Mater. Chem. 2012, 22, 767-784. [CrossRef]

49. Perera, S.D.; Liyanage, A.D.; Nijem, N.; Ferraris, J.P.; Chabal, Y.J.; Balkus, K.J. Vanadium oxide nanowire-Graphene binder free nanocomposite paper electrodes for supercapacitors: A facile green approach. J. Power Sources 2013, 230, 130-137. [CrossRef]

50. Ding, B.; Guo, D.; Wang, Y.; Wu, X.; Fan, Z. Functionalized graphene nanosheets decorated on carbon nanotubes networks for high performance supercapacitors. J. Power Sources 2018, 398, 113-119. [CrossRef]

51. Ding, B.; Wu, X. Transition metal oxides anchored on graphene/carbon nanotubes conductive network as both the negative and positive electrodes for asymmetric supercapacitor. J. Alloys Compd. 2020, 842, 155838. [CrossRef]

52. Chem, J.M.; Tarcan, R.; Todor-boer, O.; Petrovai, I.; Leordean, C. Reduced graphene oxide today. J. Mater. Chem. C 2019, 8 , 1198-1224.

53. Patil, S.J.; Chodankar, N.R.; Han, Y.K.; Lee, D.W. Carbon alternative pseudocapacitive $\mathrm{V}_{2} \mathrm{O}_{5}$ nanobricks and $\delta$ - $\mathrm{MnO}_{2}$ nanoflakes@ $\alpha-\mathrm{MnO}_{2}$ nanowires hetero-phase for high-energy pseudocapacitor. J. Power Sources 2020, 453, 227766. [CrossRef]

54. Pandey, G.P.; Liu, T.; Brown, E.; Yang, Y.; Li, Y.; Sun, X.S.; Fang, Y.; Li, J. Mesoporous Hybrids of Reduced Graphene Oxide and Vanadium Pentoxide for Enhanced Performance in Lithium-Ion Batteries and Electrochemical Capacitors. ACS Appl. Mater. Interfaces 2016, 8, 9200-9210. [CrossRef] [PubMed] 
55. Ahirrao, D.J.; Mohanapriya, K.; Jha, N. $\mathrm{V}_{2} \mathrm{O}_{5}$ nanowires-graphene composite as an outstanding electrode material for high electrochemical performance and long-cycle-life supercapacitor. Mater. Res. Bull. 2018, 108, 73-82. [CrossRef]

56. Geng, Z.D.; Wang, Y.-P. Synthesis of $\mathrm{V}_{2} \mathrm{O}_{5} \cdot 1.6 \mathrm{H}_{2} \mathrm{O} /$ graphene composite and its application in supercapacitors. J. Solid State Electrochem. 2015, 19, 3131-3138. [CrossRef]

57. Sun, W.; Gao, G.; Du, Y.; Zhang, K.; Wu, G. A facile strategy for fabricating hierarchical nanocomposites of $\mathrm{V}_{2} \mathrm{O}_{5}$ nanowire arrays on a three-dimensional N-doped graphene aerogel with a synergistic effect for supercapacitors. J. Mater. Chem. A 2018, 6, 9938-9947. [CrossRef]

58. Nagaraju, D.H.; Wang, Q.; Beaujuge, P.; Alshareef, H.N. Two-dimensional heterostructures of $\mathrm{V}_{2} \mathrm{O}_{5}$ and reduced graphene oxide as electrodes for high energy density asymmetric supercapacitors. J. Mater. Chem. A 2014, 2, 17146-17152. [CrossRef]

59. Sahu, V.; Goel, S.; Kumar Tomar, A.; Singh, G.; Sharma, R.K. Graphene Nanoribbons @ Vanadium Oxide Nanostrips for Supercapacitive Energy Storage. Electrochim. Acta 2017, 230, 255-264. [CrossRef]

60. Zhang, H.; Xie, A.; Wang, C.; Wang, H.; Shen, Y.; Tian, X. Bifunctional reduced graphene oxide $/ \mathrm{V}_{2} \mathrm{O}_{5}$ composite hydrogel: Fabrication, high performance as electromagnetic wave absorbent and supercapacitor. ChemPhysChem 2014, 15, 366-373. [CrossRef]

61. Tabatabai Yazdi, S.; Mousavi, M.; Khorrami, G.H. Effect of Co-doping in $\mathrm{V}_{2} \mathrm{O}_{5}$ nanoparticles synthesized via a gelatin-based sol-gel method. Mater. Today Commun. 2021, 26, 101955. [CrossRef]

62. Yilmaz, G.; Lu, X.; Ho, G.W. Cross-linker mediated formation of sulfur-functionalized $\mathrm{V}_{2} \mathrm{O}_{5}$ /graphene aerogels and their enhanced pseudocapacitive performance. Nanoscale 2017, 9, 802-811. [CrossRef] [PubMed]

63. Kiruthiga, R.; Nithya, C.; Karvembu, R.; Venkata Rami Reddy, B. Reduced Graphene Oxide Embedded $\mathrm{V}_{2} \mathrm{O}_{5} \mathrm{Nanorods}$ and Porous Honey Carbon as High Performance Electrodes for Hybrid Sodium-ion Supercapacitors. Electrochim. Acta 2017, 256, 221-231.

64. Wang, L.; Shu, T.; Guo, S.; Lu, Y.; Li, M.; Nzabahimana, J.; Hu, X. Fabricating strongly coupled $\mathrm{V}_{2} \mathrm{O}_{5} @ P E D O T$ nanobelts/graphene hybrid films with high areal capacitance and facile transferability for transparent solid-state supercapacitors. Energy Storage Mater. 2020, 27, 150-158. [CrossRef]

65. Liu, H.; Tang, Y.; Wang, C.; Xu, Z.; Yang, C.; Huang, T.; Zhang, F.; Wu, D.; Feng, X. A Lyotropic Liquid-Crystal-Based Assembly Avenue toward Highly Oriented Vanadium Pentoxide/Graphene Films for Flexible Energy Storage. Adv. Funct. Mater. 2017, 27, 1606269. [CrossRef]

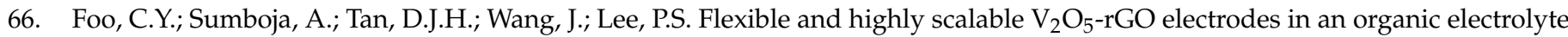
for supercapacitor devices. Adv. Energy Mater. 2014, 4, 1400236. [CrossRef]

67. Van Hoa, N.; Quyen, T.T.H.; Nghia, N.H.; Van Hieu, N.; Shim, J.J. In situ growth of flower-like $\mathrm{V}_{2} \mathrm{O}_{5}$ arrays on graphene@nickel foam as high-performance electrode for supercapacitors. J. Alloys Compd. 2017, 702, 693-699. [CrossRef]

68. Wang, A.Y.; Chaudhary, M.; Lin, T.W. Enhancing the stability and capacitance of vanadium oxide nanoribbons/3D-graphene binder-free electrode by using $\mathrm{VOSO}_{4}$ as redox-active electrolyte. Chem. Eng. J. 2019, 355, 830-839. [CrossRef]

69. Korkmaz, S.; Tezel, F.M.; Kariper, A. Synthesis and Characterization of GO/ $/ \mathrm{V}_{2} \mathrm{O}_{5}$ Thin Film Supercapacitor. Synth. Met. 2018, 242, 37-48. [CrossRef]

70. Li, G.; Wang, X.; Hassan, F.M.; Li, M.; Batmaz, R.; Xiao, X.; Yu, A. Vanadium Pentoxide Nanorods Anchored to and Wrapped with Graphene Nanosheets for High-Power Asymmetric Supercapacitors. ChemElectroChem 2015, 2, 1264-1269. [CrossRef]

71. Saravanakumar, B.; Purushothaman, K.K.; Muralidharan, G. Fabrication of two-dimensional reduced graphene oxide supported $\mathrm{V}_{2} \mathrm{O}_{5}$ networks and their application in supercapacitors. Mater. Chem. Phys. 2016, 170, 266-275. [CrossRef]

72. Ramadoss, A.; Saravanakumar, B.; Kim, S.J. Vanadium Pentoxide/Reduced Graphene Oxide Composite as an Efficient Electrode Material for High-Performance Supercapacitors and Self-Powered Systems. Energy Technol. 2015, 3, 913-924. [CrossRef]

73. Lee, M.; Balasingam, S.K.; Jeong, H.Y.; Hong, W.G.; Lee, H.B.R.; Kim, B.H.; Jun, Y. One-step hydrothermal synthesis of Graphene decorated $\mathrm{V}_{2} \mathrm{O}_{5}$ nanobelts for enhanced electrochemical energy storage. Sci. Rep. 2015, 5, srep08151. [CrossRef] [PubMed]

74. Fu, M.; Zhuang, Q.; Zhu, Z.; Zhang, Z.; Chen, W.; Liu, Q.; Yu, H. Facile synthesis of $\mathrm{V}_{2} \mathrm{O}_{5}$ /graphene composites as advanced electrode materials in supercapacitors. J. Alloys Compd. 2021, 862, 158006. [CrossRef]

75. Yao, L.; Zhang, C.; Hu, N.; Zhang, L.; Zhou, Z.; Zhang, Y. Three-dimensional skeleton networks of reduced graphene oxide nanosheets/vanadium pentoxide nanobelts hybrid for high-performance supercapacitors. Electrochim. Acta 2019, $295,14-21$. [CrossRef]

76. Choudhury, A.; Bonso, J.S.; Wunch, M.; Yang, K.S.; Ferraris, J.P.; Yang, D.J. In-situ synthesis of vanadium pentoxide nanofibre/exfoliated graphene nanohybrid and its supercapacitor applications. J. Power Sources 2015, 287, 283-290. [CrossRef]

77. Deng, L.; Gao, Y.; Ma, Z.; Fan, G. Free-standing graphene/vanadium oxide composite as binder-free electrode for asymmetrical supercapacitor. J. Colloid Interface Sci. 2017, 505, 556-565. [CrossRef]

78. Ndiaye, N.M.; Ngom, B.D.; Sylla, N.F.; Masikhwa, T.M.; Madito, M.J.; Momodu, D.; Ntsoane, T.; Manyala, N. Three dimensional vanadium pentoxide/graphene foam composite as positive electrode for high performance asymmetric electrochemical supercapacitor. J. Colloid Interface Sci. 2018, 532, 395-406. [CrossRef]

79. Li, M.; Sun, G.; Yin, P.; Ruan, C.; Ai, K. Controlling the formation of rodlike $\mathrm{V}_{2} \mathrm{O}_{5}$ nanocrystals on reduced graphene oxide for high-performance supercapacitors. ACS Appl. Mater. Interfaces 2013, 5, 11462-11470. [CrossRef]

80. Liu, Z.; Zhang, H.; Yang, Q.; Chen, Y. Graphene $/ \mathrm{V}_{2} \mathrm{O}_{5}$ hybrid electrode for an asymmetric supercapacitor with high energy density in an organic electrolyte. Electrochim. Acta 2018, 287, 149-157. [CrossRef] 
81. Thangappan, R.; Kalaiselvam, S.; Elayaperumal, A.; Jayavel, R. Synthesis of graphene oxide/vanadium pentoxide composite nanofibers by electrospinning for supercapacitor applications. Solid State Ionics 2014, 268, 321-325. [CrossRef]

82. Lee, S.M.; Park, Y.J.; Van Lam, D.; Kim, J.H.; Lee, K. Effects of annealing on electrochemical performance in graphene/ $\mathrm{V}_{2} \mathrm{O}_{5}$ supercapacitor. Appl. Surf. Sci. 2020, 512, 145626. [CrossRef]

83. Lazauskas, A.; Marcinauskas, L.; Andrulevicius, M. Modification of Graphene Oxide $/ \mathrm{V}_{2} \mathrm{O}_{5} \cdot n \mathrm{H}_{2} \mathrm{O}$ Nanocomposite Films via Direct Laser Irradiation. ACS Appl. Mater. Interfaces 2020, 12, 18877-18884. [CrossRef] [PubMed]

84. Zhu, S.; Ni, J.; Li, Y. Carbon nanotube-based electrodes for flexible supercapacitors. Nano Res. 2020, 13, 1825-1841. [CrossRef]

85. Kumar, S.; Saeed, G.; Zhu, L.; Hui, K.N.; Kim, N.H.; Lee, J.H. OD to 3D carbon-based networks combined with pseudocapacitive electrode material for high energy density supercapacitor: A review. Chem. Eng. J. 2021, 403, 126352. [CrossRef]

86. Lin, Z.; Yan, X.; Lang, J.; Wang, R.; Kong, L. Bin Adjusting electrode initial potential to obtain high-performance asymmetric supercapacitor based on porous vanadium pentoxide nanotubes and activated carbon nanorods. J. Power Sources 2015, 279, 358-364. [CrossRef]

87. Wallar, C.J.; Poon, R.; Zhitomirsky, I. High Areal Capacitance of $\mathrm{V}_{2} \mathrm{O}_{3}$-Carbon Nanotube Electrodes. J. Electrochem. Soc. 2017, 164, A3620-A3627. [CrossRef]

88. Jiang, H.; Cai, X.; Qian, Y.; Zhang, C.; Zhou, L.; Liu, W.; Li, B.; Lai, L.; Huang, W. $\mathrm{V}_{2} \mathrm{O}_{5}$ embedded in vertically aligned carbon nanotube arrays as free-standing electrodes for flexible supercapacitors. J. Mater. Chem. A 2017, 5, 23727-23736. [CrossRef]

89. Wang, X.; Zuo, C.; Jia, L.; Liu, Q.; Guo, X.; Jing, X.; Wang, J. Synthesis of sandwich-like vanadium pentoxide/carbon nanotubes composites for high performance supercapacitor electrodes. J. Alloys Compd. 2017, 708, 134-140. [CrossRef]

90. Jampani, P.H.; Velikokhatnyi, O.; Kadakia, K.; Hong, D.H.; Damle, S.S.; Poston, J.A.; Manivannan, A.; Kumta, P.N. High energy density titanium doped-vanadium oxide-vertically aligned CNT composite electrodes for supercapacitor applications. J. Mater. Chem. A 2015, 3, 8413-8432. [CrossRef]

91. Shakir, I.; Ali, Z.; Bae, J.; Park, J.; Kang, D.J. Layer by layer assembly of ultrathin $\mathrm{V}_{2} \mathrm{O}_{5}$ anchored MWCNTs and graphene on textile fabrics for fabrication of high energy density flexible supercapacitor electrodes. Nanoscale 2014, 6, 4125-4130. [CrossRef]

92. Hu, T.; Liu, Y.; Zhang, Y.; Chen, M.; Zheng, J.; Tang, J.; Meng, C. 3D hierarchical porous $\mathrm{V}_{3} \mathrm{O}_{7} \cdot \mathrm{H}_{2} \mathrm{O}$ nanobelts $/$ CNT/reduced graphene oxide integrated composite with synergistic effect for supercapacitors with high capacitance and long cycling life. $J$. Colloid Interface Sci. 2018, 531, 382-393. [CrossRef]

93. Mtz-enriquez, A.I.; Gomez-solis, C.; Oliva, A.I.; Zakhidov, A.; Martinez, P.M.; Garcia, C.R.; Herrera-ramirez, A.; Oliva, J. Enhancing the voltage and discharge times of graphene supercapacitors depositing a $\mathrm{CNT} / \mathrm{V}_{2} \mathrm{O}_{5}$ layer on their electrodes. Mater. Chem. Phys. 2020, 244, 122698. [CrossRef]

94. Saravanakumar, B.; Purushothaman, K.K.; Muralidharan, G. $\mathrm{V}_{2} \mathrm{O}_{5}$ /functionalized MWCNT hybrid nanocomposite: The fabrication and its enhanced supercapacitive performance. RSC Adv. 2014, 4, 37437-37445. [CrossRef]

95. Pandit, B.; Dubal, D.P.; Gómez-Romero, P.; Kale, B.B.; Sankapal, B.R. $\mathrm{V}_{2} \mathrm{O}_{5}$ encapsulated MWCNTs in 2D surface architecture: Complete solid-state bendable highly stabilized energy efficient supercapacitor device. Sci. Rep. 2017, 7, srep43430. [CrossRef]

96. Guo, K.; Li, Y.; Li, C.; Yu, N.; Li, H. Compact self-standing layered film assembled by $\mathrm{V}_{2} \mathrm{O}_{5} n \mathrm{H}_{2} \mathrm{O} / \mathrm{CNTs} 2 \mathrm{D} / 1 \mathrm{D}$ composites for high volumetric capacitance flexible supercapacitors. Sci. China Mater. 2019, 62, 936-946. [CrossRef]

97. Yilmaz, G.; Guo, C.X.; Lu, X. High-Performance Solid-State Supercapacitors Based on $\mathrm{V}_{2} \mathrm{O}_{5} /$ Carbon Nanotube Composites. ChemElectroChem 2016, 3, 158-164. [CrossRef]

98. Wu, J.; Gao, X.; Yu, H.; Ding, T.; Yan, Y.; Yao, B.; Yao, X.; Chen, D.; Liu, M.; Huang, L. A Scalable Free-Standing V $2 \mathrm{O}_{5} / \mathrm{CNT}$ Film Electrode for Supercapacitors with a Wide Operation Voltage (1.6 V) in an Aqueous Electrolyte. Adv. Funct. Mater. 2016, 26, 6114-6120. [CrossRef]

99. Perera, S.D.; Patel, B.; Nijem, N.; Roodenko, K.; Seitz, O.; Ferraris, J.P.; Chabal, Y.J.; Balkus, K.J. Vanadium oxide nanowire-carbon nanotube binder-free flexible electrodes for supercapacitors. Adv. Energy Mater. 2011, 1, 936-945. [CrossRef]

100. Sathiya, M.; Prakash, A.S.; Ramesha, K.; Tarascon, J.M.; Shukla, A.K. $\mathrm{V}_{2} \mathrm{O}_{5}$-anchored carbon nanotubes for enhanced electrochemical energy storage. J. Am. Chem. Soc. 2011, 133, 16291-16299. [CrossRef] [PubMed]

101. Sun, G.; Ren, H.; Shi, Z.; Zhang, L.; Wang, Z.; Zhan, K.; Yan, Y.; Yang, J.; Zhao, B. $\mathrm{V}_{2} \mathrm{O}_{5}$ /vertically-aligned carbon nanotubes as negative electrode for asymmetric supercapacitor in neutral aqueous electrolyte. J. Colloid Interface Sci. 2021, 588, 847-856. [CrossRef] [PubMed]

102. Wang, Q.; Zou, Y.; Xiang, C.; Chu, H.; Zhang, H.; Xu, F.; Sun, L.; Tang, C. High-performance supercapacitor based on $\mathrm{V}_{2} \mathrm{O}_{5} /$ carbon nanotubes-super activated carbon ternary composite. Ceram. Int. 2016, 42, 12129-12135. [CrossRef]

103. Shakir, I.; Choi, J.H.; Shahid, M.; Shahid, S.A.; Rana, U.A.; Sarfraz, M.; Kang, D.J. Ultra-thin and uniform coating of vanadium oxide on multiwall carbon nanotubes through solution based approach for high-performance electrochemical supercapacitors. Electrochim. Acta 2013, 111, 400-404. [CrossRef]

104. Zhou, X.; Wang, Y.; Gong, C.; Liu, B.; Wei, G. Production, structural design, functional control, and broad applications of carbon nanofiber-based nanomaterials: A comprehensive review. Chem. Eng. J. 2020, 402, 126189. [CrossRef]

105. Adam, A.A.; Dennis, J.O.; Al-Hadeethi, Y.; Mkawi, E.M.; Abdulkadir, B.A.; Usman, F.; Hassan, Y.M.; Wadi, I.A.; Sani, M. State of the art and new directions on electrospun lignin/cellulose nanofibers for supercapacitor application: A systematic literature review. Polymers 2020, 12, 2884. [CrossRef] [PubMed]

106. Song, Y.; Liu, T.Y.; Yao, B.; Kou, T.Y.; Feng, D.Y.; Liu, X.X.; Li, Y. Amorphous Mixed-Valence Vanadium Oxide/Exfoliated Carbon Cloth Structure Shows a Record High Cycling Stability. Small 2017, 13, 1700067. [CrossRef] 
107. Zhou, X.; Chen, Q.; Wang, A.; Xu, J.; Wu, S.; Shen, J. Bamboo-like Composites of $\mathrm{V}_{2} \mathrm{O}_{5}$ /Polyindole and Activated Carbon Cloth as Electrodes for All-Solid-State Flexible Asymmetric Supercapacitors. ACS Appl. Mater. Interfaces 2016, 8, 3776-3783. [CrossRef]

108. Azadian, F.; Rastogi, A.C. $\mathrm{V}_{2} \mathrm{O}_{5}$ Film Embedded Carbon Fiber Paper Synthesized by Sol Process as Highly Pseudocapacitive Electrode for Energy Storage. ECS Meet. Abstr. 2020, 97, 25.

109. Zhou, X.; Gao, X.; Liu, M.; Wang, C.; Chu, F. Synthesis of 3D phosphorus doped graphene foam in carbon cloth to support $\mathrm{V}_{2} \mathrm{O}_{5} / \mathrm{CoMoS}_{4}$ hybrid for flexible all-solid-state asymmetry supercapacitors. J. Power Sources 2020, 453, 227902. [CrossRef]

110. Xiao, Y.; Xu, Y.; Zhang, K.; Tang, X.; Huang, J.; Yuan, K.; Chen, Y. Coaxial electrospun free-standing and mechanical stable hierarchical porous carbon nanofiber membrane for flexible supercapacitors. Carbon 2020, 160, 80-87. [CrossRef]

111. Wang, H.; Niu, H.; Wang, H.; Wang, W.; Jin, X.; Wang, H.; Zhou, H.; Lin, T. Micro-meso porous structured carbon nanofibers with ultra-high surface area and large supercapacitor electrode capacitance. J. Power Sources 2021, 482, 228986. [CrossRef]

112. Kim, B.H.; Kim, C.H.; Yang, K.S.; Rahy, A.; Yang, D.J. Electrospun vanadium pentoxide/carbon nanofiber composites for supercapacitor electrodes. Electrochim. Acta 2012, 83, 335-340. [CrossRef]

113. Kim, B.H.; Yang, K.S.; Yang, D.J. Electrochemical behavior of activated carbon nanofiber-vanadium pentoxide composites for double-layer capacitors. Electrochim. Acta 2013, 109, 859-865. [CrossRef]

114. Choudhury, A.; Kim, J.; Yang, K.; Yang, D. Electrochimica Acta Facile synthesis of self-standing binder-free vanadium pentoxidecarbon nano fi ber composites for high-performance supercapacitors. Electrochim. Acta 2016, 213, 400-407. [CrossRef]

115. Velayutham, R.; Manikandan, R.; Raj, C.J.; Kale, A.M.; Kaya, C.; Palanisamy, K.; Kim, B.C. Electrodeposition of vanadium pentoxide on carbon fiber cloth as a binder-free electrode for high-performance asymmetric supercapacitor. J. Alloys Compd. 2021, 863, 158332. [CrossRef]

116. Chen, S.; Jiang, H.; Cheng, Q.; Wang, G.; Petr, S.; Li, C. Amorphous vanadium oxides with metallic character for asymmetric supercapacitors. Chem. Eng. J. 2021, 403, 126380. [CrossRef]

117. You, M.; Zhang, W.; Yan, X.; Jiang, H.; Miao, J.; Li, Y.; Zhou, W.; Zhu, Y.; Cheng, X. $\mathrm{V}_{2} \mathrm{O}_{5}$ nanosheets assembled on 3D carbon fiber felt as a free-standing electrode for flexible asymmetric supercapacitor with remarkable energy density. Ceram. Int. 2021, 47, 3337-3345. [CrossRef]

118. Guo, Y.; Li, J.; Chen, M.; Gao, G. Facile synthesis of vanadium pentoxide@carbon core-shell nanowires for high-performance supercapacitors. J. Power Sources 2015, 273, 804-809. [CrossRef]

119. Sun, W.; Gao, G.; Zhang, K.; Liu, Y.; Wu, G. Self-assembled 3D N-CNFs $/ \mathrm{V}_{2} \mathrm{O}_{5}$ aerogels with core/shell nanostructures through vacancies control and seeds growth as an outstanding supercapacitor electrode material. Carbon 2018, 132, 667-677. [CrossRef]

120. Parmar, R.; Neto, D.D.F.; Matsubara, E.Y.; Gunnella, R.; Rosolen, J.M. Electrochemical synthesis and structural characterization of nanostructured $\mathrm{V}_{2} \mathrm{O}_{5} \cdot n \mathrm{H}_{2} \mathrm{O}$ on CNTs coated/uncoated carbon felt composite. Nano-Struct. Nano-Objects 2020, $24,100538$. [CrossRef]

121. Panigrahi, K.; Howli, P.; Chattopadhyay, K.K. 3D network of $\mathrm{V}_{2} \mathrm{O}_{5}$ for flexible symmetric supercapacitor. Electrochim. Acta 2020, 337, 135701. [CrossRef]

122. Zhu, Z.; Xu, Z. The rational design of biomass-derived carbon materials towards next-generation energy storage: A review. Renew. Sustain. Energy Rev. 2020, 134, 110308. [CrossRef]

123. Daubert, J.S.; Lewis, N.P.; Gotsch, H.N.; Mundy, J.Z.; Monroe, D.N.; Dickey, E.C.; Losego, M.D.; Parsons, G.N. Effect of Meso- and Micro-Porosity in Carbon Electrodes on Atomic Layer Deposition of Pseudocapacitive $\mathrm{V}_{2} \mathrm{O}_{5}$ for High Performance Supercapacitors. Chem. Mater. 2015, 27, 6524-6534. [CrossRef]

124. Zhang, Y.; Zheng, J.; Wang, Q.; Zhang, S.; Hu, T.; Meng, C. One-step hydrothermal preparation of $\left(\mathrm{NH}_{4}\right) 2 \mathrm{~V}_{3} \mathrm{O}_{8} / \mathrm{carbon}$ composites and conversion to porous $\mathrm{V}_{2} \mathrm{O}_{5}$ nanoparticles as supercapacitor electrode with excellent pseudocapacitive capability. Appl. Surf. Sci. 2017, 423, 728-742. [CrossRef]

125. Narayanan, R. Single step hydrothermal synthesis of carbon nanodot decorated $\mathrm{V}_{2} \mathrm{O}_{5}$ nanobelts as hybrid conducting material for supercapacitor application. J. Solid State Chem. 2017, 253, 103-112. [CrossRef]

126. Sethuraman, B.; Kamatchi Kamaraj, P. Carbon Coated Flowery $\mathrm{V}_{2} \mathrm{O}_{5}$ Nanostructure as Novel Electrode Material for High Performance Supercapacitors. Electrochim. Acta 2015, 186, 285-291.

127. Ngom, B.D.; Ndiaye, N.M.; Sylla, N.F.; Mutuma, B.K.; Manyala, N. Sustainable development of vanadium pentoxide carbon composites derived from: Hibiscus sabdariffa family for application in supercapacitors. Sustain. Energy Fuels 2020, 4, 4814-4830. [CrossRef]

128. Mei, J.; Ma, Y.; Pei, C. $\mathrm{V}_{2} \mathrm{O}_{5}$ nanobelt-carbonized bacterial cellulose composite with enhanced electrochemical performance for aqueous supercapacitors. J. Solid State Electrochem. 2017, 21, 573-580. [CrossRef]

129. Fleischmann, S.; Zeiger, M.; Jäckel, N.; Krüner, B.; Lemkova, V.; Widmaier, M.; Presser, V. Tuning pseudocapacitive and battery-like lithium intercalation in vanadium dioxide/carbon onion hybrids for asymmetric supercapacitor anodes. J. Mater. Chem. A 2017, 5, 13039-13051. [CrossRef]

130. Zhang, G.; Ren, L.; Hu, D.; Zhang, S.; Gu, H. Fabrication of mesoporous carbon hollow spheres intercalated three-dimensional network structure $\mathrm{V}_{2} \mathrm{O}_{5}$ nanosheets with enhanced electrochemical performance. J. Alloys Compd. 2019, 781, 407-414. [CrossRef]

131. Zhu, C.; Hu, D.; Liu, Z. Interconnected three-dimensionally hierarchical heterostructures with homogeneously-dispersed $\mathrm{V}_{2} \mathrm{O}_{5}$ nanocrystals and carbon for high performance supercapacitor electrodes. Electrochim. Acta 2017, 229, 155-165. [CrossRef]

132. Saravanakumar, B.; Purushothaman, K.K.; Muralidharan, G. $\mathrm{V}_{2} \mathrm{O}_{5} /$ nitrogen enriched mesoporous carbon spheres nanocomposite as supercapacitor electrode. Microporous Mesoporous Mater. 2018, 258, 83-94. [CrossRef] 
133. Kudo, T.; Ikeda, Y.; Watanabe, T.; Hibino, M.; Miyayama, M.; Abe, H.; Kajita, K. Amorphous $\mathrm{V}_{2} \mathrm{O}_{5} /$ carbon composites as electrochemical supercapacitor electrodes. Solid State Ionics 2002, 152-153, 833-841. [CrossRef]

134. Peng, T.; Wang, J.; Liu, Q.; Liu, J.; Wang, P. Mesoporous $\mathrm{V}_{2} \mathrm{O}_{5}$ /Ketjin black nanocomposites for all-solid-state symmetric supercapacitors. CrystEngComm 2015, 17, 1673-1679. [CrossRef]

135. Xing, L.L.; Zhao, G.G.; Huang, K.J.; Wu, X. A yolk-shell $\mathrm{V}_{2} \mathrm{O}_{5}$ structure assembled from ultrathin nanosheets and coralline-shaped carbon as advanced electrodes for a high-performance asymmetric supercapacitor. Dalt. Trans. 2018, 47, 2256-2265. [CrossRef] [PubMed]

136. Kim, T.; Kim, H.; You, T.S.; Kim, J. Carbon-coated $\mathrm{V}_{2} \mathrm{O}_{5}$ nanoparticles derived from metal-organic frameworks as a cathode material for rechargeable lithium-ion batteries. J. Alloys Compd. 2017, 727, 522-530. [CrossRef]

137. Zhang, Y.; Zheng, J.; Wang, Q.; Hu, T.; Meng, C. Hydrothermal synthesis of vanadium dioxides/carbon composites and their transformation to surface-uneven $\mathrm{V}_{2} \mathrm{O}_{5}$ nanoparticles with high electrochemical properties. RSC Adv. 2016, 6, 93741-93752. [CrossRef]

138. Zeiger, M.; Ariyanto, T.; Krüner, B.; Peter, N.J.; Fleischmann, S.; Etzold, B.J.M.; Presser, V. Vanadium pentoxide/carbide-derived carbon core-shell hybrid particles for high performance electrochemical energy storage. J. Mater. Chem. A 2016, 4, 18899-18909. [CrossRef]

139. Narayanan, R.; Dewan, A.; Chakraborty, D. Complimentary effects of annealing temperature on optimal tuning of functionalized carbon- $\mathrm{V}_{2} \mathrm{O}_{5}$ hybrid nanobelts for targeted dual applications in electrochromic and supercapacitor devices. RSC Adv. 2018, 8, 8596-8606. [CrossRef] 